\title{
High resolution studies of the origins of polyatomic ions in inductively coupled plasma - mass spectrometry
}

\author{
by \\ Jill Wisnewski Ferguson \\ A dissertation submitted to the graduate faculty \\ in partial fulfillment of the requirements for the degree of \\ DOCTOR OF PHILOSOPHY
}

Major: Analytical Chemistry

Program of Study Committee:

R. S. Houk, Major Professor

Mark S. Gordon

David Laird

Shang-Yi Victor Lin

Marc D. Porter

Iowa State University

Ames, Iowa

2006 


\title{
Graduate College
}

Iowa State University

This is to certify that the doctoral dissertation of

\author{
Jill Wisnewski Ferguson
}

has met the dissertation requirements of Iowa State University

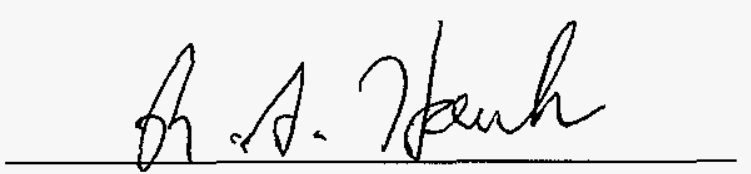

Major Professor

For the Major Program 


\section{TABLE OF CONTENTS}

CHAPTER 1. INTRODUCTION

General Introduction

Method Review

Summary

Dissertation Organization

References

CHAPTER 2. HIGH RESOLUTION STUDIES OF THE ORIGINS OF POLYATOMIC IONS IN INDUCTIVELY COUPLED PLASMA - MASS SPECTROMETRY

PART I. IDENTIFICATION METHODS AND EFFECTS OF NEUTRAL GAS DENSITY ASSUMPTIONS, EXTRACTION VOLTAGE, AND CONE MATERIAL 10

Abstract

Introduction

Theory

Experimental

Results and Discussion

Conclusions

Acknowledgements

References

Tables

Figures

CHAPTER 3. HIGH RESOLUTION STUDIES OF THE ORIGINS OF POLYATOMIC IONS IN INDUCTIVELY COUPLED PLASMA - MASS SPECTROMETRY

PART II. NOVEL CALCULATIONS OF UNUSUAL IONS

$\begin{array}{ll}\text { Abstract } & 48\end{array}$

Introduction $\quad 49$

Theory $\quad 49$

Experimental $\quad 51$

Results $\quad 52$

Discussion $\quad 57$

Conclusions $\quad 60$

Acknowledgements $\quad 60$

References $\quad 61$

Tables $\quad 63$

$\begin{array}{ll}\text { Figures } & 69\end{array}$

CHAPTER 4. HIGH RESOLUTION STUDIES OF THE ORIGINS OF POLYATOMIC IONS IN INDUCTIVELY COUPLED PLASMA - MASS SPECTROMETRY

PART III. $\mathrm{CrO}_{x} \mathrm{H}_{y}^{+}$IONS

Abstract

Introduction 
\begin{tabular}{ll} 
Experimental & 71 \\
\hline
\end{tabular}

Results and Discussion $\quad 73$

$\begin{array}{ll}\text { Conclusions } & 78\end{array}$

Acknowledgements $\quad 78$

$\begin{array}{ll}\text { References } & 79\end{array}$

Tables $\quad 82$

Figures $\quad 85$

CHAPTER 5. GENERAL CONCLUSIONS

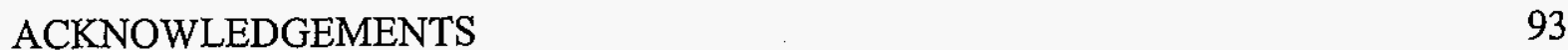




\section{CHAPTER 1. INTRODUCTION}

\section{General Introduction}

The inductively coupled plasma (ICP) is an atmospheric pressure ionization source. Traditionally, the plasma is sampled via a sampler cone. A supersonic jet develops behind the sampler, and this region is pumped down to a pressure of approximately one Torr. A skimmer cone is located inside this zone of silence to transmit ions into the mass spectrometer. The position of the sampler and skimmer cones relative to the initial radiation and normal analytical zones of the plasma is key to optimizing the useful analytical signal $[1]$.

The ICP both atomizes and ionizes the sample. Polyatomic ions form through ionmolecule interactions either in the ICP or during ion extraction [1]. Common polyatomic ions that inhibit analysis include metal oxides $\left(\mathrm{MO}^{+}\right)$, adducts with argon, the gas most commonly used to make up the plasma, and hydride species. While high resolution devices can separate many analytes from common interferences, this is done at great cost in ion transmission efficiency - a loss of $99 \%$ when using high versus low resolution on the same instrument [2]. Simple quadrupole devices, which make up the bulk of ICP-MS instruments in existence, do not present this option. Therefore, if the source of polyatomic interferences can be determined and then manipulated, this could potentially improve the figures of merit on all ICP-MS devices, not just the high resolution devices often utilized to study polyatomic interferences. 


\section{Method Review}

\section{Collision Cells}

Many techniques have been considered to control the development of polyatomic interferences. Chemical reactions can be used to the scientist's advantage through the use of collision or dynamic reaction cells. Hydrogen, methane, nitrogen, and xenon are gases that are commonly used to reduce the appearance of argon adducts and metal oxides. For example, using nitrogen as the collision gas reduces the ${ }^{40} \mathrm{Ar}^{16} \mathrm{O}^{+}$signal, but increases the abundance of ${ }^{40} \mathrm{Ar}^{14} \mathrm{~N}^{+}$and other nitrogen based interferences [2,3]. This becomes very limiting as users employ the multi-element capabilities for which ICP-MS is well known. Therefore, the use of collision cells is not a complete treatment for the polyatomic problem. Collision cells are a useful tool, but only under certain circumstances.

\section{Cool Plasma}

Another alternative is using a "cool" plasma, i.e. a lower RF power, higher nebulizer gas flow rate, and sampling position farther upstream. This technique is particularly helpful when $\mathrm{Ar}^{+}, \mathrm{ArH}^{+}$, or $\mathrm{ArO}^{+}$are an interference, as in the analyses of potassium, calcium, and iron. However, cool plasmas inefficiently ionize elements with a high ionization potential, such as selenium. This technique also tends to increase the abundance of refractory oxides and analyte hydrides $[2,3]$. Cool plasmas are suitable as a sample specific tool for controlling polyatomic interferences.

\section{Solvent Removal}

Reducing the solvent load introduced to the plasma can reduce the abundance of many polyatomic ions. Minnich and Houk compared conventional, cryogenic, and 
membrane desolvation, including combinations of the techniques [4]. $\mathrm{MO}^{+}, \mathrm{MOH}^{+}$, and $\mathrm{MH}^{+}$signals were monitored, as well as polyatomic ions containing chlorine. It was found that cryogenic desolvation removes more $\mathrm{MO}^{+}$than membrane desolvation. However, this effect is not additive when the two techniques are combined. The combination of cryogenic and membrane desolvation does reduce $\mathrm{MH}^{+}$to near background levels, but this comes at a price of reduced sensitivity, roughly to one-half that of the other methods employed singularly. Cryogenic desolvation also reduced the prevalence of chlorine polyatomic ions [4]. It is important to note that this technique is less convenient than other methods. In general, desolvation techniques often suffer from greater memory effects as well.

\section{Alternate Stability Regions}

Alternate stability regions provide improved mass resolution for quadrupole devices, which in turn allows for separation of some interferences from analytes of interest. However, the resolutions reached are still inferior to those provided by a sector field device. In addition, operation in alternate stability regions results in reduced sensitivity and increased background levels [2]. The higher RF power required for the use of alternate stability regions also limits the feasibility of the technique. The use of alternate stability regions is not a panacea for the polyatomic ion issue.

\section{Cone Composition and Geometry}

Another way that researchers have tried to reduce polyatomic ion formation is through modification of the sampler and/or skimmer cones. Helal and coworkers have studied the influence of skimmer materials on the formation of polyatomic ions [5]. While using a copper skimmer cone plated with gold, they monitored polyatomics that would be 
expected to form, such as $\mathrm{ArX}^{+}, \mathrm{XO}^{+}$, and $\mathrm{XN}^{+}$, where $\mathrm{X}$ indicates $\mathrm{Cu}$ or $\mathrm{Au}$. The signal from each polyatomic ion was compared for $\mathrm{Cu}$ and $\mathrm{Au}$. It was found that the gold was more likely to create the expected interferences than copper, and as the gold was stripped off the outer surface of the cone, the gold interferences were reduced. Over the course of forty minutes, the ratios of the copper and gold interferences neared one [5]. This result shows the impact of cone material in polyatomic ion formation.

Other variables that can impact the formation of polyatomic interferences are aperture size, cone spacing, and angle design. The aperture size should be maximized to allow for the greatest analytical signal and to avoid clogging, however the size is limited by the pumping capability, as the interface region should maintain a pressure of about 1-4 Torr [6]. Typically, this maximum size is reached in the 0.7 to $1.0 \mathrm{~mm}$ range. Oxide formation increases with a decrease in sampler orifice diameter, indicating a boundary layer around the orifice [7]. The spacing between the sampler and skimmer also impacts oxide formation. With an increased distance between the two cones, oxide signal decreases relative to analyte signal. However, the reduction in analyte sensitivity can be problematic [8].

A group headed by Jarvis studied three popular nickel skimmer cone angle designs using two different ICP-MS instruments [3]. In all cases, the instrument optics and gas flow rates were optimized to result in the maximum atomic ion signal. Common polyatomics that were monitored included ${ }^{14} \mathrm{~N}_{2}{ }^{+12}{ }^{12} \mathrm{C}^{16} \mathrm{O}_{2}{ }^{+}$, and ${ }^{40} \mathrm{Ar}^{38} \mathrm{Ar}^{+}$. The "PolySkim" design, with an internal angle smaller than $45^{\circ}$, external angle greater than $60^{\circ}$, and an orifice diameter of 0.7 $\mathrm{mm}$ demonstrated the greatest reduction in ${ }^{40} \mathrm{Ar}^{16} \mathrm{O}^{+}$and the other polyatomics monitored. This design had a smaller internal angle and intermediate external angle when compared with the other two configurations tested. The "Polyskim" model provided a more stable signal, 
with better signal to noise characteristics than the other designs. However, there was a decrease in absolute sensitivity noted [3].

\section{Sampling Position and Concomitant Elements}

The position at which the ICP is sampled heavily influences the makeup of the mass spectrum. Shifts in ionization equilibria can be seen as one scans radially and axially across the plasma. It has been demonstrated that oxide fractions $\left[\mathrm{MO}^{+} /\left(\mathrm{M}^{+}+\mathrm{MO}^{+}\right)\right]$can be used as an indicator of these shifts in ionization equilibrium because this ratio is not changed by variations in lens potentials, space-charge effects, or plasma conditions [9]. Beauchemin has studied this and the effect of concomitant elements in relation to the polyatomic interferences problem [10].

Beauchemin observed analytes $\left(\mathrm{La}^{+}\right.$and $\left.\mathrm{Ce}^{+}\right)$and their oxides while moving the plasma either across or away from the sampling interface, both with and without the presence of concomitant elements. $\mathrm{LaO}^{+}$and $\mathrm{CeO}^{+}$are strongly bound, and can cause substantial interferences in the analysis of heavier rare earth elements. She found that the oxides were present at a sampling position farther upstream than their atomic ions. This is because the plasma temperature in this region is cooler [10]. Cooler plasma conditions increase the metal oxides present [2]. As one samples at greater distances, the oxides are dissociated, and the atomic ion signal initially increases. The $\mathrm{La}^{+}$or $\mathrm{Ce}^{+}$signal then declined as all the oxides were broken up. The same behavior was noted when the test was repeated in a 0.02 molar sodium matrix [10].

While this same oxide dissociation activity was seen in the presence of concomitant elements, the sampling positions at which this dissociation took place were shifted to positions closer to the load coil (smaller sampling distances). This shift was ascribed to a 
shift in the ionization equilibrium as discussed previously. This shift in equilibrium is most evident at shorter sampling distances where the electron prevalence is changed. This shows that while similar trends were noted in the presence of additional elements, the actual distances for best atomic sampling differed [10]. This again leads us to the specificity required for each sample analysis in ICP-MS. This work shows the importance of treating polyatomic interferences in a case by case manner. The more one knows about a sample, the faster the optimal experimental parameters for a specific analysis can be reached.

Polyatomic interferences perform differently depending on additional species in solution, instrument, and experimental parameters.

\section{Mathematical Corrections}

Computational methods of correcting for interferences are beneficial for the lab technician, often requiring no adjustment of current analytical protocol or of the instrument itself. In simple cases on a quadrupole device, one could correct for the presence of ${ }^{40} \mathrm{Ar}^{12} \mathrm{C}^{+}$ interference on ${ }^{52} \mathrm{Cr}^{+}$by monitoring the signal at $\mathrm{m} / \mathrm{z} 13$ and $52 . \mathrm{m} / \mathrm{z} 13$ is monitored to detect carbon rather than $m / z 12$ because the ${ }^{12} \mathrm{C}^{+}$signal would overload the detector, especially if the carbon is mainly coming from carbonate in solution. Through repeated trials, the signal ratio ${ }^{40} \mathrm{Ar}^{12} \mathrm{C}^{+} / 3 \mathrm{C}^{+}$can be estimated. By repeatedly analyzing a blank that does not contain chromium, but has similar carbon content to the sample, one can establish a simple correction factor for $m / z 52$, where ${ }^{40} \mathrm{Ar}^{12} \mathrm{C}^{+}$would ordinarily prevent analysis [11]. This simple computational method requires repeated tests and knowledge of the sample and its matrix. The correction factor is specific for each analytical run and would need to be repeated from day to day for superior accuracy. These corrections break down when the signal from the interferent is close to or greater than the analyte signal. Of course, it is 
always preferable to remove the source of error, the interference, rather than correct for its estimated abundance.

Much more advanced computational methods exist, often employing principal components analysis. Software has been developed that automates much of this process. Existing multicomponents analysis (MCA) software allows a model to be initialized from a full mass scan $(m / z=6-238$.) This program takes into account shot noise and plasma flicker characteristics. It then excludes interferents from the model when their signal is below the detection limits projected for the sample matrix. The model is then used to give a picture of what the "true" spectrum should look like [11]. Computational methods for removing polyatomic interferences are only as good as the models they develop. Eliminating the interferences themselves is generally preferred over regulating their presence with statistical models.

\section{Summary}

Researchers currently have numerous ways to address the interferences caused by polyatomic ions. All of these methods are limited by their poorer sensitivity, creation of other interferences, or the uncertainty of mathematical corrections. While there are volumes of ICP-MS research dedicated to methods of reducing polyatomic interferences, few have studied how they may develop in the first place. Since the ICP is thought of as a complete atomization and ionization source at a temperature of approximately $7000 \mathrm{~K}$, the presence of these unusual ions is remarkable. Fundamental research aimed at understanding the formation or dissociation of these ions, as well as determining the location of these processes, may be the basis for truly being able to successfully influence the prevalence of polyatomic ions in spectra. 


\section{Dissertation Organization}

This dissertation is organized into chapters. Chapters 2,3 , and 4 are each complete scientific journal articles prepared for submission to Spectrochimica Acta Part B. Chapter 2 is part one in a three part series concerning the study of polyatomic ions in ICP-MS using a high resolution device. This chapter discusses ion identification techniques as well as the effect of instrumental parameters on the appearance of common polyatomic ions such as $\mathrm{H}_{2} \mathrm{O}^{+}, \mathrm{ArO}^{+}$, and $\mathrm{NO}^{+}$. Chapter 3 is the second paper in the series. It discusses polyatomic ions not often studied, such as $\mathrm{N}_{2} \mathrm{H}^{+}$and $\mathrm{H}_{\mathrm{x}} \mathrm{CO}^{+}$, where $\mathrm{x}=1-3$. Novel calculations of the energy states of these ions have been done by members of the Gordon group, and this collaboration brings to light some interesting questions about polyatomic ions. Chapter 4 completes the current series, and provides insight into unusual spectral interferences seen in the analysis of palladium. These curious polyatomic ions contain chromium and challenge the traditional position held by most about the relative abundance of polyatomic ions. General conclusions and the directions of future research are summarized in chapter 5 .

\section{References}

[1] H. Niu and R. S. Houk, Fundamental aspects of ion extraction in inductively coupled plasma mass spectrometry, Spectrochim. Acta Part B 51 (1996) 779-815.

[2] F. Vanhaecke and L. Moens, Recent trends in trace element determination and speciation using inductively coupled plasma mass spectrometry, Fresenius J. Anal. Chem. 364 (1999) 440-451.

[3] K. E. Jarvis, P. Mason, T. Platzner, J. G. Williams, Critical assessment of the effects of skimmer cone geometry on spectroscopic and non-spectroscopic interferences in inductively coupled plasma mass spectrometry, J. Anal. Atom. Spectrom. 13 (1998) 689-696. 
[4] M. G. Minnich, R. S. Houk, Comparison of cryogenic and membrane desolvation for attenuation of oxide, hydride and hydroxide ions and ions containing chlorine in inductively coupled plasma mass spectrometry, J. Anal. Atom. Spectrom. 13 (1998) 167-174.

[5] N. F. Zahran, A. I. Helal, M. A. Amr, A. Abdel-Hafiez, H. T. Mohsen, Formation of polyatomic ions from the skimmer cone in the inductively coupled plasma mass spectrometry, Int. J. Mass Spectrom. 226 (2003) 271-278.

[6] A. Montaser, ed. Inductively Coupled Plasma Mass Spectrometry, New York: Wiley, $1998,425$.

[7] M. A. Vaughan, G. Horlick, Effect of sampler and skimmer orifice size on analyte and analyte oxide signals in inductively coupled plasma - mass spectrometry, Spectrochim. Acta Part B 45 (1990) 1289-1299.

[8] J. W. H. Lam, G. Horlick, Effects of sampler - skimmer separation in inductively coupled plasma - mass spectrometry, Spectrochim. Acta Part B 45 (1990) 1327-1338.

[9] S. D. Tanner, ICP-MS tectonics: moving the atomic and oxide ion 'mountains', paper F1. Proceedings of the 1994 Winter Conference on Plasma Spectrochemistry, San Diego, January 1994.

[10] M. M. Fraser and D. Beauchemin, Effect of concomitant elements on the distribution of ions in inductively coupled plasma mass spectrometry - part 2: polyatomic ions, Spectrochim. Acta Part B 56 (2001) 2479-2495.

[11] A. Montaser, ed. Inductively Coupled Plasma Mass Spectrometry, New York: Wiley, $1998,539-540,765-769$. 


\title{
CHAPTER 2. HIGH RESOLUTION STUDIES OF THE ORIGINS OF POLYATOMIC IONS IN INDUCTIVELY COUPLED PLASMA - MASS SPECTROMETRY \\ PART I. IDENTIFICATION METHODS AND EFFECTS OF NEUTRAL GAS DENSITY ASSUMPTIONS, EXTRACTION VOLTAGE, AND CONE MATERIAL
}

A paper accepted for publication in Spectrochimica Acta Part B pending revisions Jill Wisnewski Ferguson and R. S. Houk

\begin{abstract}
Common polyatomic ions $\left(\mathrm{ArO}^{+}, \mathrm{NO}^{+}, \mathrm{H}_{2} \mathrm{O}^{+}, \mathrm{H}_{3} \mathrm{O}^{+}, \mathrm{Ar}_{2}^{+}, \mathrm{ArN}^{+}, \mathrm{OH}^{+}, \mathrm{ArH}^{+}, \mathrm{O}_{2}^{+}\right.$) in inductively coupled plasma - mass spectrometry (ICP-MS) are identified using high mass resolution and studied using gas kinetic temperatures $\left(\mathrm{T}_{\text {gas }}\right)$ determined from a dissociation reaction approach. Methods for making accurate mass measurements, confirming ion identifications, and correcting for mass bias are discussed. The effects of sampler and skimmer cone composition and extraction voltage on polyatomic ion formation are also explored. Neutral species densities at several locations in the extraction interface are estimated and the corresponding effects of the $\mathrm{T}_{\text {gas }}$ value are calculated. The results provide information about the origins of background ions and indicate possible locations for their formation or removal.
\end{abstract}

\section{Introduction}

Inductively coupled plasma - mass spectrometry (ICP-MS) is a highly sensitive and selective technique for the identification and quantification of elements in diverse samples. Ideally, the ICP would produce only atomic ions. Unfortunately, some polyatomic ions 
persist in the spectrum, despite the high temperature of the ICP, as noted in the early experiments [1]. The location(s) where these ions are made is a common, simple question with a complex answer. This set of papers continues previous work on this key issue $[2,3]$. In particular, high mass resolution and accurate mass measurements are used to identify the polyatomic ions definitively, and ways to critically evaluate the conclusions about ion origins are discussed. The present method evaluates several experimental issues concerning use of magnetic sector instruments for such fundamental studies.

Conceivably, methods to discern the origins of undesirable polyatomic ions could lead to new methodology to suppress them, in addition to existing options such as high resolution $[4,5,6,7]$, cool plasma $[8,9,10,11]$, solvent removal $[12,13]$, and collision cells $[14,15,16,17]$. The value of all these polyatomic ion attenuation methods for practical scientific applications would be enhanced if levels of polyatomic ions were lower initially.

\section{Previous investigations}

The origins of polyatomic ions in ICP-MS have been studied for some time by workers such as Nonose [9, 18, 19], Tanner [11, 17, 20], Becker [21], Evans [22], Beauchemin [23, 24], and Longerich [7, 25]. Most of this work has been done using quadrupole mass analyzers. In terms of high-resolution studies of polyatomic ions, Reed et al. [26] catalogued common interferences using accurate mass measurements, and Taylor et al. [7] identified and proposed structures for a number of unexpectedly abundant ions from fragments of carbohydrate molecules. 


\section{Theory}

\section{Overview}

Our general method for investigating the origin of a particular polyatomic ion has been described [3]. Basically, a dissociation reaction is written involving two measurable ions $\mathrm{A}^{+}$and $\mathrm{AB}^{+}$

$$
\begin{aligned}
& \mathrm{AB}^{+} \rightleftharpoons \mathrm{A}^{+}+\mathrm{B} \quad \Delta \mathrm{H}=\mathrm{D}_{0}\left(\mathrm{~A}^{+}-\mathrm{B}\right) \\
& \mathrm{K}_{\mathrm{d}}=\frac{\mathrm{n}_{\mathrm{A}^{+}}}{\mathrm{n}_{\mathrm{AB}^{+}}} \mathrm{n}_{\mathrm{B}}=\mathrm{f}\left(\mathrm{T}_{\text {gas }}, \mathrm{D}_{0}\right)
\end{aligned}
$$

where $\mathrm{D}_{0}=$ dissociation energy of $\mathrm{AB}^{+}$and $\mathrm{T}_{\mathrm{gas}}=$ gas kinetic temperature of region where $\mathrm{AB}^{+}$is made. $\mathrm{A}^{+}$may have two or more atoms; $\mathrm{AB}^{+}$has one more atom than $\mathrm{A}^{+}$.

The dissociation constant $\mathrm{K}_{d}$ is measured by determining the signal ratio for the pair of ions $\mathrm{A}^{+} / \mathrm{AB}^{+}$, including corrections for mass bias. The density of the neutral product $\mathrm{B}$ is estimated from general knowledge of ICP conditions, e.g., solvent load. The value of $n_{B}$ is itself a weak function of $T_{\text {gas, }}$ so $n_{B}$ is calculated iteratively for all temperatures. New refinements to this procedure that account for variable values of $n_{B}$, depending on the proposed location where the ion $\mathrm{AB}^{+}$is made, are discussed below.

The value of $T_{\text {gas }}$ that yields the experimentally measured $K_{d}$ value is evaluated by calculating the partition functions for the theoretical dissociation reaction

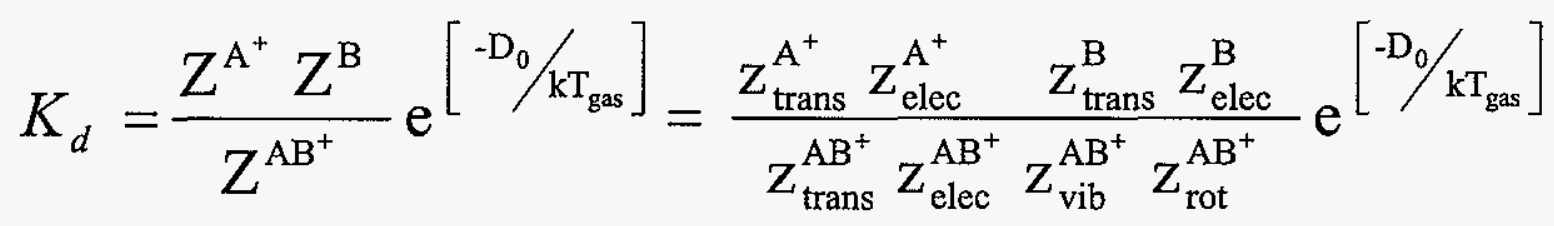


Here $\mathrm{Z}=$ total partition function and $\mathrm{z}=$ partition function for translational, vibrational, rotational, and electronic degrees of freedom. Each partition function is also a function of temperature, so the theoretical $\mathrm{K}_{d}$ is calculated iteratively at each possible $T_{\text {gas }}$ value and then compared with the measured $\mathrm{K}_{\mathrm{d}}$. Various reduced versions of Eq. 3 are available to simplify this task $[3,27]$.

\section{Diagnosis of the origin of the polyatomic ion $\mathrm{AB}^{+}$}

The comparison of the theoretical and experimental dissociation equilibrium expressions yields a value of $T_{\text {gas }}$ that is believed to be characteristic of the region where the ion is produced. Various ions are measured at abundances corresponding to different $T_{\text {gas }}$ values, which is yet another indication that the spectra measured from the ICP do not reflect a source fully at equilibrium. Three general situations are common. First, some polyatomic ions are observed at relative abundances close to those expected from the ICP itself just outside the sampler cone. Here $\mathrm{T}_{\text {gas }}$ is typically $5500 \mathrm{~K}$ to $6000 \mathrm{~K}$ for an ICP operated under conditions that maximize atomic ion signals from injected analyte element $\mathrm{M}^{+}$. In our experience, strongly bound metal oxide ions like $\mathrm{CeO}^{+}$typify this situation. Our diagnosis is that this ion is present in the ICP, and its abundance is not altered greatly relative to that for

$\mathrm{Ce}^{+}$by additional processes that might occur during extraction.

The second scenario is when the $T_{\text {gas }}$ value that corresponds to the measured $K_{d}$ value is lower than this cited range, $5500-6000 \mathrm{~K}$. This means there is more polyatomic ion $\mathrm{AB}^{+}$ in the spectrum than expected from the ICP itself. One explanation is that the dissociation reactions did not reach equilibrium in the $\mathrm{ICP}$, as is apparently the case for the $\mathrm{C}_{\mathrm{x}} \mathrm{H}_{\mathrm{y}} \mathrm{O}_{\mathrm{z}}{ }^{+}$ions observed by Taylor and others [7,28]. Alternatively, additional $\mathrm{AB}^{+}$ions could be made during the ion extraction process. $\mathrm{ArO}^{+}$is an example of an ion in this category. 
The final situation is when the $T_{\text {gas }}$ value that corresponds to the measured $\mathrm{K}_{d}$ value is higher than the range $5500-6000 \mathrm{~K}$. This means there is less polyatomic ion $\mathrm{AB}^{+}$in the spectrum than expected from the ICP alone. Some process may occur that removes the polyatomic ion as it is extracted. $\mathrm{NO}^{+}$is one ion that displays gas kinetic temperatures in this regime. This correlates well with previous observations by Houk, who found less $\mathrm{NO}^{+}$than expected in the mass spectrum [3].

\section{Experimental}

\section{Instrumental conditions}

The instrument parameters were optimized to provide maximum signal for elemental standards. Typically, these resulted in "hot" plasma conditions (Table 1). The ThermoFinnigan ELEMENT 1 used for the experiments is a high resolution, double focusing magnetic sector device. Most experiments were conducted in medium resolution $(\mathrm{m} / \Delta \mathrm{m} \approx$ 4000), which allowed for visualization of less intense ions. The experiments were often repeated in high resolution $(\mathrm{m} / \Delta \mathrm{m} \approx 12000)$ to unequivocally identify unknown ions.

Low flow nebulizers were used in this experiment, as they are especially advantageous when introducing isotopically enriched or organic solvents. Solvent load to the plasma was measured to compare different nebulizers and for use in the equilibrium reactions to follow. Nebulizer uptake and drain output were measured repeatedly after solvent vapor in the spray chamber was allowed to equilibrate for about an hour. With a $100 \mu \mathrm{L} / \mathrm{min}$ nebulizer, solvent loads for solutions of $1 \%$ nitric acid or deionized water were typically about $41 \mu \mathrm{L} / \mathrm{min}$. A $20 \mu \mathrm{L} / \mathrm{min}$ nebulizer produced a solvent load of about $23 \mu \mathrm{L} / \mathrm{min}$. 


\section{Mass bias corrections}

The experimentally-measured dissociation equilibrium expression comes from the measured signal ratio $\mathrm{A}^{+} / \mathrm{AB}^{+}$. This signal ratio is vulnerable to mass bias, as are other ratio measurements in ICP-MS. The method for mass bias correction used here is based on the work of Sharp et al. [29]. The mass bias can be substantial because of the large differences in mass of $\mathrm{A}^{+}$and $\mathrm{AB}^{+}$, as much as $40 \mathrm{Da}$ for $\mathrm{Ar}^{+} / \mathrm{Ar}_{2}^{+}$and $\mathrm{O}^{+} / \mathrm{ArO}^{+}$. Fortunately, the need for accurate corrections is much less extreme than is the case in isotope ratio measurements.

A typical mass bias plot is shown in Fig. 1. A single standard solution is prepared containing various elements at known concentrations, typically $10 \mathrm{ppb}$. Cerium was not used for mass bias measurement, since it is measured in subsequent experiments. The measured signals are adjusted for molar concentration, isotope abundance, and ionization efficiency at $7500 \mathrm{~K}$ and are plotted as shown in Fig. 1. Second order polynomial equations are fit to the plots for use in correcting measured signal ratios.

The full plot is used for high mass ions. For ions lighter than $\mathrm{Ar}_{2}{ }^{+}$, a plot only up to $\mathrm{m} / \mathrm{z}=103$ is utilized. This practice results in more stable and accurate mass bias corrections. For example, the mass bias between masses 28 and 29 is known to be $5.989 \%$ during a particular run, due to the direct measurement of silicon isotopes. Using the full mass bias plot generates a bias of $10.122 \%$. However, using the plot only for lighter mass ions, a value of $5.066 \%$ is derived.

Repetition of mass bias measurements on different days always yields plots that look like those shown in Fig. 1. The exact values of the polynomial coefficients vary from day to day, so mass bias is measured at the beginning of each day's experiments. 


\section{Results and Discussion}

\section{Identification of ions by accurate mass measurements}

The ThermoFinnigan ELEMENT is made to separate atomic analyte ions from interferences, not necessarily to measure their $\mathrm{m} / \mathrm{z}$ values accurately. The ability of the instrument to do so is the subject of this section.

A typical spectrum at $\mathrm{m} / \mathrm{z}=28$ is shown in Fig. 2. At low $\mathrm{m} / \mathrm{z}$ values, the lightest ion observed is often an atomic ion, ${ }^{28} \mathrm{Si}^{+}$in this case. These atomic ions serve as convenient mass calibration markers. Four peaks are easily resolved at medium resolution at $\mathrm{m} / \mathrm{z}=28$. Low resolution measurements which assumed all of the signal at $\mathrm{m} / \mathrm{z}=28 \mathrm{was}^{28} \mathrm{Si}^{+}$would be incorrect. The peak assignment for the atomic ion can be easily.verified by analyzing isotope ratios or an additional sample with a higher concentration of the element of interest.

The measured $\mathrm{m} / \mathrm{z}$ value of the peak centroid (called mass hereafter for brevity) for the atomic ion is not exactly equal to the expected mass, due to imperfect mass calibrations, the mass of the electron(s) lost, and instrumental imprecision. The difference in these values is called mass offset and is very important in identification of the elemental formula of the polyatomic ion by accurate mass measurements. The mass offset varies with the magnetic field value, commonly called the magnet mass setting, as indicated in Table 2 . The first four entries were obtained with the magnet mass set to $\mathrm{m} / \mathrm{z}=59.930$. Note that the mass offset increases with distance from the magnet mass setting. When the magnet mass is changed to 68.925 , a different progression of mass offset values develops. These mass offset gradients can guide the researcher in approximating the actual $\mathrm{m} / \mathrm{z}$ of a peak. Therefore, it is important to observe an atomic ion (for determination of mass offset) and the polyatomic ions of interest in a single test at the same magnet mass setting. 


\section{Identification of polyatomic ions by isotope ratios}

Isotope peaks and isotopically enriched solvents were used by Van Heuzen and Nibbering to verify identities of background ions in low-resolution measurements some time ago [30]. It is desirable to validate the initial ion identification from accurate mass measurements by examining isotope peaks.

Fig. 3 shows the isotopic verification of peaks identified as ${ }^{40} \mathrm{Ar}^{12} \mathrm{C}^{16} \mathrm{O}^{+}$and ${ }^{40} \mathrm{Ar}^{13} \mathrm{C}^{16} \mathrm{O}^{+} .{ }^{40} \mathrm{Ar}^{13} \mathrm{C}^{16} \mathrm{O}^{+}$(Fig. 3b) is observed at an intensity $1.09 \%$ of that for ${ }^{40} \mathrm{Ar}^{12} \mathrm{C}^{16} \mathrm{O}^{+}$ (Fig. 3a), compared to $1.12 \%$ predicted by the natural isotopic abundances. This small difference can be attributed to error in the measurement of the low signal intensity for the ${ }^{13} \mathrm{C}$ isotope. Therefore, the peak identities assigned from accurate $\mathrm{m} / \mathrm{z}$ measurements are further validated.

In Fig. 4 the identification of ${ }^{15} \mathrm{~N}^{16} \mathrm{O}^{+}$is confirmed via isotope ratio comparison with ${ }^{14} \mathrm{~N}^{16} \mathrm{O}^{+}$. The peak ascribed to ${ }^{15} \mathrm{~N}^{16} \mathrm{O}^{+}$is present at $0.356 \%$ of ${ }^{14} \mathrm{~N}^{16} \mathrm{O}^{+}$(data not shown), close to the value of $0.367 \%$ expected for the ${ }^{15} \mathrm{~N}$ isotope. The tentative identification of ${ }^{14} \mathrm{~N}^{17} \mathrm{O}^{+}$(the minor peak) is substantiated as well, because the intensity of this peak is too great to be ${ }^{13} \mathrm{C}^{18} \mathrm{O}^{+}$, as confirmed by comparing to ${ }^{13} \mathrm{C}^{16} \mathrm{O}^{+}$, which displays an integrated intensity of 1244 in another segment of this scan. This high resolution spectrum allows for separation of ${ }^{14} \mathrm{~N}^{17} \mathrm{O}^{+}$from ${ }^{14} \mathrm{~N}^{16} \mathrm{OH}^{+}$, a much more intense peak. ${ }^{14} \mathrm{~N}^{17} \mathrm{O}^{+}$is effectively hidden in a medium resolution mass spectrum.

$\mathrm{D}_{2} \mathrm{O}$ (heavy water) can be used to shift peaks containing $\mathrm{H}$ atoms to confirm identifications $[30,31,32]$. Isopropanol (IPA) is a convenient additive to enhance the abundance of ions containing carbon for purposes of identification. On our particular instrument, the low-flow nebulizers used in this work allow introduction of up to $20 \%$ IPA without additional solvent removal procedures. Fig. 5 illustrates these capabilities. The 
integrated intensities of ${ }^{12} \mathrm{C}_{2}{ }^{+}$and ${ }^{12} \mathrm{C}^{13} \mathrm{C}^{+}$seen in Fig. 5a and b are isotopically accurate to within $1.2 \%$, sufficient to confirm the identity of both species initially suggested by accurate mass measurements. The identity of ${ }^{12} \mathrm{C}_{2} \mathrm{H}^{+}$(Fig. 5b) is confirmed by the observation of ${ }^{12} \mathrm{C}_{2} \mathrm{D}^{+}$from an IPA in $\mathrm{D}_{2} \mathrm{O}$ solution (Fig. $5 \mathrm{c}$ ). The intensities of these two peaks are similar, and neither exists in measurable amounts in nitric acid blanks using high resolution. In Fig. 5d, the major peak is ${ }^{12} \mathrm{C}_{2}{ }^{1} \mathrm{H}_{2}{ }^{+}$from $10 \%$ IPA in $\mathrm{H}_{2} \mathrm{O}$. This peak becomes ${ }^{12} \mathrm{C}_{2} \mathrm{D}^{+}$when the solvent is $10 \%$ IPA in $\mathrm{D}_{2} \mathrm{O}$, as seen in Figure $5 \mathrm{c}$. Note that the ${ }^{12} \mathrm{C}_{2} \mathrm{D}^{+}$spectrum from the IPA/ $\mathrm{D}_{2} \mathrm{O}$ solution is different from the ${ }^{12} \mathrm{C}_{2} \mathrm{H}_{2}{ }^{+}$spectrum generated from IPA in deionized water. These two species are not resolvable by this instrument, but it is logical that the deuterated species is being formed. This is because it is assumed that $\mathrm{D}_{2} \mathrm{O}$ would behave much the same way as $\mathrm{H}_{2} \mathrm{O}$, meaning it dissociates extensively and the resulting atoms are available for ionization and polyatomic ion formation (although they are not depleted substantially by these processes) $[2,3]$.

\section{Comparison of $\mathbf{T}_{\text {gas }}$ values, magnetic sector vs. quadrupole instrument}

Table 3 compares $\mathrm{T}_{\text {gas }}$ values measured in the present work to previous temperatures measured using a home-made quadrupole instrument in our lab. Both sets of measurements were made with a shielded load coil and hot plasma conditions. Both experiments used a nickel sampler cone, but the quadrupole device was run with a stainless steel skimmer, while the high resolution device used a nickel skimmer. The $\mathrm{T}_{\text {gas }}$ values measured for several sets of ions $\left(\mathrm{ArN}^{+} / \mathrm{N}^{+}, \mathrm{OH}^{+} / \mathrm{O}^{+}, \mathrm{CeO}^{+} / \mathrm{Ce}^{+}\right)$using the two different instruments are remarkably similar. There is only one ion for which the $\mathrm{T}_{\text {gas }}$ values are strikingly different; $\mathrm{Ar}_{2}{ }^{+}$is apparently much less abundant relative to $\mathrm{Ar}^{+}$for the magnetic sector instrument. However, it is important to note that this $T_{\text {gas }}$ value is very sensitive to the ion ratio measured. A very 
small change in the measured ratio $(\approx 0.0001)$ is significant (because of the high abundance of $\mathrm{Ar}^{+}$to $\mathrm{Ar}_{2}^{+}$), and changes the calculated $\mathrm{T}_{\mathrm{gas}}$ by about $1000 \mathrm{~K}$.

One obvious difference between the two devices is the fact that in the sector instrument, the ions are quickly accelerated to about $-2 \mathrm{kV}$ right behind the skimmer cone. In contrast, the extraction lens was set to -70 volts in the quadrupole instrument. It makes sense that the commercial instrument with the greater accelerating voltage provides a calculated $\mathrm{T}_{\mathrm{gas}}$ indicative of the polyatomic ion $\mathrm{Ar}_{2}{ }^{+}$being removed, possibly through collisionally induced dissociation. Meanwhile, the homebuilt instrument with the lower accelerating voltage does not fragment the $\mathrm{Ar}_{2}{ }^{+}$species, and a $\mathrm{T}_{\text {gas }}$ indicating formation of the polyatomic ion is observed. Nevertheless, the similarity of $\mathrm{T}_{\text {gas }}$ values for a given pair of ions between the two instruments argues that most ions have similar origins in the two devices, with the possible exception of $\mathrm{Ar}_{2}{ }^{+}$. The $\mathrm{T}_{\text {gas }}$ values for the background ions are all much higher than the terminal $\mathrm{T}_{\text {gas }}$ of the supersonic expansion $(\sim 150 \mathrm{~K})$, indicating the composition of the ion beam has "frozen" earlier in the extraction process. A similar effect occurs with ionization temperatures, which are typically $\sim 7000 \mathrm{~K}$, as expected in the ICP itself [33].

\section{Effect of cone material}

One curiosity evinced by Table 3 is the high value of $\mathrm{T}_{\text {gas }}$ for $\mathrm{NO}^{+} / \mathrm{N}^{+}$. This effect is seen on both the quadrupole and magnetic sector instruments; the value is particularly high for the sector instrument. Perhaps there is a chemical reaction that occurs inside the sampler and/or skimmer cone tips that removes much of the $\mathrm{NO}^{+}$, resulting in a high $\mathrm{T}_{\text {gas }}$ value. $\mathrm{NO}^{+}$ is isoelectronic with $\mathrm{CO}$, which is known to be reactive on transition metal surfaces such as $\mathrm{Ni}$ and $\mathrm{Pt}$, which are common cone materials [34]. By comparing the spectra generated by 
cones of different materials, one may be able to investigate whether species are formed or removed chemically from the hot metal surface of sampler or skimmer cones.

To test this hypothesis, we used two types of metal cones on the sector instrument. Nickel cones were tested as well as cones made of aluminum, which is not a transition metal. Several sets of each type of cone were tested. This was done to ensure that the results seen were due to the differences in cone material, and not a random defect on one set of cones. The cones are supposed to have the same dimensions and sampler-skimmer tip spacing, although two different sets seldom yield exactly the same performance. The cones tend to have slightly different optimum operating conditions, requiring slightly different values of aerosol gas flow rate and RF power to attain maximum signal. This might indicate slight differences in thermal transfer from the plasma to the cones [35].

Aluminum cones generally have lower sensitivity for atomic ions in a multielement standard. This can be seen in Fig. 6a, which shows results taken on the same day with optimal conditions for four sets of cones, two nickel and two aluminum. The lower sensitivity for aluminum cones is not constant, as the sensitivity difference between the two types of cones changes across the mass range. This can be seen in Fig. $6 \mathrm{~b}$, which shows data collected from nickel cones for a $10 \mathrm{ppb}$ standard, normalized to that gathered by aluminum cones. Interestingly, low mass ions are suppressed almost seven times more by aluminum cones than high mass ions. Note that this is separate from traditional mass bias, as elements at the same $\mathrm{m} / \mathrm{z}$ are being compared for the two cone types. The data from plots such as Fig. $6 \mathrm{~b}$ can be used to create a correction factor for this extra suppression related to mass to charge ratio. These differences must be accounted for if any comparisons are to be valid.

Fig. 7 shows the suppression factor estimated from Fig. $6 \mathrm{~b}$ applied to background ion intensities. Ions seem to fall in three groups. The first is where the ion signals from 
aluminum cones matches what is predicted from the sensitivity curve (Fig. 6b), giving a y axis value of approximately one. $\mathrm{Ce}^{+}$is the only such ion in this study. $\mathrm{Ce}^{+}$is still less abundant in spectra obtained by aluminum cones compared to nickel ones, but its intensity is proportional to the additional suppression normally seen. This further validates the bias correction method used here, as the adjustment based on other atomic standards accurately accounts for the suppression of this additional atomic ion.

The second group of ions $\left(\mathrm{NO}^{+}, \mathrm{O}_{2}{ }^{+}, \mathrm{Ar}^{+}, \mathrm{Ar}_{2}{ }^{+}, \mathrm{ArH}^{+}, \mathrm{ArO}^{+}, \mathrm{H}_{3} \mathrm{O}^{+}\right.$, and $\left.\mathrm{H}_{2} \mathrm{O}^{+}\right)$are much more abundant from aluminum cones than is expected from the sensitivity curve (Fig. 6b). Finally, $\mathrm{N}^{+}, \mathrm{O}^{+}, \mathrm{ArN}^{+}, \mathrm{OH}^{+}$, and $\mathrm{CeO}^{+}$are more abundant in aluminum cone spectra than predicted, but are not nearly as abundant at those ions in the second group. Note that these ions are more abundant from aluminum cones than predicted by the suppression factor, but their raw intensity is still below that seen with nickel cones.

The $\mathrm{NO}^{+} / \mathrm{N}^{+}$ratio is much larger with aluminum cones, as can be seen in Table 4. In comparing ion intensities adjusted for the increased mass bias from aluminum cones, it is found that the $\mathrm{NO}^{+}$intensity is suppressed much less than predicted, while the $\mathrm{N}^{+}$amount more closely resembles the behavior of atomic standards. Therefore, the ratio is larger because there is more $\mathrm{NO}^{+}$. It is possible that $\mathrm{NO}^{+}$, like $\mathrm{CO}$, is reactive on hot transition metal surfaces, such as nickel cones. $\mathrm{NO}^{+}$may react at or cling to nickel cones, removing it from the spectra. $\mathrm{NO}^{+}$does not show this reactivity when aluminum sampler and skimmer cones are used. Therefore the overproduction/lower suppression seen with aluminum cones may be due to the "free" $\mathrm{NO}^{+}$being extracted into the mass spectrometer, whereas some $\mathrm{NO}^{+}$ is trapped, neutralized or dissociated on the reactive nickel cones.

Only two ions, $\mathrm{H}_{3} \mathrm{O}^{+}$and $\mathrm{H}_{2} \mathrm{O}^{+}$, are more intense in spectra obtained with aluminum cones. We suggest the following tentative explanation. Perhaps the radical ion $\mathrm{H}_{2} \mathrm{O}^{+}$is more 
reactive on hot nickel than $\mathrm{H}_{3} \mathrm{O}^{+}$, with its stable octet electronic configuration. It would then follow that more $\mathrm{H}_{2} \mathrm{O}^{+}$would be seen in aluminum cone spectra. More $\mathrm{H}_{3} \mathrm{O}^{+}$would then also be observed, because its precursor $\mathrm{H}_{2} \mathrm{O}^{+}$is more abundant.

All of the ion ratios (polyatomic to dissociated ion) are larger with aluminum sampler and skimmer cones than with nickel (Table 4). This makes the calculated kinetic gas temperatures smaller. However, these changes are not so significant as to change the equilibrium assignment proposed. $\mathrm{T}_{\text {gas }}$ is mainly determined by the energies and partition functions of the ions. For many sets of ions, $\mathrm{T}_{\text {gas }}$ is not strongly dependent on the observed ion ratio, which can change with cone material.

\section{Effect of assumed neutral gas densities on diagnosis of ion origin}

For each dissociation reaction (Eq. 1), the measured value of $K_{d}$ depends on an assumed value for $n_{B}$, the number density of the neutral product species, usually $\mathrm{Ar}, \mathrm{H}$, or O atoms. So far, these $n_{B}$ values have been calculated based on their expected abundances in the ICP. This was considered valid as an initial approximation. Suppose a polyatomic ion yields a value of $T_{\text {gas }}$ greatly different from that of the ICP region sampled. The value of $n_{B}$ corresponding to conditions in different regions of the ion extraction process would be expected to differ from that outside in the ICP. Does use of an adjusted value of $n_{B}$, one deemed characteristic of the region where this ion is thought to be made, change the diagnosis of the ion's origin?

We examined three such scenarios. First, consider the density of B for the collisionrich region just behind the sampler (Fig. 8). This zone is clearly seen by the scattered light just behind the sampler in photographic studies of the region between the sampler and the skimmer $[36,37,38]$. The density here is described by 


$$
n(z)=0.161\left(D_{0} / z\right)^{2} n_{0}
$$

where $n(z)$ is the density at axial position $z, D_{0}$ is the orifice diameter $(1.0 \mathrm{~mm})$, and $\mathrm{n}_{0}$ is the original calculated density of the species in the ICP region sampled [33]. The density falls off rapidly enough that most collisions occur within the first $1 \mathrm{~mm}$ or so behind the sampler. We took the position $z=0.5 \mathrm{~mm}$. Here the $T_{\text {gas }}$ should drop to $4300 \mathrm{~K}$ if the ICP is $6000 \mathrm{~K}$ [33].

The second zone modeled is just before the skimmer tip, $z=8.0 \mathrm{~mm}$. If the expansion is clean and there is no shock wave outside the skimmer tip, this expression should be valid. Here the gas density is reduced by a factor of 256 from that in the $\mathrm{z}=0.5 \mathrm{~mm}$ region described above. The temperature at the skimmer tip in a clean expansion should be much lower than that of the ICP, only about $150 \mathrm{~K}$ [33].

In the third scenario, a shock wave is assumed to occur near the skimmer tip. The shock wave could be just before the tip or possibly inside the throat of the skimmer $[2,33]$. We multiply the gas density from a clean expansion by a factor of $8 / 5$, in accord with that found by electron density measurements by Niu and Houk [2]. It is hard to say what $\mathrm{T}_{\text {gas }}$ should be in such a shock wave. Measurements of $\mathrm{T}_{\text {gas }}$ in a Mach disk (not quite the same thing, as no skimmer was present) gave values of $\sim 3000 \mathrm{~K}$ [39]. We therefore estimate $T_{\text {gas }}$ in a shock wave to be 2000 to $3000 \mathrm{~K}$. If the shock wave is hotter than this estimate, the resulting $T_{\text {gas }}$ will be closer to that of the ICP.

Table 5 lists comparative values of $\mathrm{T}_{\text {gas }}$, all resulting from the same experimentallymeasured ion signal ratio. The neutral density $\mathrm{n}_{\mathrm{B}}$ is varied, corresponding to equilibrium formation of ions at three different positions during the ion extraction process. Some general observations are possible from this table. A position farther back in the extraction has a lower neutral density, and the kinetic gas temperature calculated for that position is lower. 
Since use of an adjusted $n_{B}$ value can only decrease $T_{\text {gas }}$, observation of $T_{\text {gas }}$ values above that of the ICP clearly indicates net loss of the corresponding polyatomic ion during extraction. Such is the case for $\mathrm{NO}^{+}$in our experiments.

Except for possibly $\mathrm{ArO}^{+} / \mathrm{O}^{+}$, the $\mathrm{T}_{\text {gas }}$ values resulting from the measured ion ratios are not consistent with equilibration of ions in a clean supersonic expansion, i.e., $\mathrm{T}_{\text {gas }}$ is way too high, $\mathrm{AB}^{+}$is not abundant enough. Even for $\mathrm{ArO}^{+}$, the measured $\mathrm{T}_{\text {gas }}$ is about $500 \mathrm{~K}$, consistent with formation of some additional $\mathrm{ArO}^{+}$in the expansion, but not enough to reflect equilibrium conditions there. It is interesting to compare this result with that of Becker [21], who measured the abundance of $\mathrm{ArM}^{+}$ions, where the $\mathrm{M}^{+}$ions were from injected solutions, not the cone material. These ions are also weakly bound ( $\mathrm{D}_{0}$ values of 0.15 to $\left.0.5 \mathrm{eV}\right)$ and have neutral Ar atoms as the second atom. She reports a Boltzmann plot with a slope corresponding to $T_{\text {gas }}=540 \mathrm{~K}$, similar to that found for $\mathrm{ArO}^{+} / \mathrm{Ar}^{+}$in the present work. The fact that the signals for these $\mathrm{ArM}^{+}$ions all fall on one line indicates they have a common origin.

In both the present and previous work [3], a number of ions are observed at abundances consistent with $\mathrm{T}_{\text {gas }} \approx 4300 \mathrm{~K}$, close to that expected at the $\mathrm{M} \approx 1$ position $0.5 \mathrm{~mm}$ behind the sampler. Ions in this temperature range in both studies include $\operatorname{ArN}^{+} / \mathrm{N}^{+}$, $\mathrm{H}_{2} \mathrm{O}^{+} / \mathrm{OH}^{+}$, and $\mathrm{OH}^{+} / \mathrm{O}^{+}$. The $\mathrm{T}_{\text {gas }}$ values from these ions are fairly close together, suggesting that they arise from a region where $\mathrm{T}_{\mathrm{gas}}$ approaches equilibrium. Most of the collisions experienced by the ions have already occurred by the time they have traveled to the $M=1$ position. Since collisions are necessary to make more polyatomic ions, it is reasonable that additional amounts of some ions would be made there. It would be interesting to vary parameters in some way to further test the possibility that additional polyatomic ions can be made between the ICP and the $\mathrm{M}=1$ position. 
These experimental measurements were done on different days than those reported in Table 3. Assuming the ions to be present as such in the ICP, the resulting $\mathrm{T}_{\text {gas }}$ values in these two tables are very reproducible. The signal ratios $\mathrm{CeO}^{+} / \mathrm{Ce}^{+}, \mathrm{O}_{2}{ }^{+} / \mathrm{O}^{+}$, and $\mathrm{ArH}^{+} / \mathrm{Ar}^{+}$are the ones that are most sensitive in these experiments, as they change the most with $\mathrm{T}_{\text {gas }}$. Comparative $T_{\text {gas }}$ values for these species between Tables 3 and 5 are 5720 vs. 5680 for $\mathrm{CeO}^{+} / \mathrm{Ce}^{+}, 4960$ vs. 4950 for $\mathrm{O}_{2}^{+} / \mathrm{O}^{+}$, and 5050 vs. 5040 for $\mathrm{ArH}^{+} / \mathrm{Ar}^{+}$. Our method for reproducing plasma conditions based on maximizing the $\mathrm{M}^{+}$signal is very consistent day to day and is preferable to reproducing external parameters like aerosol gas flow rate, power and sampling position.

\section{Effect of extraction voltage on ion ratios and $T_{\text {gas }}$ values}

The high extraction voltage in a sector instrument could affect the diagnosis of ion origin, especially if ions are made in a shock wave inside the skimmer tip [33] or dissociated by collisions with the gas in the beam through the skimmer. All studies reported above were done with -2000 volts on the extraction lenses (Fig. 8), the value typically used for analysis with this device. In this section, the extraction voltage was varied in 100 volt increments from -2000 to -1000 volts. Two general protocols were used. First, only the extraction voltage was changed; all other ICP and ion optical parameters were kept constant. Second, these other parameters were re-adjusted to maximize atomic ion signal from standards at each new extraction lens voltage. This latter procedure mimics actual analytical practice. Mass bias curves were measured at each new extraction lens setting, although the mass bias did not change greatly across the voltage range investigated.

Naturally, the basic transmission of the instrument changes with extraction voltage. The extent of the change depends on whether other conditions are re-optimized at each 
extraction lens voltage. Fig. 9 compares sensitivity at -2000 volts to that at -1000 volts for atomic analyte ions. Behavior between these extremes was consistent and is not shown for brevity. If the operating parameters are re-optimized, this sensitivity ratio is fairly uniform and less than a factor of two for all analyte ions. If the other parameters are not re-optimized, the sensitivity ratio is larger and varies more. This variation from element to element is due in part to the poor signal to noise ratio for low $\mathrm{m} / \mathrm{z}$ and low abundance ions at -1000 volt extraction voltage. However, a greater variation is still seen for the constant parameters scenario when comparing data from -1500 volt and -2000 volt extractions, a situation where signal intensities are improved.

These variations of atomic ion signals are thought to reflect the basic transmission of the instrument and are used to normalize the polyatomic ion signals as extraction voltage is changed (Fig. 10). Basically, if the ordinate in Fig. 10 is close to unity, the polyatomic ion signal is affected by extraction voltage to about the same extent as the atomic analyte ion. This is the situation for all ions if other parameters are kept constant at the two extraction voltages.

If the other parameters are re-optimized (Fig. 10), there are substantial variations in behavior for different background and polyatomic ions. In most cases the ratios for these ions remain within a window of 0.75 to 1.75 , with three exceptions. Signals for $\mathrm{Ar}^{+}$and $\mathrm{Ar}_{2}{ }^{+}$ are reduced over two-fold more than the corresponding atomic analyte ion going from -2000 to -1000 volts. Thus, a higher extraction voltage generates much more $\mathrm{Ar}^{+}$and $\mathrm{Ar}_{2}{ }^{+}$in the spectrum relative to $\mathrm{M}^{+}$ions. It is interesting to note that this ICP-MS device yields small but measurable levels of multiply charged $\mathrm{Ar}$ ions, including $\mathrm{Ar}^{3+}$ and $\mathrm{Ar}^{4+}$ [40]. These highly energetic species cannot be in the ICP and are probably made between the skimmer tip and the extraction lens. An electrical discharge between the skimmer and extraction lens, 
or the presence of high energy electrons that have passed through the skimmer and then been accelerated back toward the skimmer tip by the high negative voltage on the extraction lens, could cause such energetic ionization processes. Few or no such ions are seen from quadrupole instruments. This effect would also enhance the abundance of $\mathrm{Ar}^{+}$, apparently slightly more than $\mathrm{Ar}_{2}^{+}$.

$\mathrm{CeO}^{+}$exhibits a value of well under 1.0 in Fig. 10. This indicates that the spectral intensity of $\mathrm{CeO}^{+}$is more stable with changes in extraction voltage than that of atomic ions. This ion is not as affected by a 1000 Volt drop as the ions produced from atomic standards. This ion is thought to be formed in the plasma, and the $T_{\text {gas }}$ calculated is indicative of this process. Fig. 10 supports this, as it indicates that $\mathrm{CeO}^{+}$is not produced or removed by changes in extraction voltage.

\section{Conclusions}

Polyatomic ions can be correctly identified by accurate mass measurements using a high resolution instrument. The diagnosis of ion origins are similar for quadrupole and magnetic sector instruments, except that $\mathrm{Ar}_{2}{ }^{+}$is dissociated by the high extraction voltage of the magnetic sector device. Identities can be confirmed using minor isotopes and/or isotopically enriched solvents. Mass bias is accounted for using curves developed from atomic standards. A second mass bias effect is seen in the comparison of aluminum and nickel cones. The signal difference between aluminum and nickel cones is greater at low $\mathrm{m} / \mathrm{z}$. Therefore, any assessment of the effects of cone material on polyatomic ion origin must take into account this graduated difference.

The dissociation equilibrium method used here to calculate gas kinetic temperatures can be used to study polyatomic ions in ICP-MS. Ratios of background ions can change 
based on the cones used (aluminum or nickel) and instrument conditions, such as extraction voltage. This information can be used to maximize sensitivity for analytes at the same nominal mass as background ions for quadrupole devices. The calculated gas kinetic temperature does not change enough with manipulation of experimental parameters to alter the proposed formation or reduction regions or processes for the polyatomic ions studied. The ability to estimate neutral density at specific points in the interface region is displayed and then applied to the proposed dissociation reactions. This paper sets the experimental stage for further work into the origins and behavior of polyatomic ions in ICP-MS.

\section{Acknowledgements}

Ames Laboratory is operated for the U.S. Department of Energy by Iowa State University under Contract No. W-7405-Eng-82. This research was supported by the National Science Foundation through the Institute for Physical Research and Technology at ISU. JWF was also supported by the Velmer A. and Mary K. Fassel Fellowship. The nebulizers used were provided by Elemental Scientific Inc. The ICP-MS device was obtained with funds provided by the U. S. Department of Energy, Office of Nuclear Nonproliferation (NA-22) and the Office of Basic Energy Sciences.

\section{References}

[1] R. S. Houk, V. A. Fassel, G. D. Flesch, H. J. Svec, A. L. Gray, C. E. Taylor, Inductively coupled argon plasma as an ion source for mass spectrometric determination of trace elements, Anal. Chem. 52 (1980) 2283-2289.

[2] H. Niu, R. S. Houk, Fundamental aspects of ion extraction in inductively coupled plasma - mass spectrometry, Spectrochim. Acta Part B 51 (1996) 779-815. 
[3] R. S. Houk, N. Praphairaksit, Dissociation of polyatomic ions in the inductively coupled plasma, Spectrochim. Acta Part B 56 (2001) 1069-1096.

[4] N. Bradshaw, E. F. H. Hall, N. E. Sanderson, Inductively coupled plasma as an ion source for high-resolution mass spectrometry, J. Anal. Atom. Spectrom. 8 (1989) 801-803.

[5] I. Feldmann, W. Tittes, N. Jakubowski, D. Stuewer, U. Giessmann, Performance characteristics of inductively coupled plasma mass spectrometry with high mass resolution, J. Anal. Atom. Spectrom. 9 (1994) 1007-1014.

[6] W. Tittes, N. Jakubowski, D. Stüwer, G. Tölg, J. A. C. Broekaert, Reduction of some selected spectral interferences in inductively coupled plasma mass spectrometry, J. Anal. Atom. Spectrom. 9 (1994) 1015-1020.

[7] V. F. Taylor, R. E. March, H. P. Longerich, C. J. Stadey, A mass spectrometric study of glucose, sucrose, and fructose using an inductively coupled plasma and electrospray ionization, Int. J. Mass Spectrom. 243 (2005) 71-84.

[8] S. J. Jiang, R. S. Houk, M. A. Stevens, Alleviation of overlap interferences for determination of potassium isotope ratios by inductively coupled plasma mass spectrometry, Anal. Chem. 60 (1988) 1217-1221.

[9] N. S. Nonose, N. Matsuda, N. Fudagawa, M. Kubota, Some characteristics of polyatomic ion spectra in inductively coupled plasma - mass spectrometry, Spectrochim. Acta Part B 49 (1994) 955-974.

[10] K. Sakata, K. Kawabata, Reduction of fundamental polyatomic ions in inductively coupled plasma mass spectrometry, Spectrochim. Acta Part B 49 (1994) 1027-1038. [11] S. D. Tanner, Characterization of ionization and matrix suppression in inductively coupled 'cold' plasma mass spectrometry, J. Anal. Atom. Spectrom. 10 (1995) 905-921. 
[12] L. C. Alves, D. R. Wiederin, R. S. Houk, Reduction of polyatomic ion interferences in inductively coupled plasma mass spectrometry by cryogenic desolvation, Anal. Chem. 64 (1992) 1164-1169.

[13] M. G. Minnich, R. S. Houk, Comparison of cryogenic and membrane desolvation for attenuation of oxide, hydride and hydroxide ions and ions containing chlorine in inductively coupled plasma mass spectrometry, J. Anal. Atom. Spectrom. 13 (1998) 167-174.

[14] J. T. Rowan, R. S. Houk, Attenuation of polyatomic ion interferences in inductively coupled plasma mass spectrometry by gas-phase collisions, Appl. Spectrosc. 43 (1989) 976980.

[15] D. J. Douglas, Some current perspectives on ICP-MS, Can. J. Spectroscopy 34 (1989) $38-49$.

[16] G. C. Eiden, C. J. Barinaga, D. W. Koppenaal, Selective removal of plasma matrix ions in plasma source mass spectrometry, J. Anal. Atom. Spectrom. 11 (1996) 317-322.

[17] S. D. Tanner, V. I. Baranov, D. R. Bandura, Reaction cells and collision cells for ICPMS: a tutorial review, Spectrochim. Acta Part B 57 (2002) 1361-1452.

[18] N. Nonose, M. Kubota, Non-spectral and spectral interferences in inductively coupled plasma high resolution mass spectrometry Part I: optical characteristics, J. Anal. Atom. Spectrom. 16 (2001) 551-559.

[19] N. Nonose, M. Kubota, Non-spectral and spectral interferences in inductively coupled plasma high resolution mass spectrometry Part II: comparison of interferences in quadrupole and high resolution, J. Anal. Atom. Spectrom. 16 (2001) 560-566.

[20] S. D. Tanner, Plasma temperature from ion kinetic energies and implications for the source of diatomic oxide ions in inductively coupled plasma - mass spectrometry, J. Anal. Atom. Spectrom. 8 (1993) 891-897. 
[21] J. S. Becker, H.-J. Dietze, Investigations on cluster and molecular ion formation by plasma mass spectrometry, Fresenius J. Anal. Chem. 359 (1997) 338-345.

[22] E. H. Evans, L. Ebdon, L. Rowley, Comparative study of the determination of equilibrium dissociation temperature in inductively coupled plasma - mass spectrometry, Spectrochim. Acta Part B 57 (2002) 741-754.

[23] M. M. Fraser, D. Beauchemin, Effect of concomitant elements on the distribution of ions in inductively coupled plasma - mass spectrometry - Part 2: polyatomic ions, Spectrochim. Acta Part B 56 (2001) 2479-2495.

[24] A. E. Holliday, D. Beauchemin, Spatial profiling of ion distributions in a nitrogen-argon plasma in inductively coupled plasma mass spectrometry, J. Anal. Atom. Spectrom. 18 (2003) 289-295.

[25] Guenther, D.; Longerich, H. P.; Jackson, S. E.; Forsythe, L. Effect of sampler orifice diameter on dry plasma inductively coupled plasma mass spectrometry (ICP-MS) backgrounds, sensitivities, and limits of detection using laser ablation sample introduction, Fresenius J. Anal. Chem. 355 (1996) 771-773.

[26] N. M. Reed, R. O. Cairns, R. C. Hutton, Y. Takaku, Characterization of polyatomic ion interferences in inductively coupled plasma - mass spectrometry using a high resolution mass spectrometer, J. Anal. Atom. Spectrom. 9 (1994) 881-896.

[27] R. S. Houk, Erratum to "Dissociation of polyatomic ions in inductively coupled plasma-mass spectrometry", Spectrochim. Acta Part B 61 (2006) 235-236. [28] R. S. Houk, V. A. Fassel, H. J. Svec, Mass spectra of polar organic compounds in aqueous solutions introduced into an inductively coupled plasma, Org. Mass Spectrom., 17 (1982) 240-244. 
[29] C. P. Ingle, B. L. Sharp, M. S. A. Horstwood, R. R. Parrish, D. J. Lewis, Instrument response functions, mass bias and matrix effects in isotope ratio measurements and semiquantitative analysis by single and multi-collector ICP-MS, J. Anal. Atom. Spectrom. 18 (2003) 219-229.

[30] A. A. van Heuzen, N. M. M. Nibbering, Elemental composition and origin of (polyatomic) ions in inductively coupled plasma mass spectrometry disclosed by means of isotope exchange experiments. Spectrochim. Acta Part B 48 (1993) 1013-1021.

[31] F. G. Smith, R. S. Houk, Alleviation of polyatomic ion interferences for determination of chlorine isotope ratios by inductively coupled plasma - mass spectrometry, J. Am. Soc. Mass Spectrom. 1 (1990) 284-287.

[32] M. V. Zoriy, L. Halicz, M. E. Ketterer, C. Pickhardt, P. Ostapczuk, J. S. Becker, Reduction of $\mathrm{UH}^{+}$formation for ${ }^{236} \mathrm{U} /{ }^{238} \mathrm{U}$ isotope ratio measurements at ultratrace levels in double focusing sector field ICP-MS using $\mathrm{D}_{2} \mathrm{O}$ as solvent, J. Anal. Atom. Spectrom. 19 (2004) $362-367$.

[33] D. J. Douglas, J. B. French, Gas dynamics of the inductively coupled plasma mass spectrometry interface, J. Anal. Atom. Spectrom. 3 (1988) 743-747.

[34] J. Joyce, A. Martin-Rodero, F. Flores, P. J. Grout, N. H. March, Indirect interactions between $\mathrm{CO}$ molecules on transition-metal surfaces and the interpretation of thermal desorption experiments, J. Phys. C: Solid State Phys. 20 (1987) 3381-3389.

[35] S. A. Lehn, K. A. Warner, M. Huang, G. M. Hieftje, Effect of an inductively coupled plasma mass spectrometry sampler interface on electron temperature, electron number density, gas-kinetic temperature and analyte emission intensity upstream in the plasma, Spectrochim. Acta Part B 57 (2002) 1739-1751. 
[36] A. L. Gray, Stabilization of an inductively coupled plasma for inductively coupled plasma mass spectrometry with a flared torch extension, J. Anal. Atom. Spectrom. 7 (1992) 1151-1153.

[37] A. T. Ince, J. G. Williams, A. L. Gray, Noise in inductively coupled plasma mass spectrometry: some preliminary measurements, J. Anal. Atom. Spectrom. 8 (1993) 899-903. [38] A. L. Gray, R. S. Houk, J. G. Williams, Langmuir probe potential measurements in the plasma and their correlation with mass spectral characteristics in inductively coupled plasma mass spectrometry, J. Anal. Atom. Spectrom. 2 (1987) 13-20.

[39] H.B. Lim, R.S. Houk, M.C. Edelson, K.P. Carney, Some fundamental characteristics of a reduced-pressure plasma extracted from an ICP, J. Anal. Atom. Spectrom. 4 (1989) 365370.

[40] L. Moens, N. Jakubowski, Double-focusing mass spectrometers in ICP-MS, Anal. Chem. (1998) 251A-256A. 


\section{Tables}

Table 1: Experimental Parameters

Instrument: ThermoFinnigan ELEMENT 1

Resolution: Medium $(\mathrm{m} / \Delta \mathrm{m} \approx 4000)$, except where otherwise stated

Nebulizer: Elemental Scientific Inc. PFA $100 \mu \mathrm{L} / \mathrm{min}$ or $20 \mu \mathrm{L} / \mathrm{min}$ as needed

Spray Chamber: Teflon Scott type double pass

Cones: Nickel sampler and skimmer used most commonly, others as indicated

Power: $1200 \mathrm{~W}$, changed marginally to improve performance

Gas flow rates: Optimized to produce greatest signal for standards

Solutions: Standards in 1\% nitric acid. Other solutions used as indicated

Torch was shielded with the shield grounded

Table 2: Importance of magnet mass. Mass offset is difference between actual mass and measured mass. Note a) variation of mass offset with mass at constant magnet mass, and b) change of mass offset with magnet mass.

$\begin{array}{llll}\text { Magnet Mass } & \text { Ion } & \text { Measured Mass } & \text { Mass Offset } \\ 59.930 & { }^{64} \mathrm{Zn}^{+} & 63.9203 & -0.00885 \\ 59.930 & { }^{65} \mathrm{Cu}^{+} & 64.9184 & -0.00939 \\ 59.930 & { }^{66} \mathrm{Zn}^{+} & 65.9166 & -0.00944 \\ 59.930 & { }^{67} \mathrm{Zn}^{+} & 66.9177 & -0.00943 \\ 59.930 & { }^{68} \mathrm{Zn}^{+} & 67.9152 & -0.00965 \\ 68.925 & { }^{69} \mathrm{Ga}^{+} & 68.9247 & -0.00088 \\ 68.925 & { }^{70} \mathrm{Zn}^{+} & 69.9244 & -0.00092\end{array}$


Table 3: Comparison of measured $\mathrm{T}_{\text {gas }}$ values from background ions and $\mathrm{CeO}^{+}$between quadrupole and magnetic sector instrument. Nickel cones and shielded torch were used with the sector instrument. A nickel sampler, stainless steel skimmer, and shielded torch were used with the quadrupole instrument.

$\begin{array}{llll} & \mathrm{D}_{0} & \mathrm{~T}_{\text {gas }} \text { Values (K) } & \mathrm{T}_{\text {gas Values }}(\mathrm{K}) \\ \text { Ions } & (\mathrm{eV}) & \text { Quadrupole [Ref. 3] } & \text { Magnetic Sector } \\ \mathrm{ArO}^{+} / \mathrm{O}^{+} & 0.312 & 1810 & 2930 \\ \mathrm{Ar}^{+} / \mathrm{Ar}^{+} & 1.2 & 4050 & 7030 \\ \mathrm{ArN}^{+} / \mathrm{N}^{+} & 1.866 & 4220 & 4340 \\ \mathrm{OH}^{+} / \mathrm{O}^{+} & 5.09 & 4690 & 4700 \\ \mathrm{H}_{2} \mathrm{O}^{+} / \mathrm{OH}^{+} & 5.43 & 3170 & 3870 \\ \mathrm{H}_{3} \mathrm{O}^{+} / \mathrm{H}_{2} \mathrm{O}^{+} & 6.508 & 4410 & 4950 \\ \mathrm{ArH}^{+} / \mathrm{Ar}^{+} & 6.16 & 4190 & 5040 \\ \mathrm{O}_{2}^{+} / \mathrm{O}^{+} & 6.663 & 4780 & 4960 \\ \mathrm{NO}^{+} / \mathrm{N}^{+} & 11.76 & 6440 & 7330 \\ \mathrm{CeO}^{+} / \mathrm{Ce}^{+} & 8.81 & 5800 & 5720\end{array}$


Table 4: Comparison of measured $T_{\text {gas }}$ values and signal ratios from background ions and $\mathrm{CeO}^{+} / \mathrm{Ce}^{+}$. Ion ratios are corrected for basic mass bias. Magnetic sector instrument, nickel or aluminum cones.

\begin{tabular}{llllll} 
& \multicolumn{2}{l}{$\mathrm{D}_{0}$} & \multicolumn{2}{l}{$\mathrm{T}_{\text {gas }}$ Values $(\mathrm{K})$} & \multicolumn{2}{l}{ Signal Ratios } \\
lons & $(\mathrm{eV})$ & $\mathrm{Ni}$ Cones & $\mathrm{Al}$ Cones & Ni Cones & $\mathrm{Al}$ Cones \\
$\mathrm{ArO}^{+} / \mathrm{O}^{+}$ & 0.312 & 2880 & 1410 & 0.000387 & 0.00596 \\
$\mathrm{Ar}_{2}{ }^{+} / \mathrm{Ar}^{+}$ & 1.2 & 7180 & 6080 & 0.000211 & 0.000317 \\
$\mathrm{ArN}^{+} / \mathrm{N}^{+}$ & 1.866 & 4370 & 3830 & 0.00729 & 0.0123 \\
$\mathrm{OH}^{+} / \mathrm{O}^{+}$ & 5.09 & 4710 & 4470 & 0.107 & 0.243 \\
$\mathrm{H}_{2} \mathrm{O}^{+} / \mathrm{OH}^{+}$ & 5.43 & 3960 & 3560 & 0.723 & 9.12 \\
$\mathrm{H}_{3} \mathrm{O}^{+} / \mathrm{H}_{2} \mathrm{O}^{+}$ & 6.508 & 4960 & 4750 & 0.119 & 0.247 \\
$\mathrm{ArH}^{+} / \mathrm{Ar}^{+}$ & 6.16 & 5050 & 4880 & 0.213 & 0.366 \\
$\mathrm{O}_{2}^{+} / \mathrm{O}^{+}$ & 6.663 & 5070 & 4590 & 0.0399 & 0.201 \\
$\mathrm{NO}^{+} / \mathrm{N}^{+}$ & 11.76 & 7390 & 6850 & 0.224 & 1.13 \\
$\mathrm{CeO}^{+} / \mathrm{Ce}^{+}$ & 8.81 & 5790 & 5540 & 0.0467 & 0.115
\end{tabular}


Table 5: Comparison of measured $\mathrm{T}_{\text {gas }}$ values from background ions and $\mathrm{CeO}^{+} / \mathrm{Ce}^{+}$for a magnetic sector instrument with nickel cones and using various values of gas number density corresponding to different locations in the ion extraction process. If the dissociation reactions all reached equilibrium at the various positions, the measured $\mathrm{T}_{\text {gas }}$ values would be $4300 \mathrm{~K} 0.5 \mathrm{~mm}$ behind the sampler, about $150 \mathrm{~K}$ at the skimmer tip, and 2000 to $3000 \mathrm{~K}$ if there were a shock wave at the skimmer tip.

Calculated $\mathrm{T}_{\text {gas }}(\mathrm{K})$ for $\mathrm{n}_{\mathrm{B}}$ calculated at following positions

$\begin{array}{lllll}\text { Ions } & \text { In Plasma } & \begin{array}{l}0.5 \mathrm{~mm} \text { behind } \\ \text { Sampler }\end{array} & \begin{array}{l}\text { Clean Expansion } \\ \text { Skimmer Tip }\end{array} & \begin{array}{l}\text { Shock Wave at } \\ \text { Skimmer Tip }\end{array} \\ \mathrm{ArO}^{+} / \mathrm{O}^{+} & 2830 & 2270 & 580 & 620 \\ \mathrm{Ar}_{2}{ }^{+} / \mathrm{Ar}^{+} & 6840 & 5800 & 1900 & 2020 \\ \mathrm{ArN}^{+} / \mathrm{N}^{+} & 4510 & 4160 & 2100 & 2200 \\ \mathrm{OH}^{+} / \mathrm{O}^{+} & 4710 & 4580 & 3260 & 3340 \\ \mathrm{H}_{2} \mathrm{O}^{+} / \mathrm{OH}^{+} & 3960 & 3870 & 2920 & 2980 \\ \mathrm{H}_{3} \mathrm{O}^{+} / \mathrm{H}_{2} \mathrm{O}^{+} & 4990 & 4730 & 3510 & 3590 \\ \mathrm{ArH}^{+} / \mathrm{Ar}^{+} & 5040 & 4910 & 3610 & 3690 \\ \mathrm{O}_{2}^{+} / \mathrm{O}^{+} & 4950 & 4830 & 3630 & 3710 \\ \mathrm{NO}^{+} / \mathrm{N}^{+} & 7400 & 7250 & 5650 & 5760 \\ \mathrm{CeO}^{+} / \mathrm{Ce}^{+} & 5680 & 5580 & 4380 & 4460\end{array}$




\section{Figures}

Figure 1: Mass bias plot for $10 \mathrm{ppb}$ standards in medium resolution. This plot is used for ions above $80 \mathrm{Da}$.

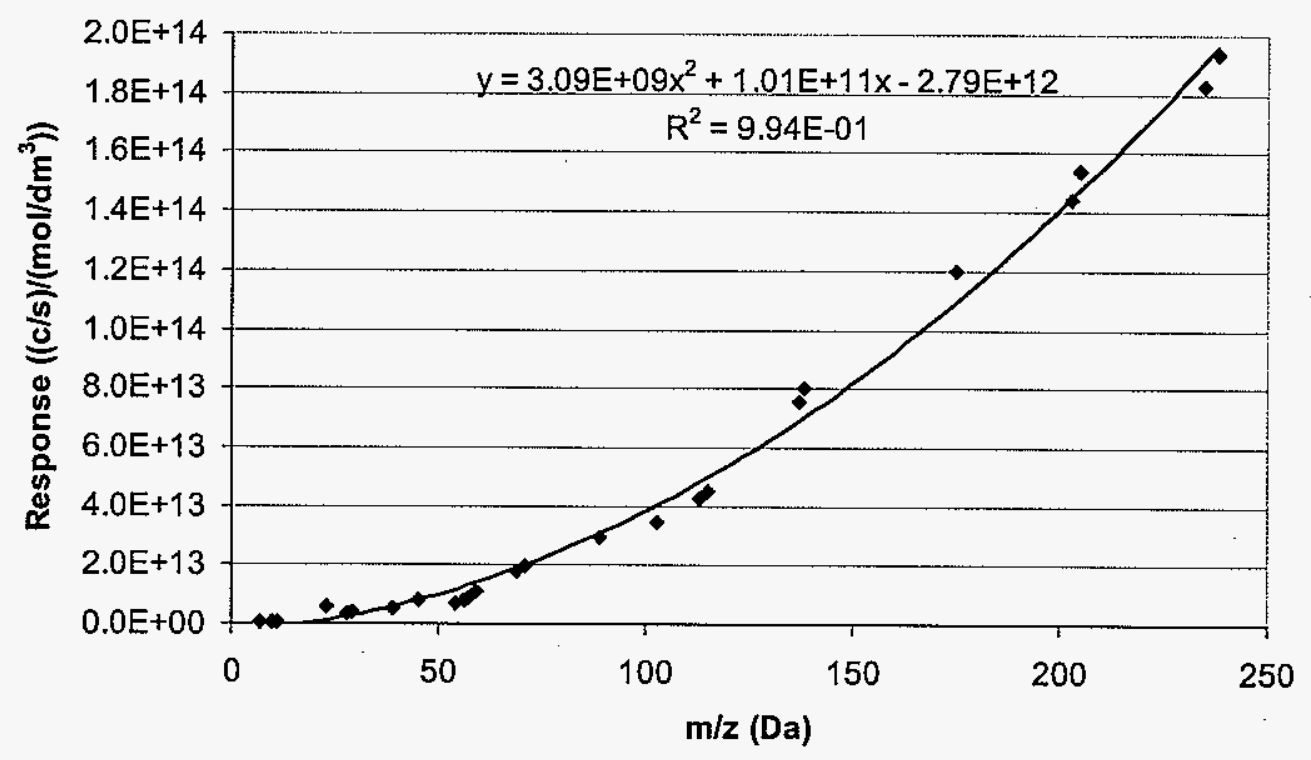


Figure 2: Medium resolution mass spectrum showing ${ }^{28} \mathrm{Si}^{+}$and polyatomic peaks from a solution of $10 \mathrm{ppb}$ silicon in $20 \%$ isopropyl alcohol. There are 4 peaks of interest. The vertical axis has been limited to show the less intense peaks.

Peak Centroid Integrated Intensity Assigned Identity

27.9626

$1.17 \times 10^{6}$

${ }^{28} \mathrm{Si}^{+}$

27.9806

$4.73 \times 10^{8}$

${ }^{12} \mathrm{C}^{16} \mathrm{O}^{+}$

27.9920

$5.79 \times 10^{5}$

${ }^{14} \mathrm{~N}_{2}^{+}$

28.0045

$7.07 \times 10^{4}$

${ }^{12} \mathrm{C}^{14} \mathrm{~N}^{1} \mathrm{H}_{2}^{+}$

\section{Medium Resolution Spectrum}

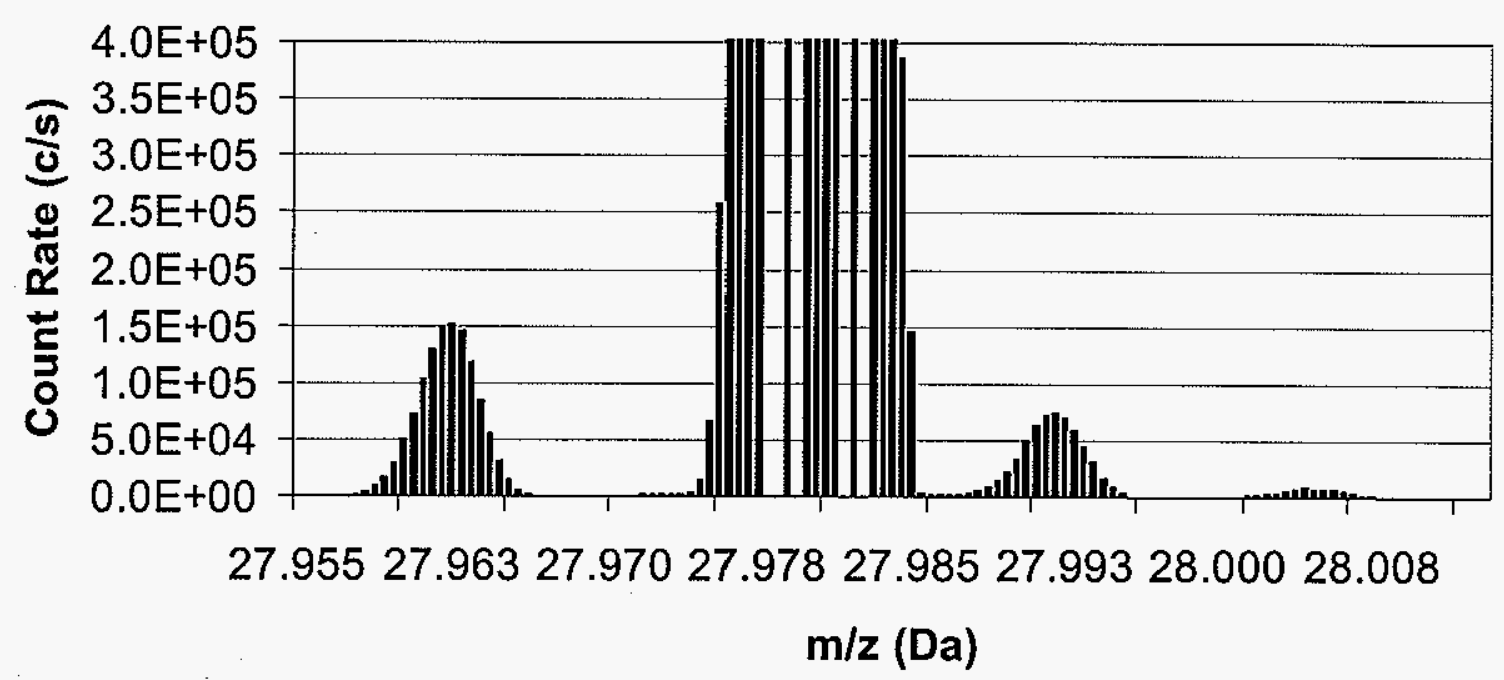


Figure 3a: Medium resolution spectrum of ${ }^{40} \mathrm{Ar}^{12} \mathrm{C}^{16} \mathrm{O}^{+}$from a nebulized solution of $20 \%$ isopropyl alcohol in deionized water. Peak centroid $=67.9538$. Integrated intensity $=3.73 \times 10^{4}$.

Medium Resolution Spectrum

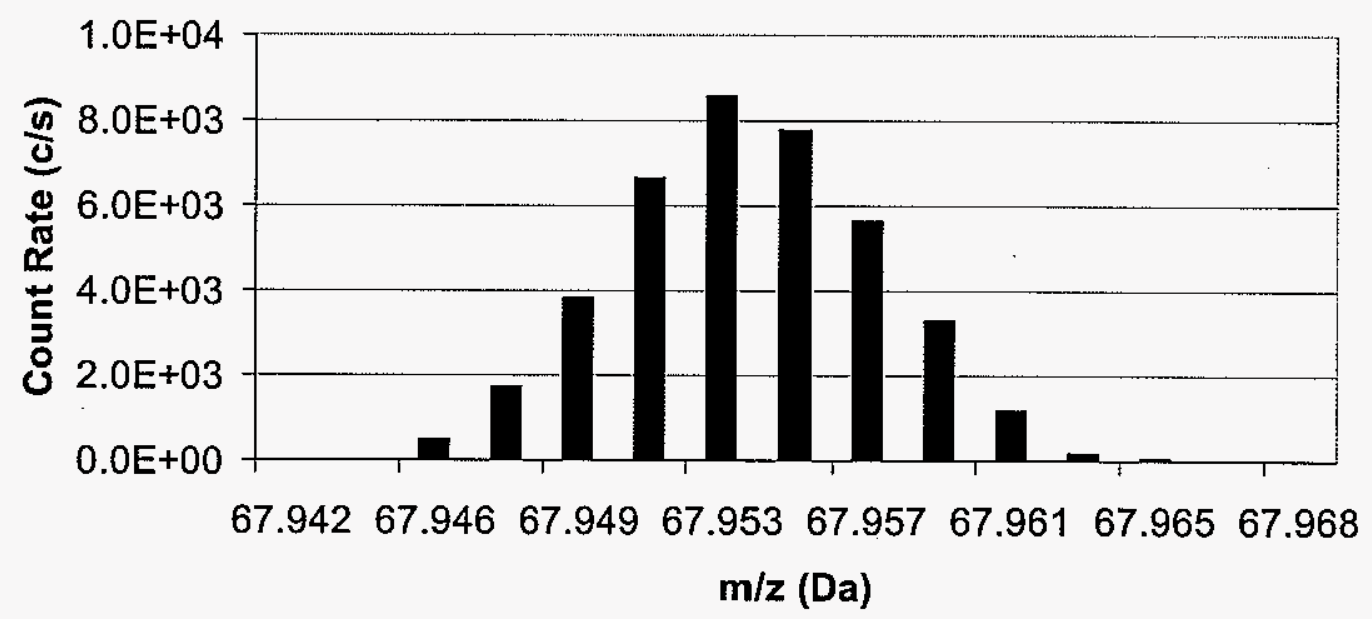

Figure 3b: Medium resolution spectrum of ${ }^{40} \mathrm{Ar}^{13} \mathrm{C}^{16} \mathrm{O}^{+}$from a nebulized solution of $20 \%$ isopropyl alcohol in deionized water. Peak centroid $=68.9570$. Integrated intensity $=409$.

\section{Medium Resolution Spectrum}

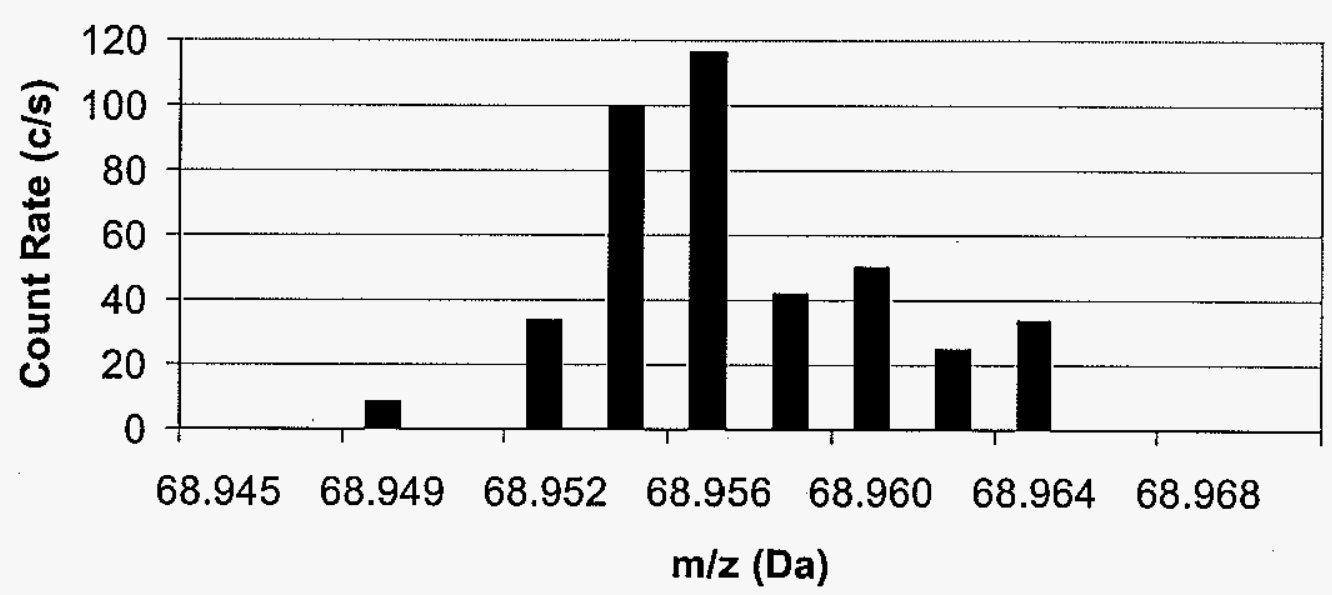


Figure 4: High resolution spectrum of ${ }^{15} \mathrm{~N}^{16} \mathrm{O}^{+},{ }^{14} \mathrm{~N}^{17} \mathrm{O}^{+}$, and ${ }^{14} \mathrm{~N}^{16} \mathrm{OH}^{+}$from a nebulized solution of $1 \%$ nitric acid in deionized water. ${ }^{31} \mathrm{P}^{+}$would be to the left of the window shown.

Peak Centroid Integrated Intensity

Assigned Identity

30.9810

$3.69 \times 10^{4}$

${ }^{15} \mathrm{~N}^{16} \mathrm{O}^{+}$

30.9884

$4.64 \times 10^{3}$

${ }^{14} \mathrm{~N}^{17} \mathrm{O}^{+}$

30.9919

$7.36 \times 10^{4}$

${ }^{14} \mathrm{~N}^{16} \mathrm{O}^{1} \mathrm{H}^{+}$

High Resolution Spectrum

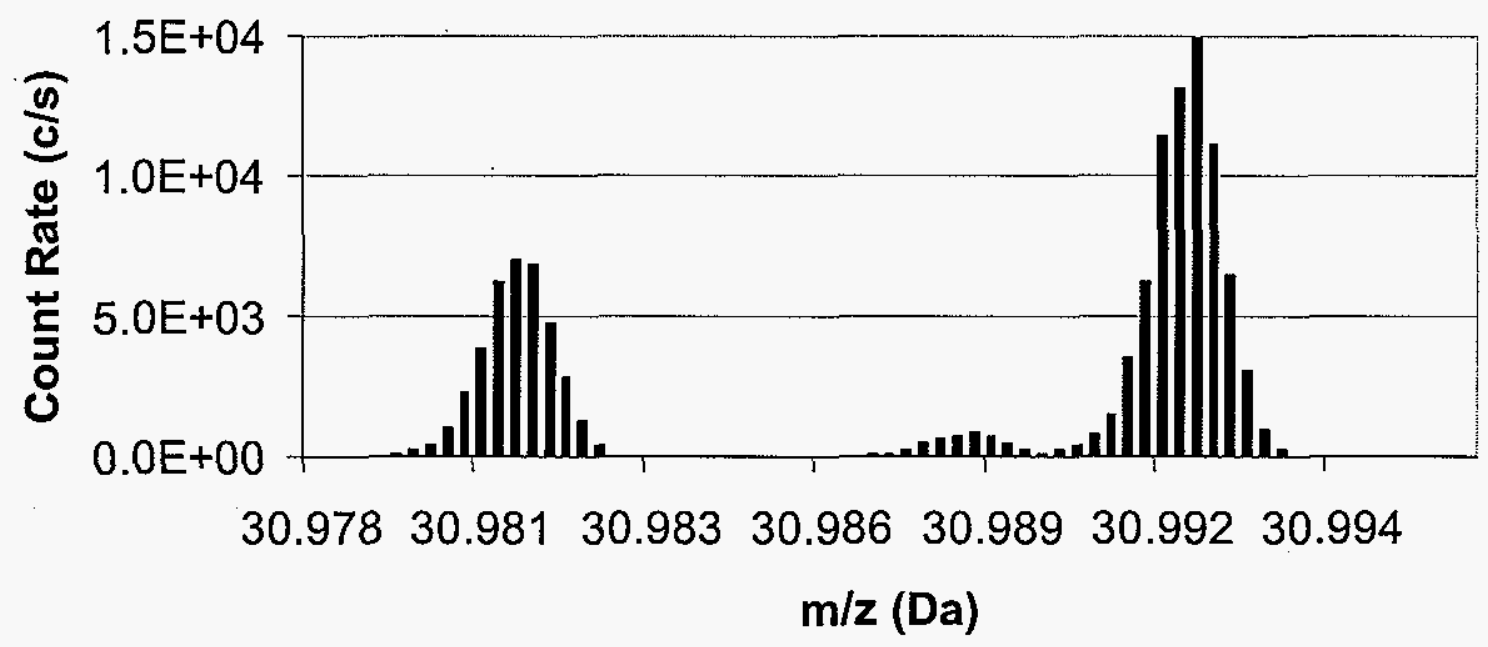


Figure 5a: High resolution spectrum of ${ }^{12} \mathrm{C}_{2}{ }^{+}$from $10 \%$ IPA in deionized water. Peak centroid $=23.9871$. Integrated intensity $=3.63 \times 10^{5}$.

High Resolution Spectrum

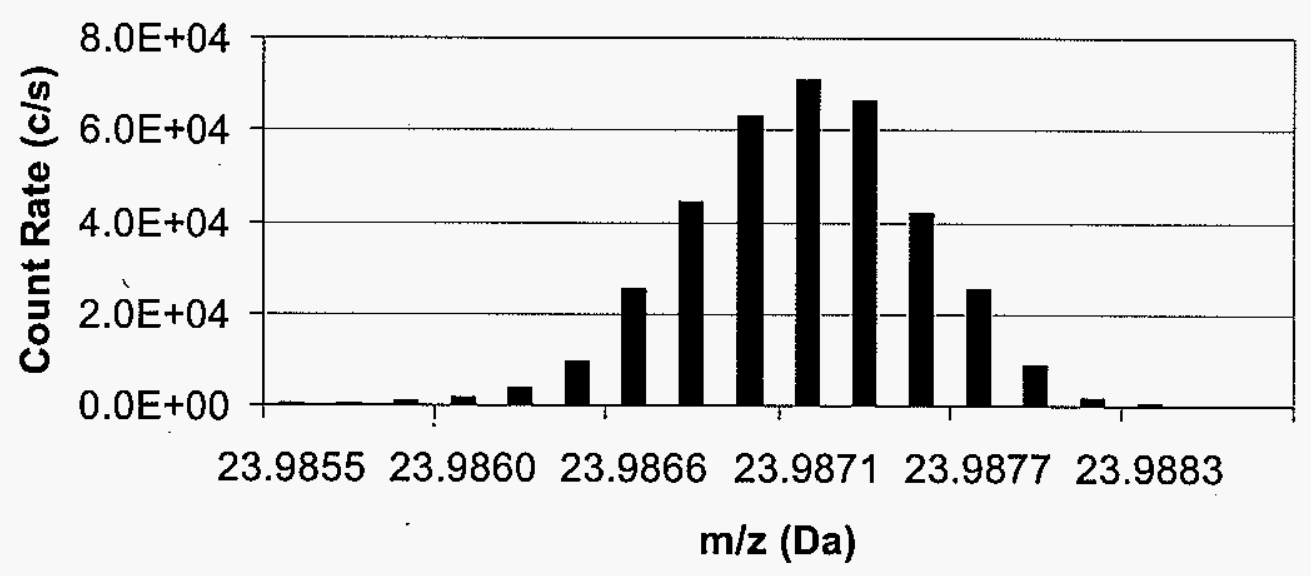

Figure 5b: High resolution spectrum of ${ }^{12} \mathrm{C}^{13} \mathrm{C}^{+}$(low mass) and ${ }^{12} \mathrm{C}_{2} \mathrm{H}^{+}$(high mass) from $10 \% \mathrm{IPA}$ in deionized water

$\begin{array}{lll}\text { Peak Centroid } & \text { Integrated Intensity } & \text { Assigned Identity } \\ 24.9901 & 8.04 \times 10^{3} & { }^{12} \mathrm{C}^{13} \mathrm{C}^{+} \\ 24.9946 & 4.42 \times 10^{3} & { }^{12} \mathrm{C}_{2}{ }^{1} \mathrm{H}^{+}\end{array}$

High Resolution Spectrum

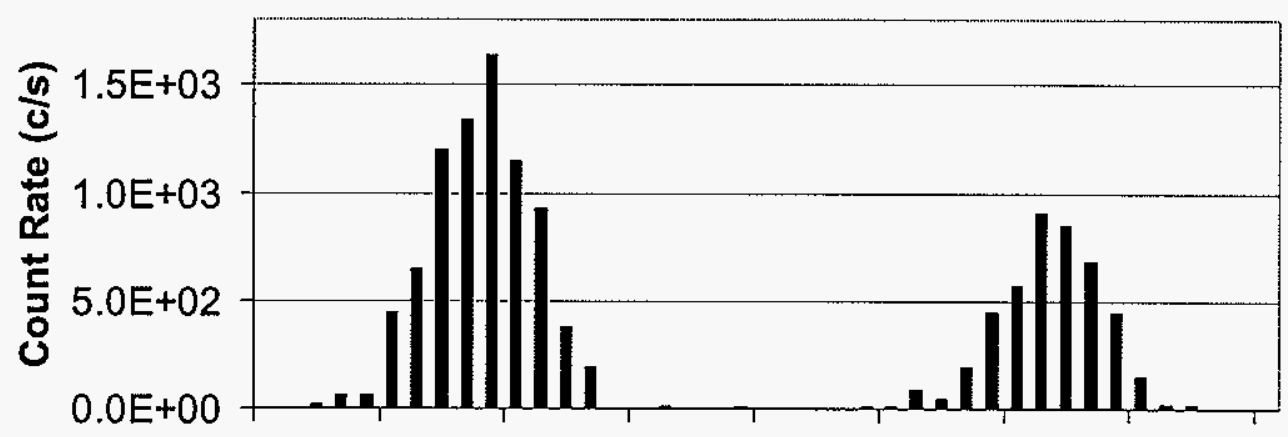

$\begin{array}{llllll}24.9885 & 24.9898 & 24.9912 & 24.9926 & 24.9939 & 24.9953\end{array}$

$\mathrm{m} / \mathbf{z}(\mathrm{Da})$ 
Figure 5c: High resolution spectrum of ${ }^{12} \mathrm{C}_{2} \mathrm{D}^{+}$from $10 \%$ IPA in $\mathrm{D}_{2} \mathrm{O}$. The unresolved signal to the low mass side may be ${ }^{12} \mathrm{C}^{13} \mathrm{CH}^{+}$. Peak centroid $=26.0010$. Integrated intensity $=3.53 \times 10^{3}$.

High Resolution Spectrum

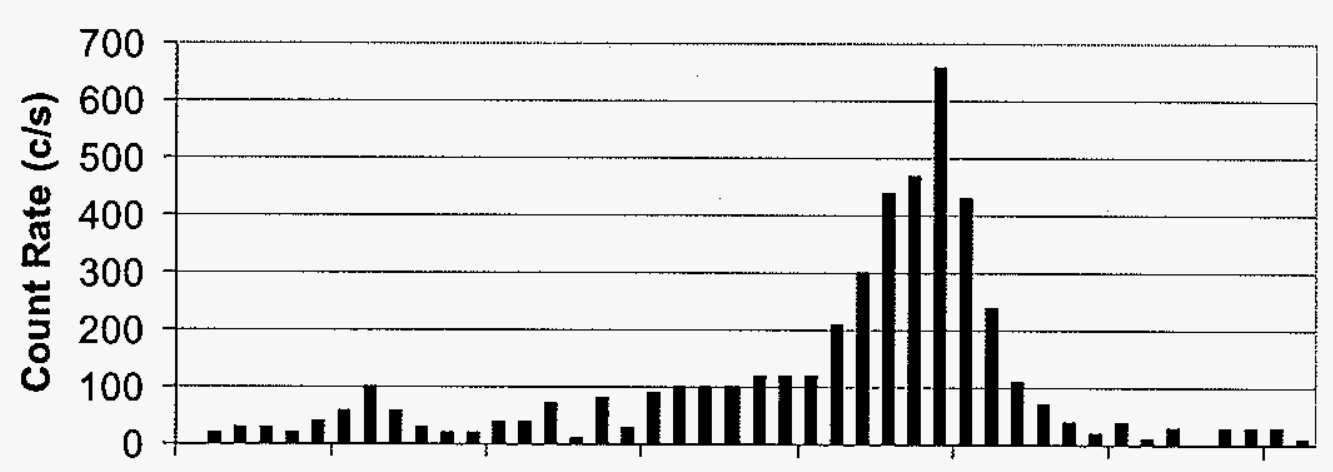

25.995425 .996625 .997825 .999126 .000326 .001526 .002726 .0040 $\mathrm{m} / \mathbf{z}(\mathrm{Da})$

Figure 5d: High resolution spectrum of ${ }^{12} \mathrm{C}_{2} \mathrm{H}_{2}{ }^{+}$from $10 \%$ IPA in deionized water. Peak centroid $=26.0021$. Integrated intensity $=1.77 \times 10^{3}$.

High Resolution Spectrum

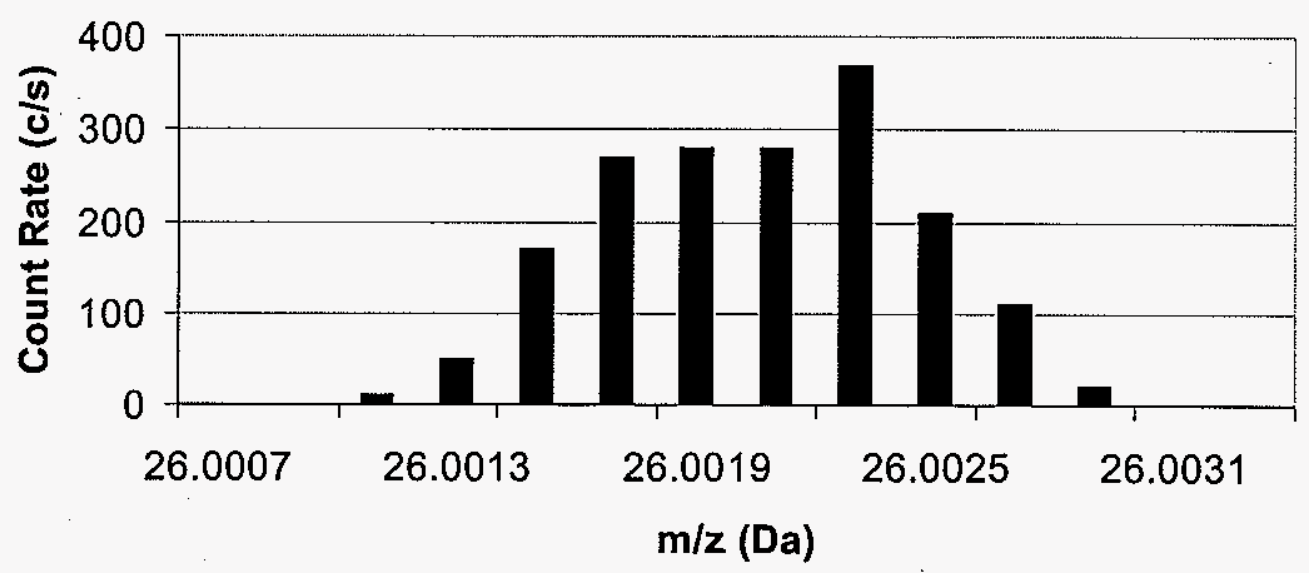


Figure 6a: Mass bias plot comparing sensitivity from aluminum and nickel cones. Data taken from a $10 \mathrm{ppb}$ multielement standard in medium resolution.

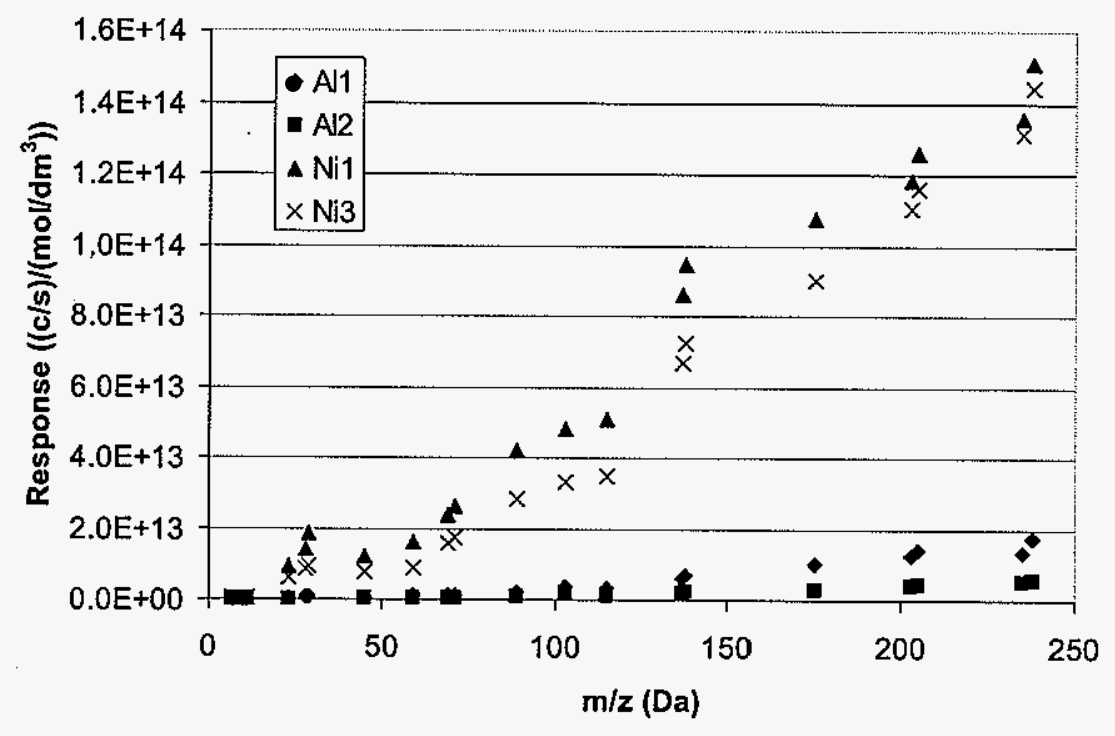

Figure 6b: Comparison of signal intensity from nickel cones versus aluminum cones.

Vertical axis is nickel data normalized to aluminum experiments. Data taken from a $10 \mathrm{ppb}$ multielement standard in medium resolution.

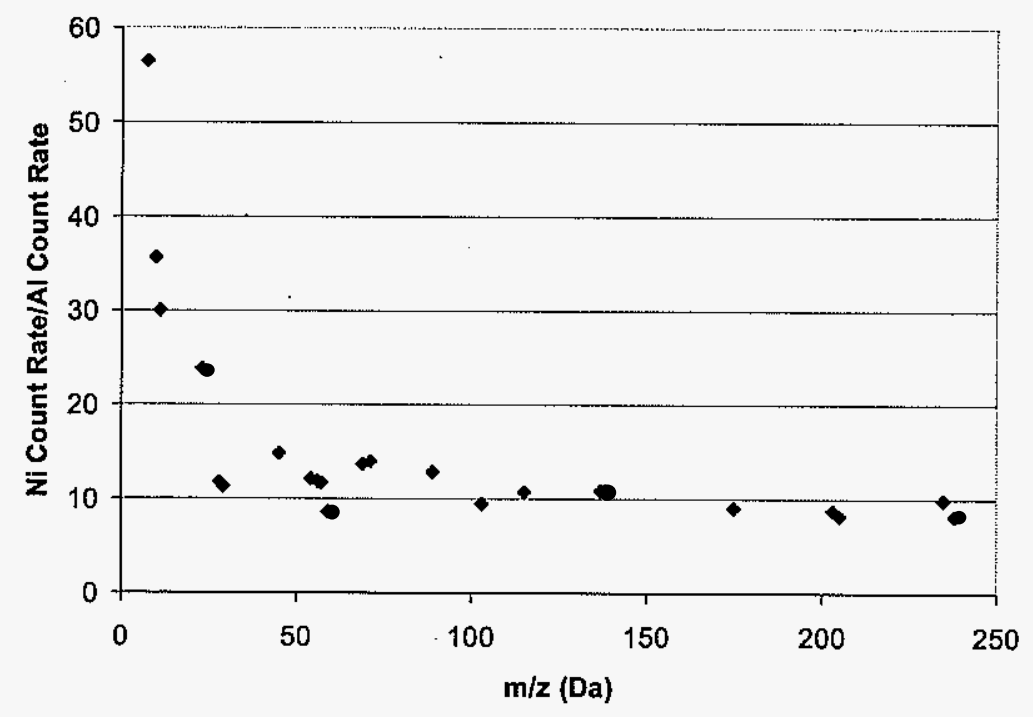


Figure 7: Ion intensity comparison between nickel and aluminum cones normalized to the bias factor between nickel and aluminum cones.

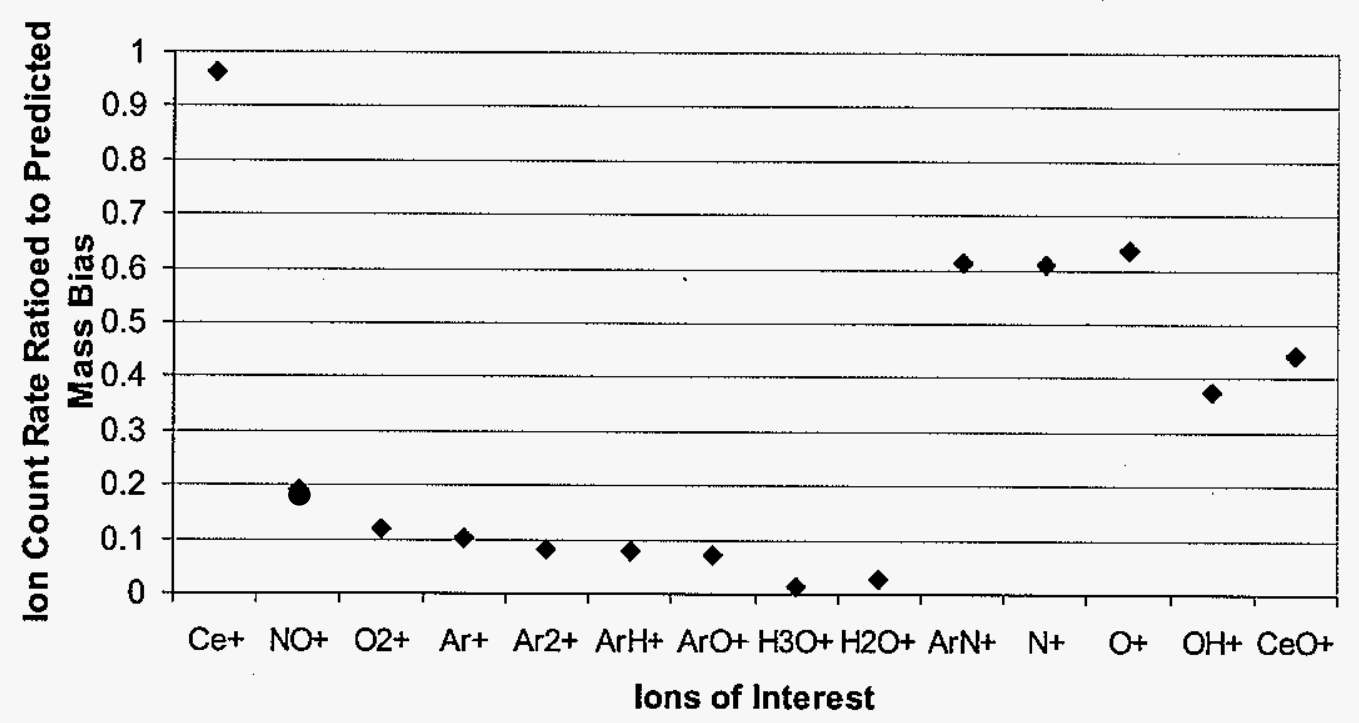


Figure 8: Depiction of gas dynamics in the interface region.
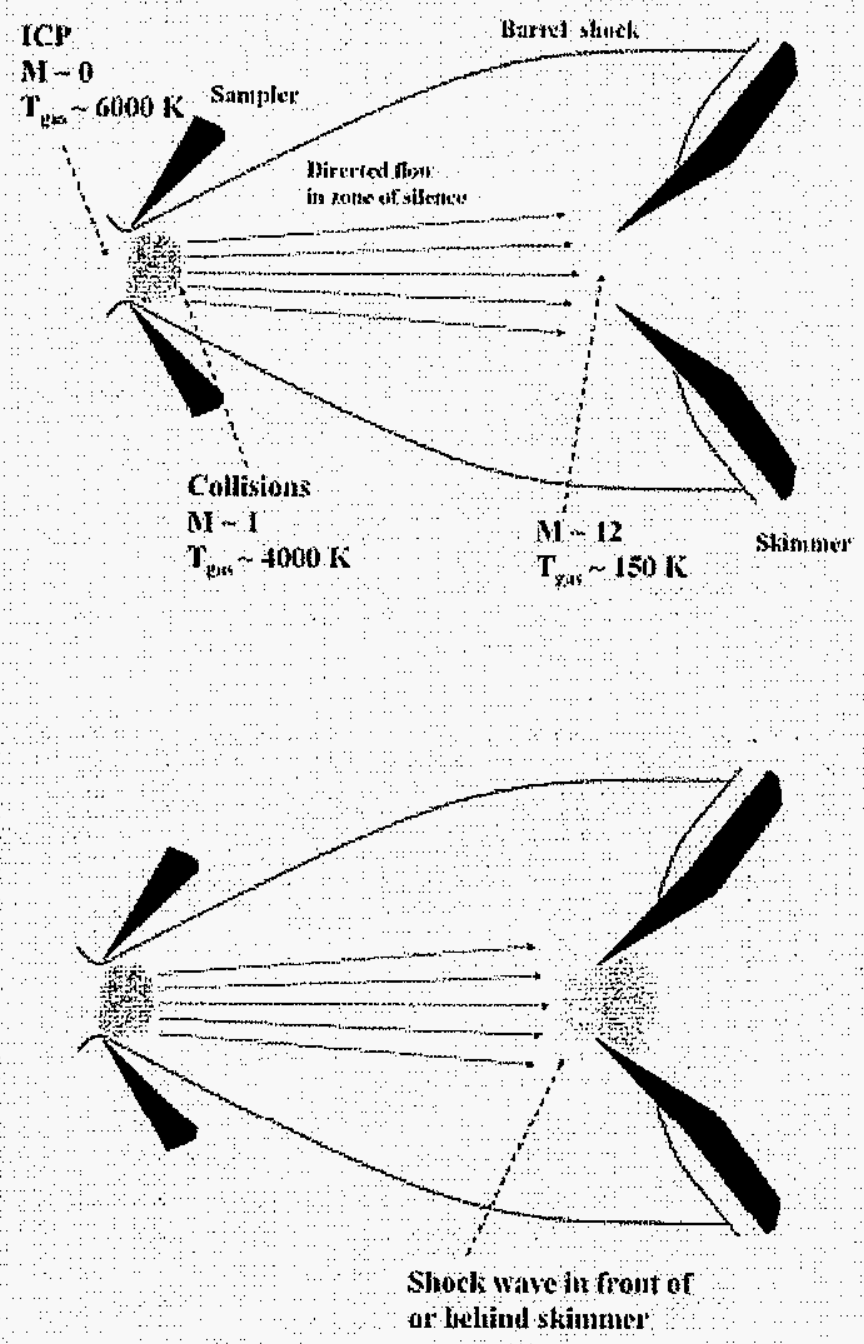
Figure 9: Medium resolution data taken from $10 \mathrm{ppb}$ multielement standard. Vertical axis shows response (mass bias) data at an extraction voltage of $-2000 \mathrm{~V}$ normalized to that at $-1000 \mathrm{~V}$.

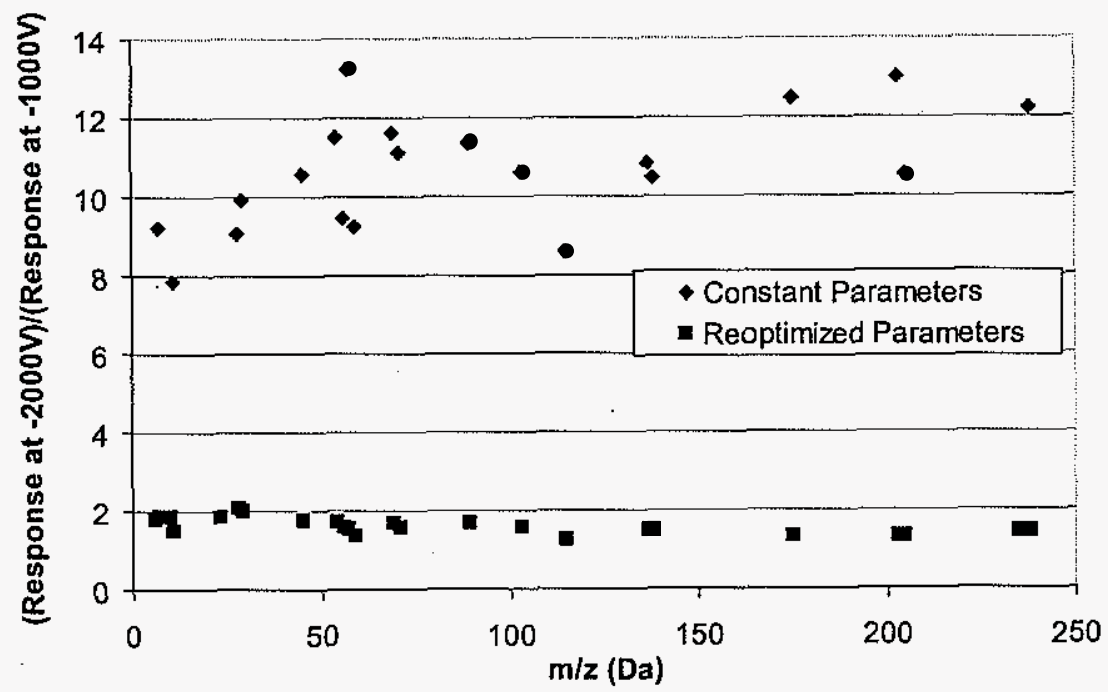

Figure 10: Comparison of ion intensities at $-2000 \mathrm{~V}$ versus $-1000 \mathrm{~V}$. Ions of interest are normalized to ions from atomic standards.

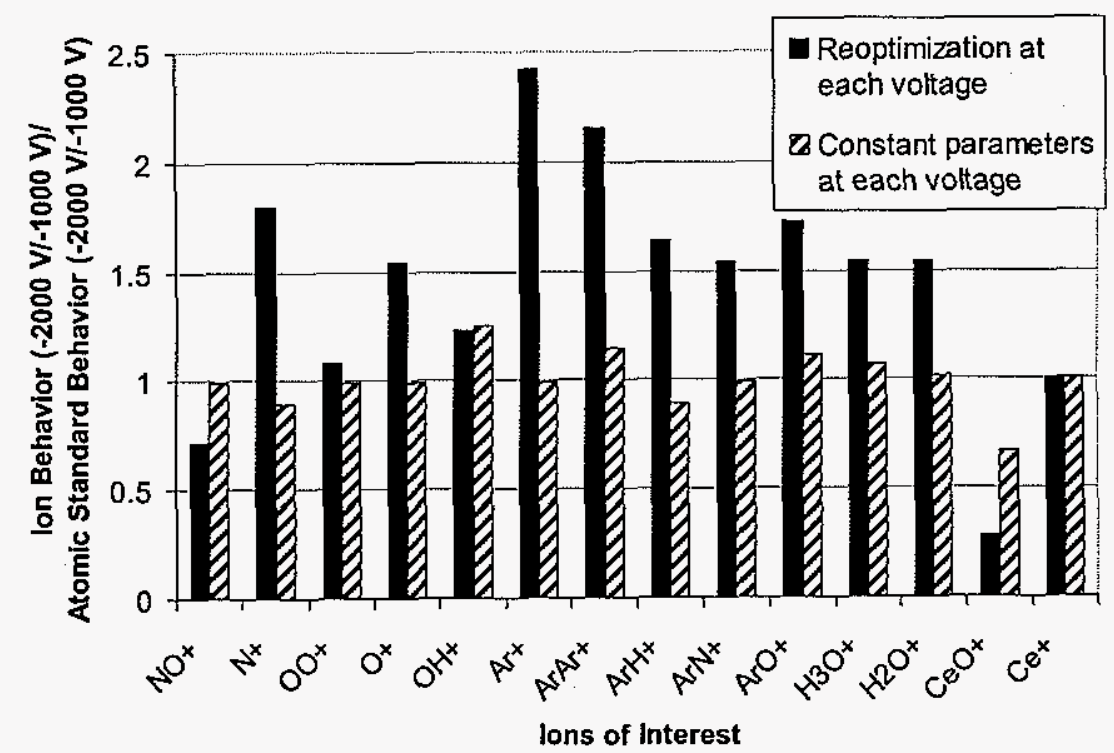




\title{
CHAPTER 3. HIGH RESOLUTION STUDIES OF THE ORIGINS OF POLYATOMIC IONS IN INDUCTIVELY COUPLED PLASMA - MASS \\ SPECTROMETRY \\ PART II. NOVEL CALCULATIONS OF UNUSUAL IONS
}

\author{
A paper submitted to Spectrochimica Acta Part B \\ Jill Wisnewski Ferguson, Timothy J. Dudley, Kyle C. Sears, Mark S. Gordon, \\ and R. S. Houk
}

\begin{abstract}
Several polyatomic ions in ICP-MS are studied experimentally and by computational chemistry. Novel calculations based on spin-restricted open shell second order perturbation theory (ZAPT2) and coupled cluster (CCSD(T)) theory are performed to determine the energies and partition functions of the ions. These values are combined with experimental data to evaluate a dissociation constant for the proposed reaction. The outcome of this equation is a gas kinetic temperature $\left(\mathrm{T}_{\mathrm{gas}}\right)$ value that describes the location where the polyatomic ion of interest is generated. The examination of $\mathrm{N}_{2} \mathrm{H}^{+}$leads to a calculated $\mathrm{T}_{\text {gas }}$ of 4550 to $4900 \mathrm{~K}$, depending on the theoretical modeling system used. The study of $\mathrm{HCO}^{+}$ produces a similar temperature, which is not surprising considering the similar energies of $\mathrm{HCO}^{+}$and $\mathrm{N}_{2} \mathrm{H}^{+}$. The evaluation of $\mathrm{H}_{2} \mathrm{CO}^{+}$leads to a much lower $\mathrm{T}_{\text {gas }}(<1000$ to $2000 \mathrm{~K}$ ). Finally, the dissociation of $\mathrm{H}_{3} \mathrm{CO}^{+}$generates a $\mathrm{T}_{\text {gas }}$ value between those from the other $\mathrm{H}_{\mathrm{x}} \mathrm{CO}^{+}$ions studied here. All of these calculated $\mathrm{T}_{\mathrm{gas}}$ values correspond to formation of extra polyatomic ion in the interface or extraction region. The calculations reveal the existence of isomers such as $\mathrm{HCO}^{+}$and $\mathrm{COH}^{+}$, and $\mathrm{H}_{2} \mathrm{CO}^{+}$and $\mathrm{HCOH}^{+}$, which complicate the interpretation of results.
\end{abstract}




\section{Introduction}

Inductively coupled plasma-mass spectrometry (ICP-MS) is a highly sensitive technique for the identification and quantification of elements in diverse samples. One strength of this technique is the ability of the ICP to atomize and ionize the sample. However, because of both the ICP's unique characteristics (high temperature, high concentration of electrons and argon) and the interface to the mass spectrometer, polyatomic ions may be created. Many of these ions do not readily exist in a normal environment, and little is known about them.

In this paper, unusual polyatomic ions are identified and quantified to some degree using a high resolution magnetic sector mass spectrometer (ThermoFinnigan ELEMENT). Calculations are done to determine the electronic, vibrational, and rotational energy states of the ions. With this information, both a theoretical and experimental dissociation expression can be written and compared. This comparison leads to the calculation of a $\mathrm{T}_{\mathrm{gas}}$ value that describes the temperature of the region where the particular polyatomic ion is formed [1,2]. Therefore, the origins of these previously unknown ions may be determined. Steps could then be taken to reduce the abundance of the polyatomic ions, thus improving the figures of merit of all ICP-MS devices.

\section{Theory}

In this work, the process of studying a polyatomic ion starts with writing a dissociation reaction for the ion of interest, as described elsewhere $[1,2,3]$. This dissociation reaction can be written as convenient for analytical measurement, as it does not need to take into account ionization or competing reactions. For a generic dissociation reaction such as 


$$
\mathrm{AB}^{+} \rightleftharpoons \mathrm{A}^{+}+\mathrm{B}
$$

the experimental and theoretical dissociation equilibrium expressions are written and set equal (Eq. 2), and the gas kinetic temperature is evaluated

$$
\frac{n_{A^{+}} n_{B}}{n_{A B^{+}}}=10^{\left(1.5 \log T_{\text {gas }}-\frac{5040 D_{0}}{T_{\text {gas }}}+1.5 \log \frac{M_{A^{+}} M_{B}}{M_{A B^{+}}}+\log \frac{Z_{A^{+}}^{\prime} Z_{B}^{\prime}}{Z^{\prime}{ }_{A B^{+}}}+20.274\right)}
$$

where $\mathrm{n}$ is the number density of the indicated species (particles $/ \mathrm{cm}^{-3}$ ), $\mathrm{D}_{0}$ is the dissociation energy of the ion $\mathrm{AB}^{+}(\mathrm{eV}), \mathrm{M}$ is the atomic or molecular weight of the indicated species $(\mathrm{g} / \mathrm{mol}), \mathrm{Z}^{\prime}$ is the product of the electronic, vibrational, and rotational partition function terms, and $\mathrm{T}_{\text {gas }}$ is the gas kinetic temperature $(\mathrm{K})$. Note that the both the neutral species density and partition functions are themselves dependent on $\mathrm{T}_{\mathrm{gas}}$ and are calculated discretely for each $\mathrm{T}_{\text {gas. }}$. For a single atom species such as $\mathrm{H}$ or $\mathrm{O}$, the $\mathrm{Z}^{\prime}$ term only includes the electronic partition function [1].

The calculated $T_{\text {gas }}$ identifies which way the system equilibrium lies and what process may influence the abundance of $\mathrm{AB}^{+}$. There are three major scenarios. See Table 1. The first is when the calculated $\mathrm{T}_{\text {gas }}$ is approximately $5500-6000 \mathrm{~K}$. This indicates that the theoretical dissociation is roughly equal to the experimental dissociation $\left(\mathrm{K}_{\mathrm{d} \text {, theo }} \approx \mathrm{K}_{\mathrm{d} \text {, exp }}\right)$. This finding suggests that the ions are formed in the ICP itself and is common for $\mathrm{MO}^{+}$ions such $\mathrm{CeO}^{+}$

The second arrangement is when the determined $\mathrm{T}_{\text {gas }}$ is less than $5500 \mathrm{~K}$. The theoretical dissociation constant is larger than the experimental value $\left(K_{d, \text { theo }}>K_{d \text {, exp }}\right)$. This suggests that extra $\mathrm{AB}^{+}$is being generated after the ICP, as the denominator of the experimental term is too large, making the experimental term smaller overall. The 
polyatomic ion could be generated via collisions in the supersonic jet or in the extraction process. An example of this situation is the dissociation of $\mathrm{H}_{2} \mathrm{O}^{+}$to $\mathrm{OH}^{+}$[2].

The third scenario is when the estimated $\mathrm{T}_{\text {gas }}$ is greater than $6000 \mathrm{~K}$; the theoretical dissociation constant is smaller than the experimental value $\left(\mathrm{K}_{\mathrm{d} \text {, theo }}<\mathrm{K}_{\mathrm{d} \text {, exp }}\right)$. Therefore $\mathrm{AB}^{+}$is being eliminated in the system, possibly through collision induced dissociation in the interface or extraction regions. $\mathrm{NO}^{+}$dissociating to $\mathrm{N}^{+}$models this behavior $[1,2]$.

\section{Experimental}

Table 2

In this work, some ions well known to the ICP-MS community are studied $[1,2]$ as well as others that have been scarcely discussed in this context $\left(\mathrm{N}_{2} \mathrm{H}^{+}, \mathrm{COH}^{+}\right)$. Groups of ions of similar mass to charge ratio $(\mathrm{m} / \mathrm{z})$ are measured using a high resolution ICP-MS device, capable of resolution of approximately 300,4000 , or 11000 . A single magnet mass setting is used for a particular group of ions to aid in their identification, as standard offsets develop between actual mass and measured mass at one magnetic field setting [2].

Once spectra are collected in a $\mathrm{m} / \mathrm{z}$ range of interest, the offsets determined between the $m / z$ values measured for $\mathrm{M}^{+}$ions from elemental standards and the accurate $m / z$ values can be used to determine an approximate actual mass of the unknown ions. A line correction equation can be derived from standards to assist in actual mass estimation. The approximate actual $\mathrm{m} / \mathrm{z}$ of unknown ions from the spectra are then compared to that of various combinations of atoms to help assign an identity. Suggested identities are confirmed by the examination of isotope peaks, addition of organic solvent, and/or nebulization of $\mathrm{D}_{2} \mathrm{O}$ [2].

The vibrational, rotational, and electronic partition functions are then determined for the ions in question. Through our collaborative efforts, we attain energies calculated via the 
$\operatorname{CCSD}(\mathrm{T})$ and ZAPT2 methods with a high degree of certainty. Articles by Gordon and coworkers explain the methods used and detail the work done on these specific ions $[4,5]$. It should be noted that some of these ions have been studied previously. In those cases, the calculated values are consistent with previously published values [6-10]. Other ions have not been studied or modeled in this manner, so these computational results are of interest in their own right. Finally, a Microsoft Excel spreadsheet is set up to compare the experimental and theoretical dissociation constant expressions and ultimately calculate the gas kinetic temperature.

\section{Results}

\section{$\mathrm{N}_{2} \mathrm{H}^{+}$and $\mathrm{N}_{2}^{+}$}

$\mathrm{N}_{2}{ }^{+}$is a common polyatomic ion seen in ICP-MS. The presence of $\mathrm{N}_{2}^{+}$in the mass spectrum is expected since the plasma flows into the air. However, the authors were surprised to note that $\mathrm{N}_{2} \mathrm{H}^{+}$was more abundant than $\mathrm{N}_{2}^{+}$(Figs.1 and 2). Polyatomic ions with more atoms are generally expected to be less abundant at the high temperatures present in the ICP.

Once the true identity of the ions was clear via accurate $\mathrm{m} / \mathrm{z}$ measurements, isotope ratio measurements, and solvent manipulation, we measured and modeled the following reaction.

$$
\mathrm{N}_{2} \mathrm{H}^{+} \rightleftharpoons \mathrm{N}_{2}^{+}+\mathrm{H}
$$

The calculated energies for $\mathrm{N}_{2} \mathrm{H}^{+}$are reported in Table 3 .

$\mathrm{A} \mathrm{T}_{\text {gas }}$ of about $4550 \mathrm{~K}$ is obtained using energies provided by the ZAPT2 calculation. Using the $\operatorname{CCSD}(\mathrm{T})$ data produces a kinetic gas temperature around $4900 \mathrm{~K}$. The difference in temperature is primarily attributed to the variation in calculated 
dissociation energy between the two models. The $\operatorname{CCSD}(\mathrm{T})$ method is the higher level calculation and thus is thought to be more accurate.

$\mathrm{T}_{\text {gas }}$ values of 4550 or $4900 \mathrm{~K}$ are lower than those seen from ions which originate in the plasma, such as $\mathrm{CeO}^{+}$. This indicates that additional $\mathrm{N}_{2} \mathrm{H}^{+}$is being produced in the interface or extraction. It is reasonable that since there is more $\mathrm{N}_{2} \mathrm{H}^{+}$than $\mathrm{N}_{2}^{+}$, it is being produced somewhere. In addition, $\mathrm{N}_{2} \mathrm{H}^{+}$is more stable thermodynamically than $\mathrm{N}_{2}^{+}$. Once $\mathrm{N}_{2} \mathrm{H}^{+}$is formed, it is more likely to remain than other reactive species, such as $\mathrm{N}_{2}$ or $\mathrm{N}_{2}^{+}$. Therefore, it is not surprising to the computational chemist that $\mathrm{N}_{2} \mathrm{H}^{+}$is more abundant than $\mathrm{N}_{2}{ }^{+}$, and through this work, spectroscopists can begin to understand this initially surprising result.

Interestingly, when modeling the $\mathrm{N}_{2} \mathrm{H}^{+}$system, it was found that Eq. 3 does not indicate the actual reaction mechanism. Instead, the following series of reactions is more likely to occur.

$$
\begin{array}{ll}
\mathrm{N}_{2} \mathrm{H}^{+} \rightleftharpoons \mathrm{N}_{2}+\mathrm{H}^{+} & \mathrm{K}_{\mathrm{d}_{2}} \\
\mathrm{~N}_{2}+\mathrm{H}^{+} \rightleftharpoons \mathrm{N}_{2}^{+}+\mathrm{H} & \mathrm{K}_{\mathrm{d}_{3}}
\end{array}
$$

However, whether the calculations are done in one overall step (Eq. 3) or two steps (Eq. 4-5) using the principle,

$$
\mathrm{K}_{\mathrm{d}_{1}}=\mathrm{K}_{\mathrm{d}_{2}} \mathrm{~K}_{\mathrm{d}_{3}}
$$

the same result for $\mathrm{T}_{\mathrm{gas}}$ and probable ion origin is obtained. This speaks to the accuracy of the calculations and the application of the equilibrium principle to these polyatomic ions in ICP-MS. 


\section{$\mathrm{HCO}^{+}, \mathrm{COH}^{+}$, and $\mathrm{CO}^{+}$}

The dissociation of $\mathrm{HCO}^{+}$to $\mathrm{CO}^{+}+\mathrm{H}$ is energetically similar to that of $\mathrm{N}_{2} \mathrm{H}^{+}$and $\mathrm{N}_{2}^{+}$. The reaction proceeds as

$$
\mathrm{HCO}^{+} \rightleftharpoons \mathrm{COH}^{+} \rightleftharpoons \mathrm{CO}^{+}+\mathrm{H}^{-}
$$

This system is similar to the one previously discussed in that $\mathrm{HCO}^{+}$is the most thermodynamically stable ion in Eq. 7. However, this situation is somewhat complicated by the fact that $\mathrm{HCO}^{+}$rearranges to $\mathrm{COH}^{+}$, and the two have different energies. The mass spectrometer cannot discriminate between these two species; the signal observed is that for the sum of $\mathrm{HCO}^{+}$and $\mathrm{COH}^{+}$. Since the overall energies of the ions and dissociation reactions are nearly the same for $\mathrm{N}_{2} \mathrm{H}^{+}$and $\mathrm{HCO}^{+}$(Tables 3-5), a similar ion ratio and measured $\mathrm{T}_{\text {gas }}$ are expected. However, this is not precisely the case, as the $\mathrm{HCO}^{+} / \mathrm{COH}^{+}$signal is less intense than that for $\mathrm{CO}^{+}$(Figs. 1-2). The $\mathrm{N}_{2} \mathrm{H}^{+} / \mathrm{N}_{2}{ }^{+}$signal ratio is typically around 1.7, depending on conditions, while the signal ratio $\left(\mathrm{HCO}^{+} / \mathrm{COH}^{+}\right) / \mathrm{CO}^{+}$is about 0.4 .

Eq. 2 is modified to account for the differing energies of $\mathrm{COH}^{+}$and $\mathrm{HCO}^{+}$which appear in the spectrum as aggregate $\mathrm{COH}^{+}$(not separate $\mathrm{COH}^{+}$and $\mathrm{HCO}^{+}$).

$$
\frac{n_{A^{+}} n_{B}}{n_{A B^{+}}}=10^{\left(1.5 \log T_{\text {gas }} \frac{5040 D_{0}}{T_{\text {gas }}}+1.5 \log \frac{M_{C O^{+}} M_{H}}{M_{H C O^{+}}}+\log \frac{Z_{C O^{+}}^{\prime} Z_{H}^{\prime}}{\left(Z_{H C O^{+}}^{\prime}+Z_{C O H^{+}}^{\prime}\right)}+20.274\right)}
$$

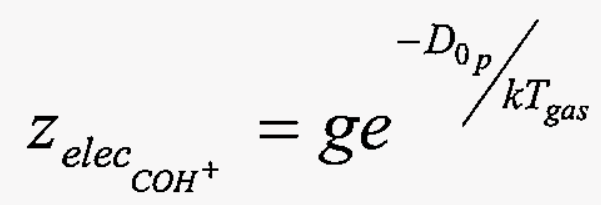


$\mathrm{D}_{0}$ in Equation 8 is the overall dissociation energy of the whole system, while $\mathrm{D}_{0_{\mathrm{p}}}$ in Equation 9 is the dissociation energy of $\mathrm{COH}^{+}$going to $\mathrm{HCO}^{+}$. g denotes the degeneracy of the electronic ground state of $\mathrm{COH}^{+}$.

Using Equation 8, the calculated kinetic gas temperature is about $4750 \mathrm{~K}$ using ZAPT2 theory or $4830 \mathrm{~K}$ using $\mathrm{CCSD}(\mathrm{T})$ theory. This means that $\mathrm{HCO}^{+}$(and probably $\mathrm{COH}^{+}$) is being formed after the plasma. These temperature values are very similar to those calculated for the $\mathrm{N}_{2} \mathrm{H}^{+} / \mathrm{N}_{2}^{+}$system. This is the expected result based on the similar energies and partition functions for these groups of ions. However, this does not explain the very different intensities noted in the experimental spectra. One possible explanation is that there is more $\mathrm{N}_{2}$ in the plasma than $\mathrm{CO}$ because of air infiltration in the argon gas lines, and this allows for a greater $\mathrm{N}_{2} \mathrm{H}^{+}$production in the interface/extraction region in relation to that of $\mathrm{HCO}^{+}$. This would result in much larger $\mathrm{N}_{2}^{+}$and $\mathrm{N}_{2} \mathrm{H}^{+}$peaks compared to those of $\mathrm{HCO}^{+}$ and $\mathrm{CO}^{+}$, mirroring what is actually seen. Yet this still does not address the fact that the $\mathrm{N}_{2} \mathrm{H}^{+} / \mathrm{N}_{2}^{+}$ratio is much larger than that of $\mathrm{HCO}^{+} / \mathrm{CO}^{+}$. Since the two reactions have similar energies and produce the same $\mathrm{T}_{\text {gas, }}$, the ion ratios are expected to be more similar than the results actually show. Why $\mathrm{N}_{2} \mathrm{H}^{+}$is being formed seemingly preferentially to $\mathrm{HCO}^{+}$is unknown, and it may be related to the $\mathrm{HCO}^{+} / \mathrm{COH}^{+}$rearrangement process. This relationship warrants further study.

\section{$\mathrm{H}_{2} \mathrm{CO}^{+}$and $\mathrm{HCOH}^{+}$}

In hoping to learn more about the peculiar behavior of $\mathrm{HCO}^{+}$and $\mathrm{CO}^{+}$, we studied $\mathrm{H}_{2} \mathrm{CO}^{+}$as well. The $\mathrm{H}_{2} \mathrm{CO}^{+}$system presented an additional challenge. Most of the ions studied here have their energies calculated by two methods, ZAPT2 and CCSD(T). The $\operatorname{CCSD}(\mathrm{T})$ method is the more sophisticated method, generally considered to be state-of-the- 
art. In general, the ZAPT2 and CCSD(T) produce results similar enough that their differences make no significant difference in our final calculations. However, for the $\mathrm{H}_{2} \mathrm{CO}^{+}$ system, the two calculation methods point to different dissociation pathways. ZAPT2 theory (Eq. 10) indicates $\mathrm{HCOH}^{+}$is the lowest energy species, while $\mathrm{CCSD}(\mathrm{T})$ calculations (Eq. 11) point to $\mathrm{HCOH}^{+}$as the intermediate. Parallel calculations were done on each series, and the results were then compared.

$$
\begin{aligned}
& \mathrm{HCOH}^{+} \rightleftharpoons \mathrm{H}_{2} \mathrm{CO}^{+} \rightleftharpoons \mathrm{HCO}^{+}+\mathrm{H} \\
& \mathrm{H}_{2} \mathrm{CO}^{+} \rightleftharpoons \mathrm{HCOH}^{+} \rightleftharpoons \mathrm{HCO}^{+}+\mathrm{H}
\end{aligned}
$$

Tables 6 and 7

When the standard matrix of $1 \%$ nitric acid is analyzed and calculations are done with ZAPT2 theory, a gas kinetic temperature of $850 \mathrm{~K}$ is calculated. The $\operatorname{CCSD}(\mathrm{T})$ method gives a $\mathrm{T}_{\text {gas }}$ of $1270 \mathrm{~K}$. The introduction of $10-20 \%$ isopropyl alcohol, which increases the abundance of carbon containing species, results in a ZAPT2 determined temperature of 1360 $\mathrm{K}$, and a $\operatorname{CCSD}(\mathrm{T})$ value of $2020 \mathrm{~K}$. These low temperatures indicate formation of the larger polyatomic ions in the interface or extraction regions. The very low temperature assessed by the ZAPT2 method with $1 \%$ nitric acid is reasonable, as even lower temperatures $(\approx 150 \mathrm{~K})$ are estimated at the skimmer orifice [11]. The difference in calculated temperatures is not surprising, as the modeled reactions are different. Again, it makes sense that such a large ion would not survive the plasma, but instead be formed mainly in the interface or extraction.

The lower temperature calculated for $\mathrm{H}_{2} \mathrm{CO}^{+}$, versus that for $\mathrm{HCO}^{+}$, seems to indicate that $\mathrm{H}_{2} \mathrm{CO}^{+}$is formed farther back in the interface region, nearer to the skimmer cone. At this location in the zone of silence, the number density is 256 times lower than at a position closer to the sampler cone $[3,11]$. Perhaps ion formation at this location is less probable because of the lower number density, in spite of the increased thermodynamic stability of the 
larger polyatomic ion. This hypothesis on the balance between thermodynamics, gas dynamics, and ICP fundamentals, will be examined again later in this article.

\section{$\mathrm{H}_{2} \mathrm{COH}^{+}$}

The dissociation reactions proposed for the final system studied in this series also differed slightly depending on the calculation level used. Eq. 12 is developed from ZAPT2 results, while Eq. 13 utilizes $\operatorname{CCSD}(\mathrm{T})$ theory.

$$
\begin{aligned}
& \mathrm{H}_{2} \mathrm{COH}^{+} \rightleftharpoons \mathrm{HCOH}^{+}+\mathrm{H} \\
& \mathrm{H}_{2} \mathrm{COH}^{+} \rightleftharpoons \mathrm{H}_{2} \mathrm{CO}^{+}+\mathrm{H}
\end{aligned}
$$

$\mathrm{H}_{2} \mathrm{COH}^{+}$is the most thermodynamically stable ion studied here, but it is the least abundant ion in the mass spectrum. To observe $\mathrm{H}_{2} \mathrm{COH}^{+}$, a $20 \%$ isopropyl alcohol solution was nebulized. Using the values in Tables 6 and 7, an average kinetic gas temperature of 3610 and $3650 \mathrm{~K}$ is calculated for the $\mathrm{CCSD}(\mathrm{T})$ and ZAPT2 systems respectively. This result is between the $\mathrm{T}_{\text {gas }}$ values determined for the $\mathrm{HCO}^{+}$and $\mathrm{HCOH}^{+}$systems.

\section{Discussion}

All of the gas kinetic temperatures calculated for the ions discussed in this article are below that of the ICP $(\approx 5500-6000 \mathrm{~K})$. This means that additional amounts of these ions are created in the interface or possibly the extraction region through collisions with other species.

$\mathrm{N}_{2} \mathrm{H}^{+}$and $\mathrm{HCO}^{+}$have similar structures and energies, and produce similar $\mathrm{T}_{\text {gas }}$ values, particularly when comparing the temperatures calculated from the more advanced CCSD(T) theory. The noted difference in ion ratios for the dissociation of $\mathrm{N}_{2} \mathrm{H}^{+}$and $\mathrm{HCO}^{+}$may stem from the abundance of $\mathrm{N}_{2}$ in the atmospheric pressure plasma, and could be influenced by the required rearrangement of $\mathrm{HCO}^{+}$to $\mathrm{COH}^{+}$for dissociation to occur. 
The two hydrogen ions $\mathrm{HCOH}^{+}$and $\mathrm{H}_{2} \mathrm{CO}^{+}$are more stable than $\mathrm{HCO}^{+} / \mathrm{COH}^{+}$, yet less abundant. The much lower $\mathrm{T}_{\text {gas }}$ points to formation farther back into the interface, where the density of species in the zone of silence is much lower. As the $\mathrm{HCO}^{+}$ion would have fewer opportunities to pick up one hydrogen atom at this cooler position, this would explain the lower intensity of $\mathrm{HCOH}^{+} / \mathrm{H}_{2} \mathrm{CO}^{+}$in the mass spectrum. The divergence in energies and dissociation mechanisms between the two computational theories also complicates this scenario:

$\mathrm{H}_{2} \mathrm{COH}^{+}$is the most stable ion discussed here, but the least abundant in the mass spectrum. This is expected to some extent, since at the high temperatures of the ICP, polyatomic ions with more atoms would be less abundant. The calculations produce a $T_{\text {gas }}$ in between the previous two values. This may mean that the ion is formed at a position in the zone of silence in between the other ions discussed here. It makes sense that $\mathrm{H}_{2} \mathrm{COH}^{+}$, with three hydrogen atoms would have to be formed at a position of higher number density than $\mathrm{HCOH}^{+} / \mathrm{H}_{2} \mathrm{CO}^{+}$, the two hydrogen counterparts.

However, the comparison between the two and one hydrogen species does not follow this logic, as $\mathrm{HCO}^{+}$is formed at a position closer to the sampler. Yet this reasoning may still hold true, as it is difficult to characterize where the required rearrangement of $\mathrm{HCO}^{+}$to $\mathrm{COH}^{+}$takes place, and if this location influences the temperature calculated for the dissociation to $\mathrm{CO}^{+}$. In addition, it is possible that the most thermodynamically stable form $\left(\mathrm{HCO}^{+}\right)$is not what exists and is being detected at that precise mass to charge ratio. Perhaps $\mathrm{COH}^{+}$is the favored species in the interface, and the energy required to go from $\mathrm{HCO}^{+}$to $\mathrm{COH}^{+}$is provided by energetic collisions or carryover from the plasma itself.

Since our current instrumental technique offers no way to experimentally discriminate between rearranged species at the same $\mathrm{m} / \mathrm{z}$, we attempted to evaluate the abundance of each 
isomer at specific $\mathrm{T}_{\text {gas }}$ values. For the isomers $\mathrm{AB}^{+}$and $\mathrm{BA}^{+}$a rearrangement reaction (Eq. 14) and corresponding equilibrium constant expression (Eq. 15) were written. This was then incorporated into equations (Eq. 16-17) which determined the amount of each isomer existing at a specific gas kinetic temperature, $5800 \mathrm{~K}$, which describes the $T_{\text {gas }}$ value of the plasma itself. Therefore, it is thought that these expressions estimate the proportion of signal to be attributed to each isomer originating in the plasma, if local equilibrium is reached.

$$
\begin{aligned}
& \mathrm{AB}^{+} \rightleftharpoons \mathrm{BA}^{+} \\
& K_{A B^{+}}=\frac{n_{B A^{+}}}{n_{A B^{+}}}=\frac{Z_{B A^{+}}^{\prime}}{Z_{A B^{+}}^{\prime}} e^{-D_{0} / k T_{\text {gas }}} \\
& \alpha_{A B^{+}}=\frac{1}{1+K_{A B^{+}}}=\frac{n_{A B^{+}}}{n_{A B^{+}}+n_{B A^{+}}} \\
& n_{A B^{+}}=\alpha_{A B^{+}} N_{t}
\end{aligned}
$$

All variables have been previously identified except $\mathrm{N}_{\mathrm{t}}$, which is the experimentally measured total amount of $\left(\mathrm{AB}^{+}+\mathrm{BA}^{+}\right)$. These ion amounts (n) can then be incorporated into the previously described equations (Eq. 2), without requiring the summation of energies seen in Eq. 8.

In the comparison of isomers $\mathrm{HCO}^{+}$and $\mathrm{COH}^{+}$, it is found that at $5800 \mathrm{~K}, 53.1 \%$ of the signal at $m / z=29.0027$ is attributed to the lower energy ion, $\mathrm{HCO}^{+}$. When comparing $\mathrm{H}_{2} \mathrm{CO}^{+}$and $\mathrm{HCOH}^{+}$at $5800 \mathrm{~K}, 54.8 \%$ of the signal at $m / z=30.0105$ is attributed to the lower energy species $\mathrm{H}_{2} \mathrm{CO}^{+}$, according to the $\operatorname{CCSD}(\mathrm{T})$ theory. When the dissociation reactions were calculated with this adjustment, $T_{\text {gas }}$ values were decreased by $150-200 \mathrm{~K}$. This decrease does not substantially change the proposed location of ion formation in the interface 
region. It is noteworthy that as $\alpha$ is calculated at higher temperatures, the proportion of the measured signal attributed to the higher energy ion increases. This result is logical, as the isomerization reactions are endothermic; as $\mathrm{T}_{\text {gas }}$ increases, the higher energy species becomes more prevalent. In addition, isomerizations that require more energy have a higher proportion of low energy species at a given temperature.

\section{Conclusions}

The dissociation of $\mathrm{N}_{2} \mathrm{H}^{+}$to $\mathrm{N}_{2}^{+}$and that of $\mathrm{HCO}^{+}$to $\mathrm{CO}^{+}$are thermodynamically similar. This is evidenced by the similar kinetic gas temperatures calculated for each dissociation. Both $\mathrm{N}_{2} \mathrm{H}^{+}$and $\mathrm{HCO}^{+}$appear to be formed in excess after the plasma, possibly in the interface region or during ion extraction. A similar process is happening in the creation of $\mathrm{H}_{2} \mathrm{CO}^{+} / \mathrm{HCOH}^{+}$and $\mathrm{H}_{2} \mathrm{COH}^{+}$, which are more thermodynamically stable than $\mathrm{HCO}^{+}$or $\mathrm{COH}^{+}$. However, different $\mathrm{T}_{\text {gas }}$ values are calculated for these polyhydrogenated species, indicating that they may be formed in a different region or farther away from the plasma (closer to the terminal $\mathrm{T}_{\text {gas }}$ of the expansion). We need to discover what the balancing force is between thermodynamic stability, gas dynamics, and traditional ICP methodology. That may be the key in understanding the difference in ion ratios seen with the $\mathrm{N}_{2} \mathrm{H}^{+}$to $\mathrm{N}_{2}^{+}$and $\mathrm{HCO}^{+}$to $\mathrm{CO}^{+}$systems.

\section{Acknowledgements}

This research was supported by the National Science Foundation through the Institute for Physical Research and Technology at ISU. JWF was also supported by the Velmer A. and Mary K. Fassel Fellowship. The nebulizers used were provided by Elemental Scientific Inc. The ICP-MS device was obtained with funds provided by the U. S. Department of 
Energy, Office of Nuclear Nonproliferation (NA-22) and the Office of Basic Energy

Sciences. Ames Laboratory is operated for the U.S. Department of Energy by Iowa State University under Contract No. W-7405-Eng-82.

\section{References}

[1] R. S. Houk, N. Praphairaksit, Dissociation of polyatomic ions in the inductively coupled plasma, Spectrochim. Acta Part B 56 (2001) 1069-1096.

[2] J. W. Ferguson, R. S. Houk, High resolution studies of the origins of polyatomic ions in inductively coupled plasma - mass spectrometry part I: identification methods and effects of neutral density assumptions, extraction voltage, and cone material, Spectrochim. Acta Part B, submitted May 2006.

[3] H. Niu, R. S. Houk, Fundamental aspects of ion extraction in inductively coupled plasma mass spectrometry, Spectrochim. Acta Part B 51 (1996) 779-815.

[4] M. W. Schmidt, K. K. Baldridge, J. A. Boatz, S. T. Elbert, M. S. Gordon, J. H. Jensen, S. Koseki, N. Matsunaga, K. A. Nguyen, S. Su, T. L. Windus, M. Dupuis, J. A. Montgomery, Jr., General atomic and molecular electronic structure system, J. Comp. Chem. 14 (1993) 1347-1363; M.S. Gordon and M.W. Schmidt, "Advances in Electronic Structure Theory: GAMESS a Decade Later", Theory and Applications of Computational Chemistry, Ch.. 41, C. E. Dykstra, G. Frenking, K.S. Kim, G.E. Scuseria, Eds., Elsevier, 2005. [5] K. C. Sears, T. J. Dudley, J. W. Ferguson, R. S. Houk, M. S. Gordon, Theoretical investigations of polyatomic interferences in inductively coupled plasma-mass spectrometry experiments, Abstracts of Papers, 229th ACS National Meeting, San Diego, CA, United States, March 13-17, 2005. 
[6] J. Crovisier, Constants for molecules of astrophysical interest in the gas phase:

photodissociation, microwave and infrared spectra. Version 4.2 (May 2002).

http://wwwusr.obspm.fr/ crovisie/basemole/

[7] NIST Chemistry Webbook, Vibrational and/or electronic energy levels.

http://webbook.nist.gov

[8] J. Liu, B. Uselman, B. Van Devener, S. L. Anderson, Vibrational mode effects as a probe

of inter-channel coupling in the reactions of formaldehyde cation with ammonia and water, J.

Phys. Chem. A 108 (2004) 9945-9956.

[9] J. Liu, B. Van Devener, S. L. Anderson, Collision-induced dissociation of formaldehyde

cations: The effects of vibrational mode, collision energy, and impact parameter, J. Chem

Phys.116 (2002) 5530-5543.

[10] P. Blowers, R. I. Masel, Calculated vibrational spectra for $\mathrm{CH}_{n} \mathrm{OH}_{m}$ species, J. Phys. Chem A 104 (2000) 34-44.

[11] D. J. Douglas, J. B. French, Gas dynamics of the inductively coupled plasma mass

spectrometry interface,, J. Anal. Atom. Spectrom. 3 (1988) 743-747.

[12] J. W. Ferguson, T. J. Dudley, R. S. Houk, A study of polyatomic ions in inductively

coupled plasma - mass spectrometry Part III: $\mathrm{CrO}_{\mathrm{x}} \mathrm{H}_{\mathrm{y}}^{+}$ions, in preparation. 


\section{Tables}

Table 1: Examples of the three possible scenarios correlating $T_{\text {gas }}$ with dissociation equilibrium

$\begin{array}{llll}\text { Equilibrium } & \text { Dissociation Reaction } & \mathrm{T}_{\text {gas }} & \text { Diagnosis } \\ \mathrm{K}_{\mathrm{d} \text {, theo }} \approx \mathrm{K}_{\mathrm{d} \text {, exp }} & \mathrm{CeO}^{+} \rightleftharpoons \mathrm{Ce}^{+}+\mathrm{O} & 5800 \mathrm{~K} \quad \mathrm{CeO}^{+} \text {in ICP } \\ \mathrm{K}_{\mathrm{d} \text {, theo }}>\mathrm{K}_{\mathrm{d} \text {, exp }} & \mathrm{H}_{2} \mathrm{O}^{+} \rightleftharpoons \mathrm{OH}^{+}+\mathrm{H} & 3900 \mathrm{~K} & \text { Extra } \mathrm{H}_{2} \mathrm{O}^{+} \text {made in extraction } \\ \mathrm{K}_{\mathrm{d} \text {, theo }}<\mathrm{K}_{\mathrm{d} \text {, exp }} & \mathrm{NO}^{+} \rightleftharpoons \mathrm{N}^{+}+\mathrm{O} & 7400 \mathrm{~K} & \mathrm{NO}^{+} \text {lost during extraction }\end{array}$

Table 2: Experimental conditions

Instrument: ThermoFinnigan ELEMENT 1

Resolution: Medium $(\mathrm{m} / \Delta \mathrm{m} \approx 4000)$, except where otherwise stated

Nebulizer: Elemental Scientific Inc. PFA $100 \mu \mathrm{L} / \mathrm{min}$ or $20 \mu \mathrm{L} / \mathrm{min}$ as needed

Spray Chamber: Teflon Scott type double pass

Cones: Nickel sampler and skimmer

Power: $1200 \mathrm{~W}$, changed marginally to improve performance

Gas flow rates: Optimized to produce greatest signal for standards

Solutions: Standards in 1\% nitric acid. Other solutions used as indicated

Torch was shielded with the shield grounded 
Table 3: Calculated properties of $\mathrm{N}_{2} \mathrm{H}^{+}$by ZAPT2 and $\operatorname{CCSD}(\mathrm{T})$ theory. ZAPT2

$\operatorname{CCSD}(\mathrm{T})$

Dissociation Energy (eV)

6.891

7.449

Vibrational Modes

4

4

Vibrational Energies $\left(\mathrm{cm}^{-1}\right)$

731.87

732.58

731.87

732.58

2151.1

2283.9

3418.2

3434.9

Rotational Constant $\left(\mathrm{cm}^{-1}\right)$

1.536

1.557

Table 4: Calculated properties of $\mathrm{HCO}^{+}, \mathrm{COH}^{+}$, and $\mathrm{CO}^{+}$by ZAPT2 theory.

$\begin{array}{llll} & \mathrm{HCO}^{+} & \mathrm{COH}^{+} & \mathrm{CO}^{+} \\ \text {Dissociation Energy to } \mathrm{CO}^{+}(\mathrm{eV}) & 6.929 & 2.03 & \\ \text { Vibrational Modes } & 4 & 4 & 1 \\ \text { Vibrational Energies }\left(\mathrm{cm}^{-1}\right) & 859.76 & 321.80 & 2115.1 \\ & 859.76 & 321.80 & \\ & 2150.4 & 1761.9 & \\ & 3251.4 & 3349.4 & \\ \text { Rotational Constant }\left(\mathrm{cm}^{-1}\right) & 1.536 & 1.487 & 1.960\end{array}$


Table 5: Calculated properties of $\mathrm{HCO}^{+}, \mathrm{COH}^{+}$, and $\mathrm{CO}^{+}$by $\mathrm{CCSD}(\mathrm{T})$ theory.

$\begin{array}{lll}\mathrm{HCO}^{+} & \mathrm{COH}^{+} & \mathrm{CO}^{+}\end{array}$

Dissociation Energy to $\mathrm{CO}^{+}(\mathrm{eV})$

6.925

1.75

Vibrational Modes

4

4

1

Vibrational Energies $\left(\mathrm{cm}^{-1}\right)$

861.84

149.43

2203.1

861.84

149.43

2212.3

1942.6

3327.1

3482.8

Rotational Constant $\left(\mathrm{cm}^{-1}\right)$

1.487

1.487

1.939 
Table 6: Calculated properties of $\mathrm{H}_{2} \mathrm{COH}^{+}, \mathrm{HCOH}^{+}$, and $\mathrm{H}_{2} \mathrm{CO}^{+}$by ZAPT2 theory.

$\begin{array}{llll} & \mathrm{H}_{2} \mathrm{COH}^{+} & \mathrm{HCOH}^{+} & \mathrm{H}_{2} \mathrm{CO}^{+} \\ \text {Dissociation Energy to } \mathrm{HCOH}^{+}(\mathrm{eV}) & 5.341 & \left(0.845 \text { to } \mathrm{HCO}^{+}\right) & 0.13 \\ \text { Vibrational Modes } & 9 & 6 & 6 \\ \text { Vibrational Energies }\left(\mathrm{cm}^{-1}\right) & 1054.3 & 971.65 & 856.28 \\ & 1123.8 & 1001.5 & 1114.1 \\ & 1266.3 & 1248.9 & 1321.9 \\ & 1396.3 & 1727.8 & 1633.3 \\ & 1510.3 & 3122.0 & 2898.2 \\ & 1688.9 & 3497.4 & 3045.6 \\ & 3150.5 & & . \\ \text { Rotational Constant } \mathrm{x}\left(\mathrm{cm}^{-1}\right) & 3301.4 & & 8.861 \\ \text { Rotational Constant } \mathrm{y}\left(\mathrm{cm}^{-1}\right) & 3610.0 & & 1.348 \\ \text { Rotational Constant } \mathrm{z}\left(\mathrm{cm}^{-1}\right) & 6.658 & 13.74 & 1.174\end{array}$


Table 7: Calculated properties of $\mathrm{H}_{2} \mathrm{COH}^{+}, \mathrm{HCOH}^{+}$, and $\mathrm{H}_{2} \mathrm{CO}^{+}$by $\mathrm{CCSD}(\mathrm{T})$ theory.

$\begin{array}{llll} & \mathrm{H}_{2} \mathrm{COH}^{+} & \mathrm{HCOH}^{+} & \mathrm{H}_{2} \mathrm{CO}^{+} \\ \text {Dissociation Energy to } \mathrm{H}_{2} \mathrm{CO}^{+}(\mathrm{eV}) & 5.17 & 0.23 & \left(1.378 \text { to } \mathrm{HCO}^{+}\right) \\ \text {Vibrational Modes } & 9 & 6 & 6 \\ \text { Vibrational Energies }\left(\mathrm{cm}^{-1}\right) & 1038.3 & 969.57 & 855.58 \\ & 1121.0 & 1000.8 & 1071.0 \\ & 1246.8 & 1254.5 & 1272.6 \\ & 1400.4 & 1691.7 & 1663.2 \\ & 1488.7 & 3076.9 & 2811.4 \\ & 1663.2 & 3515.4 & 2920.5 \\ & 3109.5 & & \\ \text { Rotational Constant } \mathrm{x}\left(\mathrm{cm}^{-1}\right) & 3255.5 & & \\ \text { Rotational Constant } \mathrm{y}\left(\mathrm{cm}^{-1}\right) & 3620.4 & & 1.3 .917 \\ \text { Rotational Constant } \mathrm{z}\left(\mathrm{cm}^{-1}\right) & 6.637 & 13.68 & \\ & 1.146 & 1.264 & 1.327 \\ & 0.9800 & 1.160 & 1.160\end{array}$


Table 8: Gas kinetic temperature results

$\begin{array}{llll}\text { Ion } & \text { Method } & \text { Solution } & \mathrm{T}_{\text {gas }}(\mathrm{K}) \\ \mathrm{N}_{2} \mathrm{H}^{+} & \text {ZAPT2 } & 1 \% \mathrm{HNO}_{3} & 4550 \\ \mathrm{~N}_{2} \mathrm{H}^{+} & \text {CCSD(T) } & 1 \% \mathrm{HNO}_{3} & 4900 \\ \mathrm{HCO}^{+} & \text {ZAPT2 } & 1 \% \mathrm{HNO}_{3} & 4750 \\ \mathrm{HCO}^{+} & \text {CCSD(T) } & 1 \% \mathrm{HNO}_{3} & 4830 \\ \mathrm{HCOH}^{+} & \text {ZAPT2 } & 1 \% \mathrm{HNO}_{3} & 850 \\ \mathrm{HCOH}^{+} & \text {ZAPT2 } & 10-20 \% \mathrm{IPA} & 1360 \\ \mathrm{H}_{2} \mathrm{CO}^{+} & \text {CCSD(T) } & 1 \% \mathrm{HNO}_{3} & 1270 \\ \mathrm{H}_{2} \mathrm{CO}^{+} & \text {CCSD(T) } & 10-20 \% \mathrm{IPA} & 2020 \\ \mathrm{H}_{2} \mathrm{COH}^{+} & \text {ZAPT2 } & 10-20 \% \mathrm{IPA} & 3650 \\ \mathrm{H}_{2} \mathrm{COH}^{+} & \text {CCSD(T) } & 10-20 \% \mathrm{IPA} & 3610\end{array}$




\section{Figures}

Figure 1: Medium resolution spectrum of $\mathrm{CO}^{+}$(left or low mass peak) and $\mathrm{N}_{2}^{+}$(right or high mass peak) in $1 \%$ nitric acid

\section{$1 \%$ Nitric Acid in Medium Resolution}

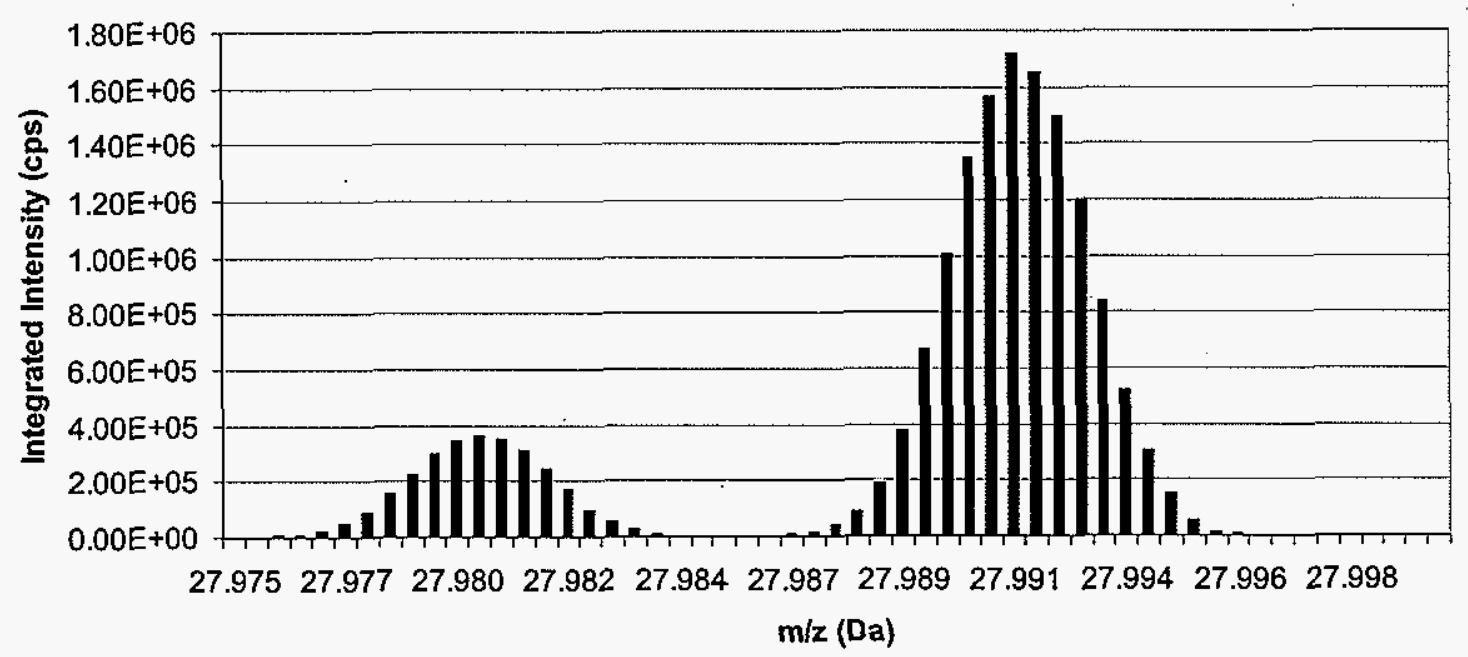

Figure 2: Medium resolution spectrum of $\mathrm{HCO}^{+}$(left or low mass peak) and $\mathrm{N}_{2} \mathrm{H}^{+}$(right or high mass peak) in $1 \%$ nitric acid

\section{$1 \%$ Nitric Acid in Medium Resolution}

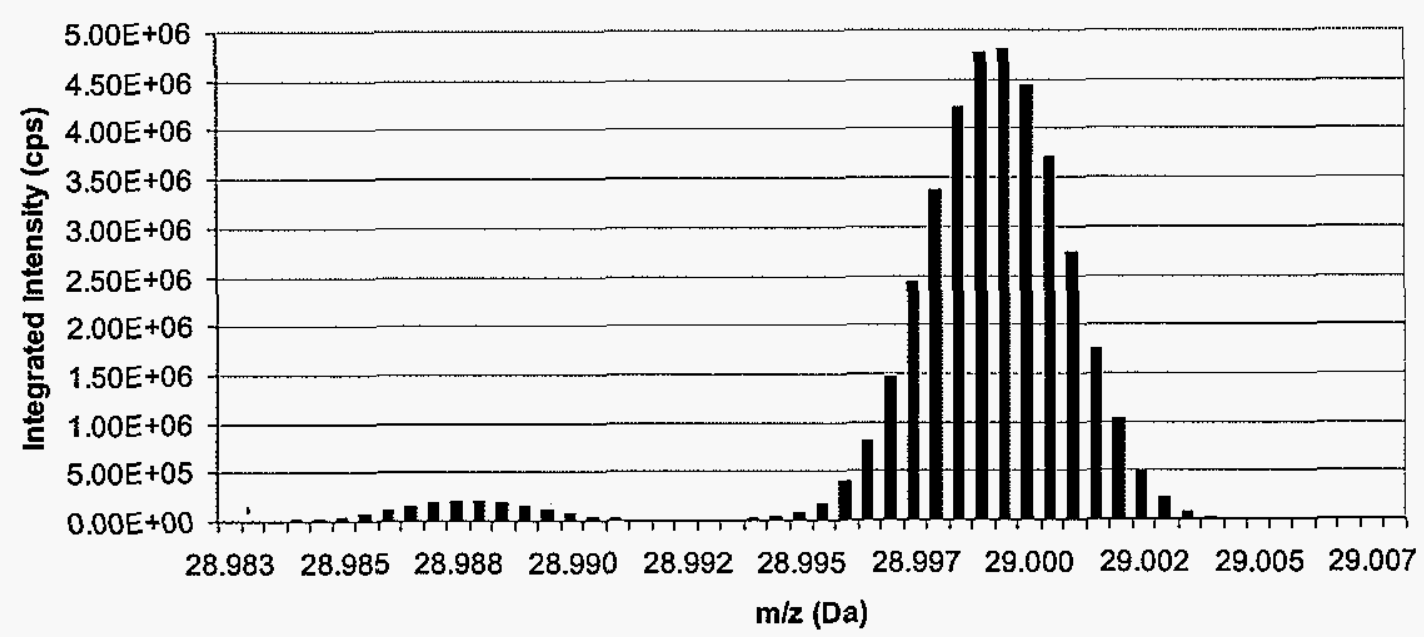




\title{
CHAPTER 4. HIGH RESOLUTION STUDIES OF THE ORIGINS OF POLYATOMIC IONS IN INDUCTIVELY COUPLED PLASMA - MASS SPECTROMETRY PART III. $\mathrm{CrO}_{\mathbf{x}} \mathrm{H}_{\mathbf{y}}^{+}$IONS
}

\author{
A paper to be submitted to Spectrochimica Acta Part B \\ Jill Wisnewski Ferguson, Timothy J. Dudley, Mark S. Gordon, and R. S. Houk
}

\begin{abstract}
Chromium polyatomic ions in ICP-MS are studied using a high resolution ICP-MS device. These ions include $\mathrm{CrO}^{+}, \mathrm{CrOH}^{+}, \mathrm{CrO}_{2}{ }^{+}, \mathrm{CrO}_{2} \mathrm{H}^{+}, \mathrm{CrO}_{2} \mathrm{H}_{2}{ }^{+}, \mathrm{CrO}_{3}{ }^{+}, \mathrm{CrO}_{3} \mathrm{H}^{+}$, and $\mathrm{CrO}_{3} \mathrm{H}_{2}{ }^{+}$. Accurate $\mathrm{m} / \mathrm{z}$ measurements are made of these previously unidentified ions. Ion identities are confirmed using isotope ratios. The prevalence of these rather abundant $\mathrm{CrO}_{x} \mathrm{H}_{y}{ }^{+}$species is found to be independent of the oxidation state of chromium introduced into the ICP. Elements surrounding chromium on the periodic table, such as W, Mo, V, Ti, $\mathrm{Mn}$, and $\mathrm{Fe}$, are also studied. Results indicate that chromium is unique in its polyatomic ion formation. Finally, dissociation constants are evaluated to determine a gas kinetic temperature $\left(\mathrm{T}_{\text {gas }}\right)$ for the dissociation of $\mathrm{CrOH}^{+}$to $\mathrm{CrO}^{+}$that is thought to describe the location of ion formation in the ICP-MS device.
\end{abstract}

\section{Introduction}

Platinum group elements (PGEs), such as $\mathrm{Pt}, \mathrm{Pd}$, and $\mathrm{Rh}$, are often used as catalysts for the control of automobile and industrial emissions. While this use limits the harmful byproducts of automobile exhausts, it also leads to PGE pollution, especially near roadways 
$[1,2,3]$. The levels of these elements are often measured by ICP-MS. Chromium is also monitored often in environmental and clinical samples and has catalytic properties.

High resolution ICP-MS devices offer a distinct advantage in chromium measurements, as common polyatomic ions are present at $m / z=52,53$, and 54. However, it is often thought that quadrupole devices are sufficient for the detection of palladium, rhodium, and ruthenium, as common polyatomic ions are not prevalent at those $\mathrm{m} / \mathrm{z}$ levels. Matrix separation, primarily employing ion exchange columns, has been used to diminish the appearance of ions such as ${ }^{40} \mathrm{Ar}^{65} \mathrm{Cu}^{+},{ }^{89} \mathrm{Y}^{16} \mathrm{O}^{+}$, and ${ }^{179} \mathrm{Hf}^{16} \mathrm{O}^{+}$during the determination of platinum and palladium in environmental samples such as dust $[4,5,6,7]$. However, results for Pd even after separation indicate recovery of over $200 \%$ in some instances, indicating the presence of unidentified interferences [7].

Researchers have not fully identified and compared polyatomic interferences stemming from chromium at these masses. Krushevska and co-workers documented interferences on rhodium seen in their laboratory with a high chromium matrix [8]. However, only the chromium interferences at $\mathrm{m} / \mathrm{z} 102$ and 103 were discussed. Polyatomic ion identities for these masses were proposed but not confirmed.

This paper describes remarkable chromium polyatomic ions such as $\mathrm{CrO}_{2}^{+}, \mathrm{CrO}_{2} \mathrm{H}_{2}^{+}$, and $\mathrm{CrO}_{3} \mathrm{H}^{+}$which obscure the measurement of $\mathrm{Sr}, \mathrm{Rb}, \mathrm{Ru}, \mathrm{Rh}$, and $\mathrm{Pd}$. These ions are unequivocally identified by the use of chromium isotope ratios and accurate $\mathrm{m} / \mathrm{z}$ measurements. While polyatomic ions with more atoms are generally expected to be less abundant from the ICP, this is not the case with these notable chromium species. The effect of the oxidation state of the chromium introduced into the ICP is also explored. Metals surrounding chromium on the periodic table, such as $\mathrm{Ti}, \mathrm{V}, \mathrm{Mn}, \mathrm{Fe}, \mathrm{Mo}$, and $\mathrm{W}$, are also studied to determine if chromium is unique in its polyatomic ion formation. Experimental 
measurements and theoretical data are combined to evaluate a dissociation constant for polyatomic ions. This generates a $T_{\text {gas }}$ value which points to the location of polyatomic ion formation.

\section{Experimental}

All experiments were done on a ThermoFinnigan ELEMENT 1 in medium or high resolution, $\mathrm{m} / \Delta \mathrm{m} \approx 4000$ and 11000 respectively. Solutions of $50 \mathrm{ppm} \mathrm{Cr}$ in $1 \%$ nitric acid were nebulized with a $100 \mu \mathrm{L} / \mathrm{min}$ PFA nebulizer from Elemental Scientific Inc. This concentration was chosen to mimic industrial measurement of palladium, where some unknown and unusual polyatomics were first noticed with a quadrupole device [8]. Solutions of $50 \mathrm{ppm} \mathrm{Ti}, \mathrm{V}, \mathrm{Mn}, \mathrm{Fe}, \mathrm{Mo}$, and $\mathrm{W}$ in $1 \%$ nitric acid were also analyzed as a basis for comparison. Nickel cones were used and conditions such as power and gas flows were optimized to maximize signal for atomic standards. Mass bias measurements were conducted as outlined by Ingle, Sharp, and coworkers [9], so that signals at different $\mathrm{m} / \mathrm{z}$ could be accurately compared.

Polyatomic ion identification techniques have been previously discussed in more detail by the authors $[10,11,12]$. Accurate mass measurements are made using wide $m / z$ acquisition windows, so known atomic ions can be captured as well. These atomic ions provide a reference $\mathrm{m} / \mathrm{z}$ measurement that determines the difference between the actual and measured masses of ions at a particular magnet mass setting. Measurements are made in medium and high resolutions. Identifications proposed for the polyatomic ions are verified by isotope ratios. 


\section{Results and Discussion}

\section{Discovery and Identification of Tons}

Unusually intense signals were repeatedly seen in the ranges $m / z=83.92-87.95$ and $97.92-103.95$ when nebulizing solutions of $50 \mathrm{ppm} \mathrm{Cr}$. These ions were not observed from blank solutions of $1 \%$ nitric acid, nor from solutions of $\mathrm{Ru}, \mathrm{Rh}$, or $\mathrm{Rb}$. The signals from these unidentified ions were equal to or more intense than the $\mathrm{M}^{+}$count rate obtained from 10 ppb solutions of $\mathrm{Rb}, \mathrm{Ru}$, and $\mathrm{Rh}$. The natural chromium isotope ratios were observed in these unknown peaks, and were eventually used in confirming the polyatomic ion identities. Spectra are shown in Figures 1 and 2.

The discovery of additional ion peaks in high resolution is an important progression in the unequivocal identifications put forth here. For example, medium resolution spectra of $50 \mathrm{ppm} \mathrm{Cr}$ at $m / z=86$ show two peaks which are not fully resolved at $\mathrm{m} / \mathrm{z} 85.9315$ and 85.9474 (Figure 1a). These peaks could be identified as ${ }^{54} \mathrm{Cr}^{16} \mathrm{O}_{2}{ }^{+}$and ${ }^{52} \mathrm{Cr}^{16} \mathrm{O}_{2} \mathrm{H}_{2}{ }^{+}$. However, an examination of this same mass range in high resolution (Figure 1b) uncovers three distinct ions in this range. Signals at $85.9385\left({ }^{54} \mathrm{Cr}^{16} \mathrm{O}_{2}{ }^{+}\right), 85.9476\left({ }^{53} \mathrm{Cr}^{16} \mathrm{O}_{2} \mathrm{H}^{+}\right)$, and $85.9555\left({ }^{52} \mathrm{Cr}^{16} \mathrm{O}_{2} \mathrm{H}_{2}{ }^{+}\right)$are observed, and isotope ratio matches can be made for ${ }^{54} \mathrm{Cr}^{16} \mathrm{O}_{2}{ }^{+}$and ${ }^{52} \mathrm{Cr}^{16} \mathrm{O}_{2} \mathrm{H}_{2}{ }^{+}$with other chromium polyatomic ions. ${ }^{53} \mathrm{Cr}^{16} \mathrm{O}_{2} \mathrm{H}^{+}$cannot be confirmed via isotope ratios, because it is not fully resolved from ${ }^{52} \mathrm{Cr}^{16} \mathrm{O}_{2} \mathrm{H}_{2}{ }^{+}$, a more intense peak, in high resolution. However, mass offsets, as well as the isotope ratio confirmed identifications of ${ }^{50} \mathrm{Cr}^{16} \mathrm{O}_{2} \mathrm{H}^{+},{ }^{52} \mathrm{Cr}^{16} \mathrm{O}_{2} \mathrm{H}^{+}$, and ${ }^{54} \mathrm{Cr}^{16} \mathrm{O}_{2} \mathrm{H}^{+}$all support the peak at 85.9476 being identified as ${ }^{53} \mathrm{Cr}^{16} \mathrm{O}_{2} \mathrm{H}^{+}$.

The ions listed in Table 1 all contain one chromium atom with oxygen and often hydrogen. Spectra were also obtained in the $\mathrm{m} / \mathrm{z}$ range ascribed to polyatomic ions with more than one chromium atom. However, these ions were much less abundant than their single 
chromium counterparts. In addition, the resolution required to resolve any probable ions is higher than that achievable from the high resolution device employed. In any case, it is known that for neutral $\mathrm{Cr}_{2} \mathrm{O}_{x}$ molecules, it takes about $1 \mathrm{eV}$ to break off a $\mathrm{Cr}$ atom, the lowest energy required of any possible dissociation. Removing one oxygen requires about 5 eV. Splitting the molecule into two, each containing a chromium atom, is the intermediate energy pathway. So it is likely that a $\mathrm{Cr}_{2} \mathrm{O}_{\mathrm{x}}$ molecule would lose a chromium atom, as it is the lowest energy dissociation pathway. Additionally, the $\mathrm{Cr}-\mathrm{O}$ bonds are stronger in $\mathrm{CrO}_{\mathrm{x}}$ than in $\mathrm{Cr}_{2} \mathrm{O}_{\mathrm{x}}$ molecules, as determined from the bond lengths calculated for these molecules [13]. This information seems to further support the high abundance of the $\mathrm{CrO}_{x} \mathrm{H}_{y}^{+}$species relative to $\mathrm{Cr}_{2} \mathrm{O}_{\mathrm{x}} \mathrm{H}_{\mathrm{y}}^{+}$.

Generally, the abundance of polyatomic ions in ICP-MS should decrease as the number of atoms in the polyatomic species increases. For instance, $\mathrm{ArH}^{+}$is more abundant than $\mathrm{ArH}_{2}{ }^{+}$. Chromium polyatomic ions blatantly breach this commonly held principle. Figure 3 outlines some of the unusual ion signals seen. This figure accounts for mass bias, which traditionally makes ions of greater $\mathrm{m} / \mathrm{z}$ more intense than ions of lower $\mathrm{m} / \mathrm{z}$ at the same concentration. Species up to $\mathrm{CrO}_{3} \mathrm{H}_{2}{ }^{+}$are abundant. $\mathrm{CrO}_{2}{ }^{+}$is more abundant than $\mathrm{CrO}^{+}$, $\mathrm{CrO}_{3} \mathrm{H}^{+}$is more profuse than $\mathrm{CrO}_{3}{ }^{+}$, and $\mathrm{CrO}_{3} \mathrm{H}^{+}$is nearly as intense as $\mathrm{CrO}^{+}$. These results are surprising and lead to further investigation of chromium polyatomic ions in ICP-MS.

\section{Chromium Oxidation State and Polyatomic Ions}

While $\mathrm{Cr}(\mathrm{III})$ is not generally considered hazardous, $\mathrm{Cr}(\mathrm{VI})$ is a known carcinogen. Solutions of $50 \mathrm{ppm} \mathrm{Cr}(\mathrm{VI}), 50 \mathrm{ppm} \mathrm{Cr}(\mathrm{III})$, and $50 \mathrm{ppm} \mathrm{Cr}$ of an unknown oxidation state were all tested separately to see if differences existed in the formation of these unusual polyatomic ions. Figure 4 compares the results from chromium solutions of different 
oxidation states. Slight differences in individual solution concentrations are accounted for in this figure. The solution with the unknown oxidation state consistently produced less polyatomic ions than either the $\mathrm{Cr}(\mathrm{III})$ or $\mathrm{Cr}(\mathrm{VI})$ solutions. This could be due to a variety of factors, including the age or origin of the standard. However, it does not appear between the $\mathrm{Cr}(\mathrm{III})$ and $\mathrm{Cr}(\mathrm{VI})$ solutions that one steadily produces more polyatomic ions than the other. This result is important to note, since it confirms that all chromium solutions produce polyatomic interferences on $\mathrm{Rb}, \mathrm{Ru}, \mathrm{Rh}$, and $\mathrm{Pd}$, not just solutions that contain chromium in a specific oxidation state. This also indicates that the effect of the plasma, interface, and/or ion extraction is more influential in creating these polyatomic interferences than the original solution composition.

\section{Comparison of Polyatomic Ions from Chromium and Other Metals}

The polyatomic ions generated from chromium are unusually intense and include a large number of atoms. Next, the elements surrounding chromium on the periodic table were studied to determine if chromium is unique in this trait. $\mathrm{Ti}, \mathrm{V}, \mathrm{Mn}, \mathrm{Fe}, \mathrm{Mo}$, and $\mathrm{W}$ were chosen for study because of their proximity to $\mathrm{Cr}$ on the periodic table. Solutions of $50 \mathrm{ppm}$ of the metal of interest were individually introduced and $\mathrm{m} / \mathrm{z}$ values corresponding to $\mathrm{MO}_{\mathrm{x}} \mathrm{H}_{\mathrm{y}}{ }^{+}$species, where $\mathrm{x}=1-3$ and $\mathrm{y}=0-3$, were monitored.

Figure 5 outlines the comparison between all the metals tested. Adjustments for mass bias, isotopic abundance, and concentration have been made. This includes a molar term, so elements of varying atomic weights can be accurately compared on a mole to mole basis. In addition, these data are normalized to the abundance of the analogous $\mathrm{CrO}_{\mathrm{x}} \mathrm{H}_{\mathrm{y}}{ }^{+}$ion from chromium of an unknown oxidation state, i.e. chromium has a consistent value of 1.0 on the y-axis for each ion shown. 
$\mathrm{W}, \mathrm{Mo}, \mathrm{Ti}$, and $\mathrm{V}$ all generate more of the $\mathrm{MO}^{+}$species than $\mathrm{Cr}$ does. This result is not surprising, as these metal cations all have higher oxygen atom affinities than the chromium cation. In an ICP/SIFT (selected ion flow tube) device the $\mathrm{M}^{+}$ions from these four elements all undergo a bimolecular oxygen atom transfer, whereas chromium exhibits a slow $\mathrm{O}_{2}$ addition pathway, resulting in $\mathrm{CrO}_{2}{ }^{+}$[14]. Similar results were seen in surface ionization ion beam experiments [15].

$$
\begin{array}{ll}
M^{+}+\mathrm{O}_{2} \rightarrow M \mathrm{O}^{+}+\mathrm{O} & \text { bimolecular } \mathrm{O} \text { atom transfer } \\
M^{+}+\mathrm{O}_{2} \rightarrow \mathrm{MO}_{2}^{+} & \mathrm{O}_{2} \text { addition }
\end{array}
$$

The only other ion that is more abundant than its chromium counterpart is $\mathrm{MoO}_{3}{ }^{+}$. Kretzschmar et al. calculated the energies of $\mathrm{MoO}_{\mathrm{x}}{ }^{+}$, where $\mathrm{x}=0-3$ [16]. The three oxygen species was found to have the lowest energy, making it the most stable ion. This may be why the abundance of $\mathrm{MoO}_{3}{ }^{+}$is higher than expected, particularly in comparison with chromium. However, the balancing of thermodynamic stability and ICP methodology still needs to be explored.

\section{Gas kinetic temperature}

Experimental data were combined with calculated energies and partition functions of the ions to evaluate dissociation constants. The resulting $\mathrm{T}_{\text {gas }}$ value indicates the polyatomic ion formation or removal process $[10,11,12]$. The reaction studied was

$$
\mathrm{CrOH}^{+} \rightleftharpoons \mathrm{CrO}^{+}+\mathrm{H}
$$

The energies of states were specifically calculated for our purposes here and are reported in Table 2. These values are similar to those calculated for neutrals by Espelid [17]. The methodology of the calculations will be described separately [18]. 
$A T_{\text {gas }}$ value of $850 \mathrm{~K}$ is calculated for the ratio $\mathrm{CrOH}^{+} / \mathrm{CrO}^{+}$using only the ground state of each ion. If the lowest excited electronic state of $\mathrm{CrOH}^{+}$is included in the partition function, the temperature is decreased by $10 \mathrm{~K}$. An alternative calculation was also employed, which estimates the amount of $\mathrm{CrOH}^{+}$in the excited state at $5800 \mathrm{~K}$, which is the gas kinetic temperature of the region of the plasma sampled (determined by the measurement of $\left.\mathrm{CeO}^{+}\right)$. The portion of the $\mathrm{CrOH}^{+}$signal attributed to the excited state then dissociates into $\mathrm{CrO}^{+}$. The $\mathrm{T}_{\text {gas }}$ value for this scenario is $600 \mathrm{~K}$. These numbers are not remarkably different, and they all indicate that $\mathrm{CrOH}^{+}$is being formed near the terminus of the interface region. This result is encouraging, as it suggests that the abundance of these polyatomic ions may be reduced with changes in the design of the interface region.

Chromium dioxide cation was also studied. This ion is more abundant than either $\mathrm{CrO}^{+}$or $\mathrm{CrOH}^{+}$. The reaction studied was

$$
\mathrm{CrO}_{2}^{+} \rightleftharpoons \mathrm{CrO}^{+}+\mathrm{O}
$$

Again, the energies of states were expressly calculated for our purposes here and are shown in Table 3 [18]. $\mathrm{CrO}_{2}{ }^{+}$has two degenerate ground states. The energies calculated agree with the work published by Fiedler [19].

The ion ratio $\mathrm{CrO}_{2}^{+} / \mathrm{CrO}^{+}$corresponds to a $\mathrm{T}_{\text {gas }}$ value of $2100 \mathrm{~K}$, indicating excess formation of $\mathrm{CrO}_{2}^{+}$after the plasma. Including the low lying electronic states of $\mathrm{CrO}_{2}{ }^{+}$and $\mathrm{CrO}^{+}$only lowers the temperature by $50 \mathrm{~K}$. It appears that $\mathrm{CrO}_{2}{ }^{+}$formation occurs at a region of higher gas density in the interface than that of $\mathrm{CrOH}^{+} . \mathrm{CrO}_{2}{ }^{+}$is more abundant than $\mathrm{CrOH}^{+}$. There are an increased number of collisions possible at the $2100 \mathrm{~K}$ region of the interface compared to a position closer to the skimmer corresponding to $850 \mathrm{~K}$. This may explain the relative abundances seen of these two ions. 


\section{Conclusions}

Polyatomic ions in the form $\mathrm{CrO}_{x} \mathrm{H}_{y}{ }^{+}$are abundant and can obscure the measurement of $\mathrm{Rb}, \mathrm{Sr}, \mathrm{Ru}, \mathrm{Rh}$, and $\mathrm{Pd}$, among other elements. Other metals near chromium on the periodic table were investigated, and chromium was the only metal tested that formed such abundant polyatomic ions. As the intensity of these polyatomic ions is not related to the oxidation state of chromium, it is important to determine the chromium levels in samples before determining the PGE concentration by quadrupole ICP-MS. By calculating the gas kinetic temperature of $\mathrm{CrOH}^{+}$and $\mathrm{CrO}_{2}^{+}$, it is determined that both of these ions are produced in excess after the plasma, most likely in the interface region. Further work is being done to calculate the $T_{\text {gas }}$ values of more of these complicated ions, to gain insight into their formation or removal processes.

\section{Acknowledgements}

The authors wish to thank Antoaneta Krushevska for bringing her interesting palladium analysis problem to our attention. This research was supported by the National Science Foundation through the Institute for Physical Research and Technology at ISU. JWF was also supported by the Velmer A. and Mary K. Fassel Fellowship. The nebulizers used were provided by Elemental Scientific Inc. The ICP-MS device was obtained with funds provided by the U. S. Department of Energy, Office of Nuclear Nonproliferation (NA-22) and the Office of Basic Energy Sciences. Ames Laboratory is operated for the U.S. Department of Energy by lowa State University under Contract No. W-7405-Eng-82. 


\section{References}

[1] E. Helmers, Platinum emission rate of automobiles with catalytic converters; comparison and assessment of results from various approaches, Environ. Sci. Pollut. Res. 4 (1997) 100103.

[2] J. Schafer, J. Echardt, Z. A. Berner, D. Stuben, Time-dependent increase of trafficemitted platinum group elements (PGE) in different environmental compartments, Environ. Sci. and Tech. 33 (1999) 3166-3170.

[3] K. Ravindra, L. Bencs, R. van Grieken, Platinum group elements in the environment and their health risk, Sci. Tot. Environ. 318 (2004) 1-43.

[4] I. Jarvis, M. M. Totland, K. E. Jarvis, Assessment of dowex-1-X8-based anion exchange procedures for the separation and determination of $\mathrm{Ru}, \mathrm{Rh}, \mathrm{Pd}, \mathrm{Ir}, \mathrm{Pt}$, and $\mathrm{Au}$ in geological samples by inductively coupled plasma - mass spectrometry, Analyst 122 (1997) 19-26.

[5] I. Jarvis, M. M. Totland, K. E. Jarvis, Determination of the platinum group elements in geological materials by ICP-MS using microwave digestion, alkali fusion, and cation exchange chromatography, Chem. Geol. 143 (1997) 27-42.

[6] J. D. Whiteley, F. Murray, Determination of platinum group elements (PGE) in environmental samples by ICP-MS: a critical assessment of matrix separation for the mitigation of interferences, Geochem.: Explor., Environ., Anal. 5 (2005) 3-10.

[7] B. A. Lesniewska, B. Godlewska-Zylkiewicz, A. Ruszczynska, E. Bulska, A. Hulanicki, Elimination of interferences in determination of platinum and palladium in environmental samples by inductively coupled plasma - mass spectrometry, Anal. Chim. Acta 564 (2006) 236-242. 
[8] A. P. Krushevska, Y. Zhou, V. Ravikumar, Y.-J. Kim, J. Hinrichs, Chromium based polyatomic intereferences on rhodium in ICP-MS, Spectrochim. Acta Part B, submitted 2006 .

[9] C. P. Ingle, B. L. Sharp, M. S. A. Horstwood, R. R. Parrish, D. J. Lewis, Instrument response functions, mass bias and matrix effects in isotope ratio measurements and semiquantitative analysis by single and multi-collector ICP-MS, J. Anal. Atom. Spectrom. 18 (2003) 219-229.

[10] R. S. Houk, N. Praphairaksit, Dissociation of polyatomic ions in the inductively coupled plasma, Spectrochim. Acta Part B 56 (2001) 1069-1096.

[11] J. W. Ferguson, R. S. Houk, High resolution studies of the origins of polyatomic ions in inductively coupled plasma - mass spectrometry part 1: identification methods and effects of neutral gas density assumptions, extraction voltage, and cone material, Spectrochim. Acta Part B, submitted May 2006.

[12] J. W. Ferguson, T. J. Dudley, K. C. Sears, M. S. Gordon, R. S. Houk, High resolution studies of the origins of polyatomic ions in inductively coupled plasma - mass spectrometry part 2: novel calculations of unusual ions, Spectrochim. Acta Part B, submitted June 2006. [13] S. Veliah, K. Xiang, R. Pandey, J. M. Recio, J. M. Newsam, Density functionality study of chromium oxide clusters: structures, bonding, vibrations, and stability, J. Phys. Chem. B 102 (1998) 1126-1135.

[14] G. K. Koyanagi, D. Caraiman, V. Blagojevic, and D. K. Bohme, Gas-phase reactions of transition metal ions with molecular oxygen: room-temperature kinetics and periodicities in reactivity, J. Phys. Chem. A 106 (2002) 4581-4590. 
[15] E. R. Fisher, J. L. Elkind, D. E. Clemmer, R. Georgiadis, S. K. Loh, Aristov, N, L. S. Sunderlin, P. B. Armentrout, Reactions of fourth-period metal ions (calcium(1+)-zinc(1+)) with oxygen: metal-oxide ion bond energies, J. Chem. Phys. 93 (1990) 2676-2691.

[16] I. Kretzschmar, A. Fieldler, J. N. Harvey, D. Schroder, and H. Schwartz, Effects of sequential ligation of molybdenum cation by chalcogenides on electronic structure and gasphase reactivity, J. Phys. Chem. A 101 (1997) 6252-6264.

[17] O. Espelid, K. J. Borve, V. R. Jensen, Structure and thermodynamics of gaseous oxides, hydroxides, and mixed oxohydroxides of chromium: $\mathrm{CrO}_{\mathrm{m}}(\mathrm{OH})_{\mathrm{n}}(\mathrm{m}, \mathrm{n}=0-2)$ and $\mathrm{CrO}_{3}$. A computational study, J. Phys Chem. A 102 (1998) 10414-10423.

[18] T. J. Dudley, M. S. Gordon, unpublished results.

[19] A. Fiedler, I. Kretzschmar, D. Schroder, H. Schwarz, Chromium dioxide cation OCrO ${ }^{+}$ in the gas phase: structure, electronic states, and the reactivity with hydrogen and hydrocarbons, J. Am. Chem. Soc. 118 (1996) 9941-9952. 


\section{Tables}

Table 1: Chromium polyatomic ion identities. All species except for ${ }^{53} \mathrm{Cr}^{16} \mathrm{O}_{2} \mathrm{H}^{+}$have been isotopically matched to another chromium polyatomic ion to within $5 \%$.

$\begin{array}{ll}\text { Ion Mass } & \text { Ion Identity } \\ 81.9363 & { }^{50} \mathrm{Cr}^{16} \mathrm{O}_{2}{ }^{+} \\ 82.9441 & { }^{50} \mathrm{Cr}^{16} \mathrm{O}_{2} \mathrm{H}^{+} \\ 83.9303 & { }^{52} \mathrm{Cr}^{16} \mathrm{O}_{2}^{+} \\ 83.9519 & { }^{50} \mathrm{Cr}^{16} \mathrm{O}_{2} \mathrm{H}_{2}^{+} \\ 84.9305 & { }^{53} \mathrm{Cr}^{16} \mathrm{O}_{2}^{+} \\ 84.9382 & { }^{52} \mathrm{Cr}^{16} \mathrm{O}_{2} \mathrm{H}^{+} \\ 85.9287 & { }^{54} \mathrm{Cr}^{16} \mathrm{O}_{2}{ }^{+} \\ 85.9383 & { }^{53} \mathrm{Cr}^{16} \mathrm{O}_{2} \mathrm{H}^{+} \\ 85.9460 & { }^{52} \mathrm{Cr}^{16} \mathrm{O}_{2} \mathrm{H}_{2}^{+} \\ 86.9365 & { }^{54} \mathrm{Cr}^{16} \mathrm{O}_{2} \mathrm{H}^{+} \\ 86.9461 & { }^{53} \mathrm{Cr}^{16} \mathrm{O}_{2} \mathrm{H}_{2}^{+} \\ 87.9444 & { }^{54} \mathrm{Cr}^{16} \mathrm{O}_{2} \mathrm{H}_{2}{ }^{+} \\ 97.9312 & { }^{50} \mathrm{Cr}^{16} \mathrm{O}_{3}^{+} \\ 98.9390 & { }^{50} \mathrm{Cr}^{16} \mathrm{O}_{3} \mathrm{H}^{+} \\ 99.9252 & { }^{52} \mathrm{Cr}^{16} \mathrm{O}_{3}^{+} \\ 99.9469 & { }^{50} \mathrm{Cr}^{16} \mathrm{O}_{3} \mathrm{H}_{2}^{+} \\ 100.9331 & { }^{52} \mathrm{Cr}^{16} \mathrm{O}_{3} \mathrm{H}^{+} \\ 101.9332 & { }^{53} \mathrm{Cr}^{16} \mathrm{O}_{3} \mathrm{H}^{+} \\ 101.9409 & { }^{52} \mathrm{Cr}^{16} \mathrm{O}_{3} \mathrm{H}_{2}^{+} \\ 102.9314 & { }^{54} \mathrm{Cr}^{16} \mathrm{O}_{3} \mathrm{H}^{+} \\ 102.9410 & { }^{53} \mathrm{Cr}^{16} \mathrm{O}_{3} \mathrm{H}_{2}^{+} \\ 103.9393 & { }^{54} \mathrm{Cr}^{16} \mathrm{O}_{3} \mathrm{H}_{2}{ }^{+}\end{array}$


Table 2: Energies of states of $\mathrm{CrOH}^{+}$and $\mathrm{CrO}^{+}$

$\begin{array}{llll} & \mathrm{CrOH}^{+} \text {(ground) } & \mathrm{CrOH}^{+} \text {(excited) } & \mathrm{CrO}^{+} \\ \text {Dissociation Energy to } \mathrm{CrO}^{+}(\mathrm{eV}) & 1.105 & 0.410 & \\ \text { Ground State Degeneracy } & 3 & 3 & 8 \\ \text { Vibrational Modes } & 3 & 3 & 1 \\ \text { Vibrational Energies }\left(\mathrm{cm}^{-1}\right) & 402.42 & 425.36 & 585.21 \\ & 748.55 & 745.77 & \\ \text { Rotational Constant } \mathrm{x}\left(\mathrm{cm}^{-1}\right) & 3854.6 & 3856.0 & 0.507 \\ \text { Rotational Constant } \mathrm{y}\left(\mathrm{cm}^{-1}\right) & 49.1 & 50.1 & \\ \text { Rotational Constant } \mathrm{z}\left(\mathrm{cm}^{-1}\right) & 0.386 & 0.385 & \end{array}$


Table 3: Energies of states of $\mathrm{CrO}_{2}^{+}$

$\begin{array}{lll} & \mathrm{CrO}_{2}^{+} & \mathrm{CrO}_{2}^{+} \\ \text {Dissociation Energy to } \mathrm{CrO}^{+}(\mathrm{eV}) & 3.711 & 3.711 \\ \text { Electronic State } & \mathrm{A}_{1} & \mathrm{~B}_{2} \\ \text { Ground State Degeneracy } & 2 & 2 \\ \text { Vibrational Modes } & 3 & 3 \\ \text { Vibrational Energies }\left(\mathrm{cm}^{-1}\right) & 348.21 & 357.24 \\ & 959.14 & 975.83 \\ & 959.14 & 1022.3 \\ \text { Rotational Constant } \mathrm{x}\left(\mathrm{cm}^{-1}\right) & 1.09 & 1.15 \\ \text { Rotational Constant } \mathrm{y}\left(\mathrm{cm}^{-1}\right) & 0.298 & 0.296 \\ \text { Rotational Constant } \mathrm{z}\left(\mathrm{cm}^{-1}\right) & 0.234 & 0.236\end{array}$




\section{Figures}

Figure 1a: Medium resolution spectrum of $50 \mathrm{ppm} \mathrm{Cr}(\mathrm{III})$ in $1 \%$ nitric acid. Asterisk denotes ions for which high resolution resolves two separate ions.

$\begin{array}{lll}\text { Peak Centroid } & \text { Integrated Intensity } & \begin{array}{l}\text { Assigned Identity } \\ 83.9328\end{array} \\ 2258839 & { }^{52} \mathrm{Cr}^{16} \mathrm{O}_{2}^{+} \\ 83.9520 & 9892 & { }^{50} \mathrm{Cr}^{16} \mathrm{O}_{2} \mathrm{H}_{2}^{+} \\ 84.9383 & 744414 & { }^{53} \mathrm{Cr}^{16} \mathrm{O}_{2}^{+} \\ 85.9315 & 83626 & { }^{54} \mathrm{Cr}^{16} \mathrm{O}_{2}^{+} \\ 85.9474 & 168948 & { }^{52} \mathrm{Cr}^{16} \mathrm{O}_{2} \mathrm{H}_{2}^{+} \\ 86.9324 & 35317 & { }^{54} \mathrm{Cr}^{16} \mathrm{O}_{2} \mathrm{H}^{+} \\ 86.9487 & 21353 & { }^{53} \mathrm{Cr}^{16} \mathrm{O}_{2} \mathrm{H}_{2}^{+}\end{array}$

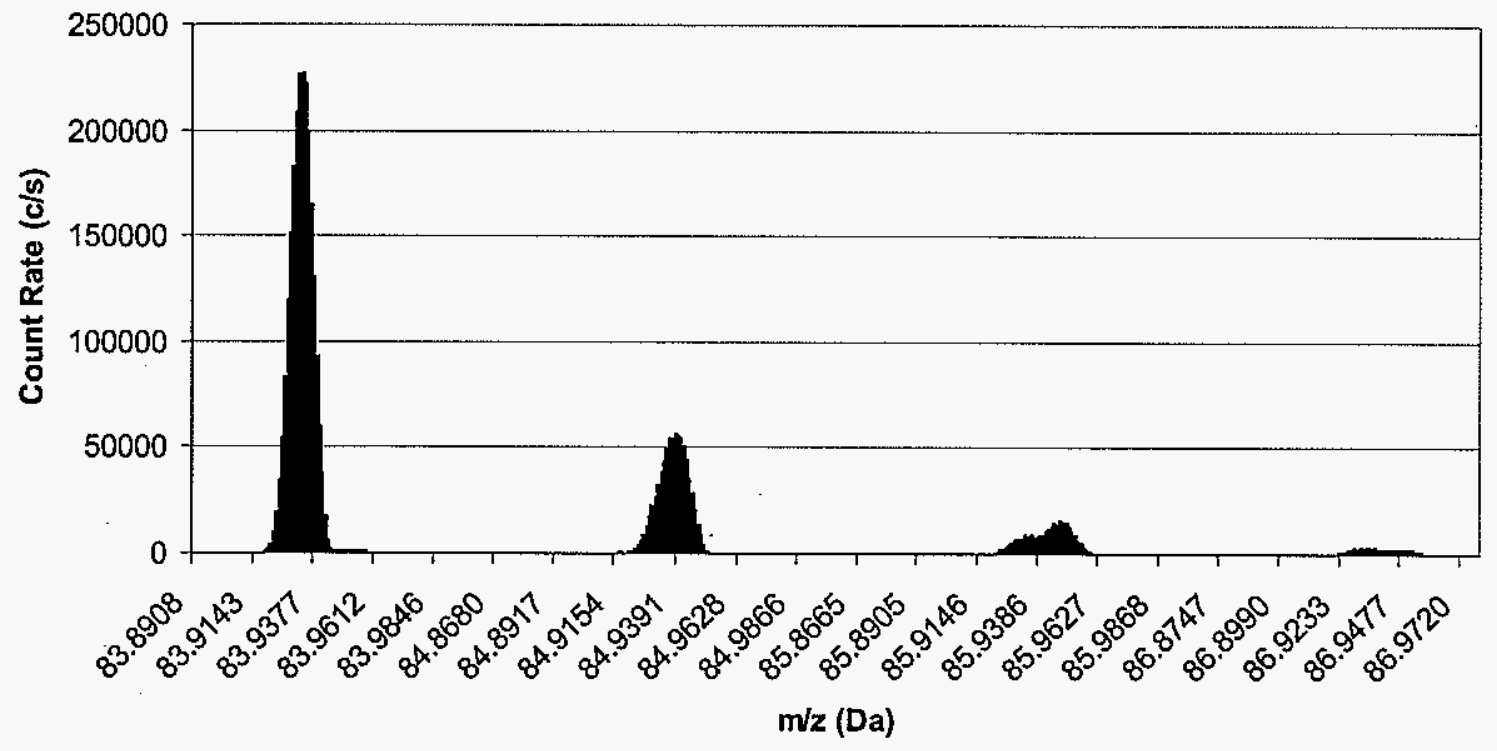


Figure 1b: High resolution spectrum of $50 \mathrm{ppm} \mathrm{Cr}$ (III) in $1 \%$ nitric acid.

$\begin{array}{lll}\text { Peak Centroid } & \text { Integrated Intensity } & \begin{array}{l}\text { Assigned Identity } \\ 83.9392\end{array} \\ 834716 & { }^{52} \mathrm{Cr}^{16} \mathrm{O}_{2}^{+} \\ 83.9605 & 12636 & { }^{50} \mathrm{Cr}^{16} \mathrm{O}_{2} \mathrm{H}_{2}^{+} \\ 84.9399 & 82677 & { }^{53} \mathrm{Cr}^{16} \mathrm{O}_{2}^{+} \\ 84.9473 & 172182 & { }^{52} \mathrm{Cr}^{16} \mathrm{O}_{2} \mathrm{H}^{+} \\ 85.9385 & 19322 & { }^{54} \mathrm{Cr}^{16} \mathrm{O}_{2}^{+} \\ 85.9476 & 30339 & { }^{53} \mathrm{Cr}^{16} \mathrm{O}_{2} \mathrm{H}^{+} \\ 85.9555 & 237313 & { }^{52} \mathrm{Cr}^{16} \mathrm{O}_{2} \mathrm{H}_{2}^{+} \\ 86.9464 & 5956 & { }^{54} \mathrm{Cr}^{16} \mathrm{O}_{2} \mathrm{H}^{+} \\ 86.9557 & 28468 & { }^{53} \mathrm{Cr}^{16} \mathrm{O}_{2} \mathrm{H}_{2}^{+}\end{array}$

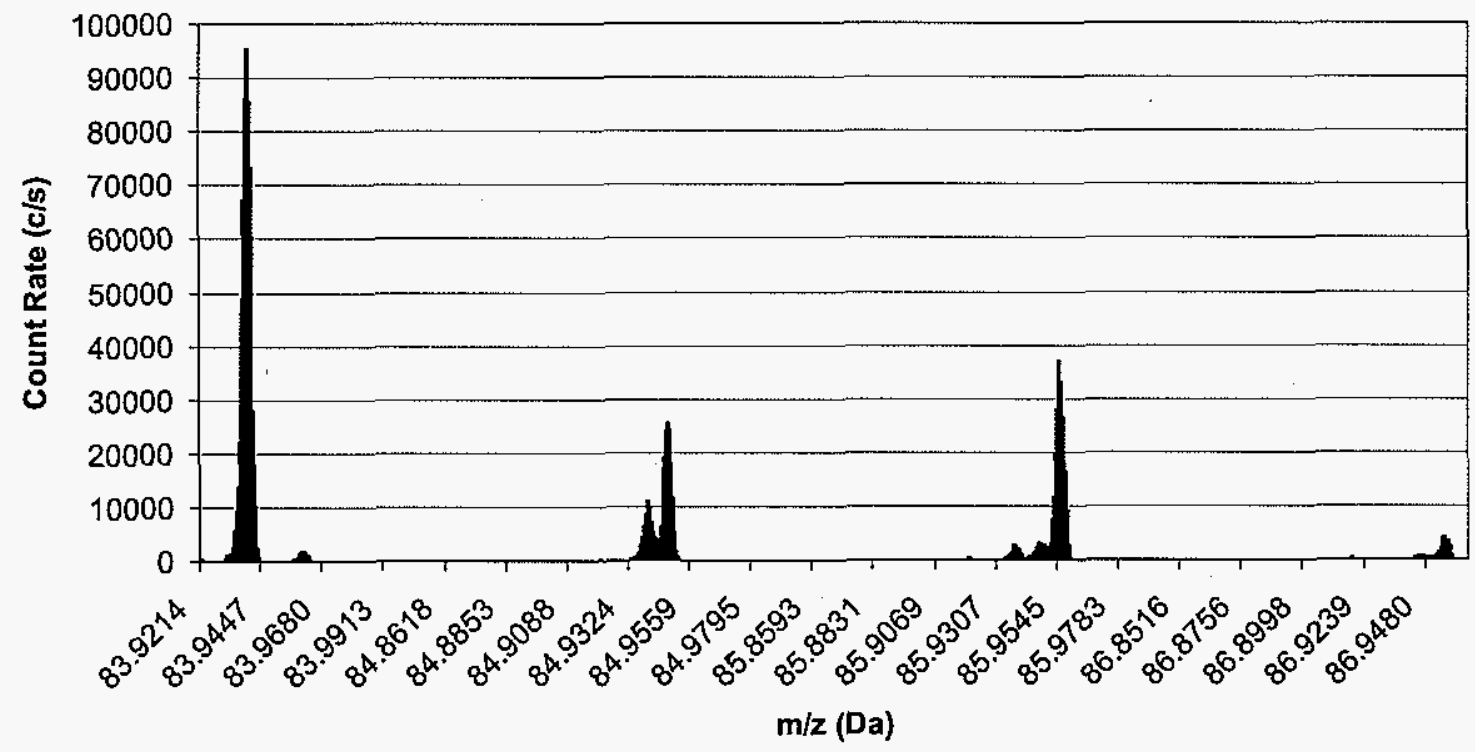


Figure 2a: Medium resolution spectrum of $50 \mathrm{ppm} \mathrm{Cr}$ (III) in 1\% nitric acid. Asterisk denotes ions for which high resolution resolves two separate ions.

$\begin{array}{lll}\text { Peak Centroid } & \text { Integrated Intensity } & \text { Assigned Identity } \\ 99.9302 & 49565 & { }^{52} \mathrm{Cr}^{16} \mathrm{O}_{3}^{+} \\ 99.9510 & 12796 & { }^{50} \mathrm{Cr}^{16} \mathrm{O}_{3} \mathrm{H}_{2}{ }^{+} . \\ 100.9380 & 1889377 & { }^{52} \mathrm{Cr}^{16} \mathrm{O}_{3} \mathrm{H}^{+} \\ 101.9426 & 467113 & *{ }^{53} \mathrm{Cr}^{16} \mathrm{O}_{3} \mathrm{H}^{+} \\ 102.9406 & 96063 & *{ }^{54} \mathrm{Cr}^{16} \mathrm{O}_{3} \mathrm{H}^{+}\end{array}$

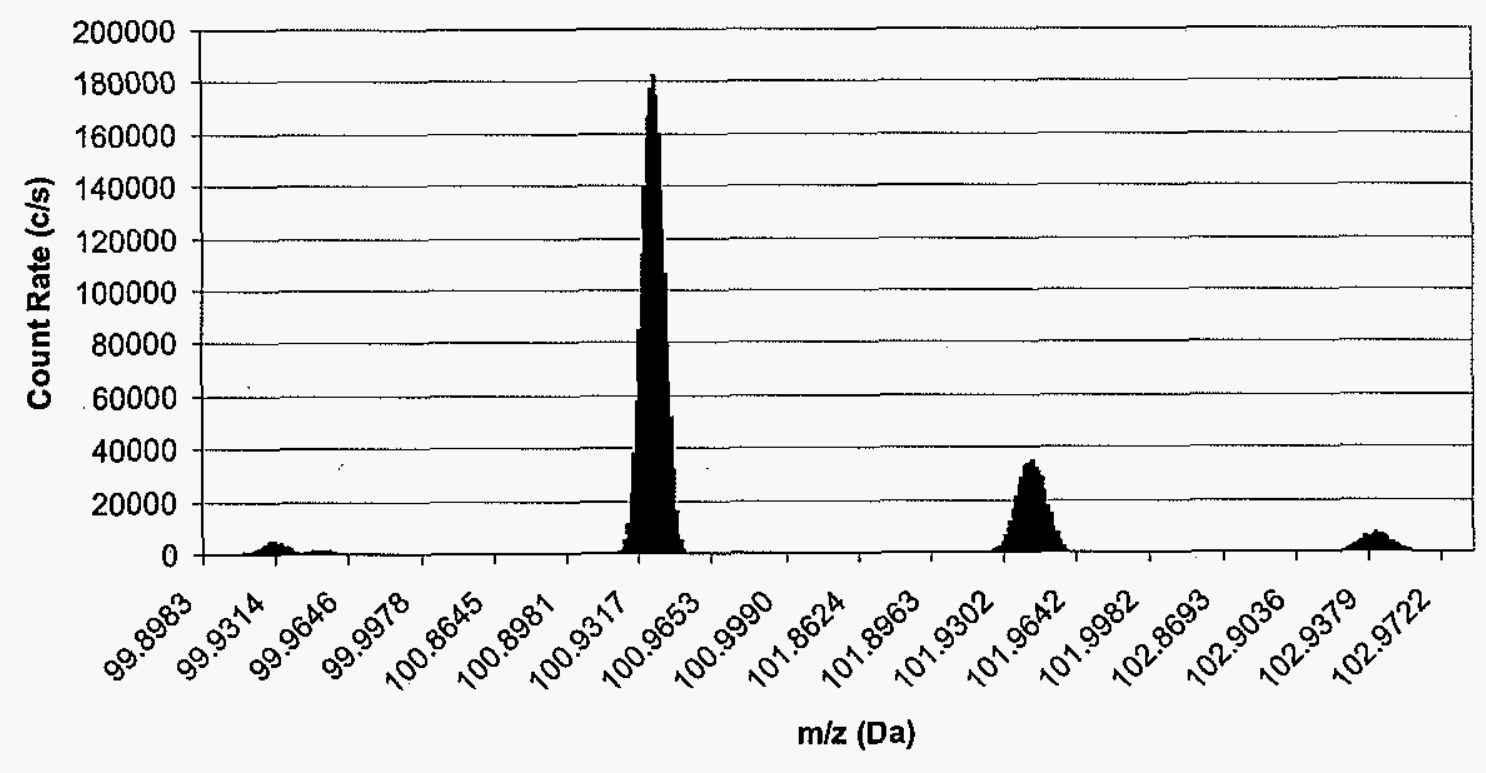


Figure 2b: High resolution spectrum of $50 \mathrm{ppm} \mathrm{Cr}(\mathrm{III})$ in $1 \%$ nitric acid. $\mathrm{Y}$ axis has been limited to allow for visualization of less intense peaks.

$\begin{array}{lll}\text { Peak Centroid } & \text { Integrated Intensity } & \begin{array}{l}\text { Assigned Identity } \\ 99.9334\end{array} \\ \begin{array}{l}{ }^{52} \mathrm{Cr}^{16} \mathrm{O}_{3}^{+} \\ 99.9546\end{array} & 6619 & { }^{50} \mathrm{Cr}^{16} \mathrm{O}_{3} \mathrm{H}_{2}^{+} \\ 100.9415 & 1181888 & { }^{52} \mathrm{Cr}^{16} \mathrm{O}_{3} \mathrm{H}^{+} \\ 101.9421 & 136916 & { }^{53} \mathrm{Cr}^{16} \mathrm{O}_{3} \mathrm{H}^{+} \\ 101.9496 & 130130 & { }^{52} \mathrm{Cr}^{16} \mathrm{O}_{3} \mathrm{H}_{2}^{+} \\ 102.9405 & 35717 & { }^{54} \mathrm{Cr}^{16} \mathrm{O}_{3} \mathrm{H}^{+} \\ 102.9492 & 19241 & { }^{53} \mathrm{Cr}^{16} \mathrm{O}_{3} \mathrm{H}_{2}^{+}\end{array}$

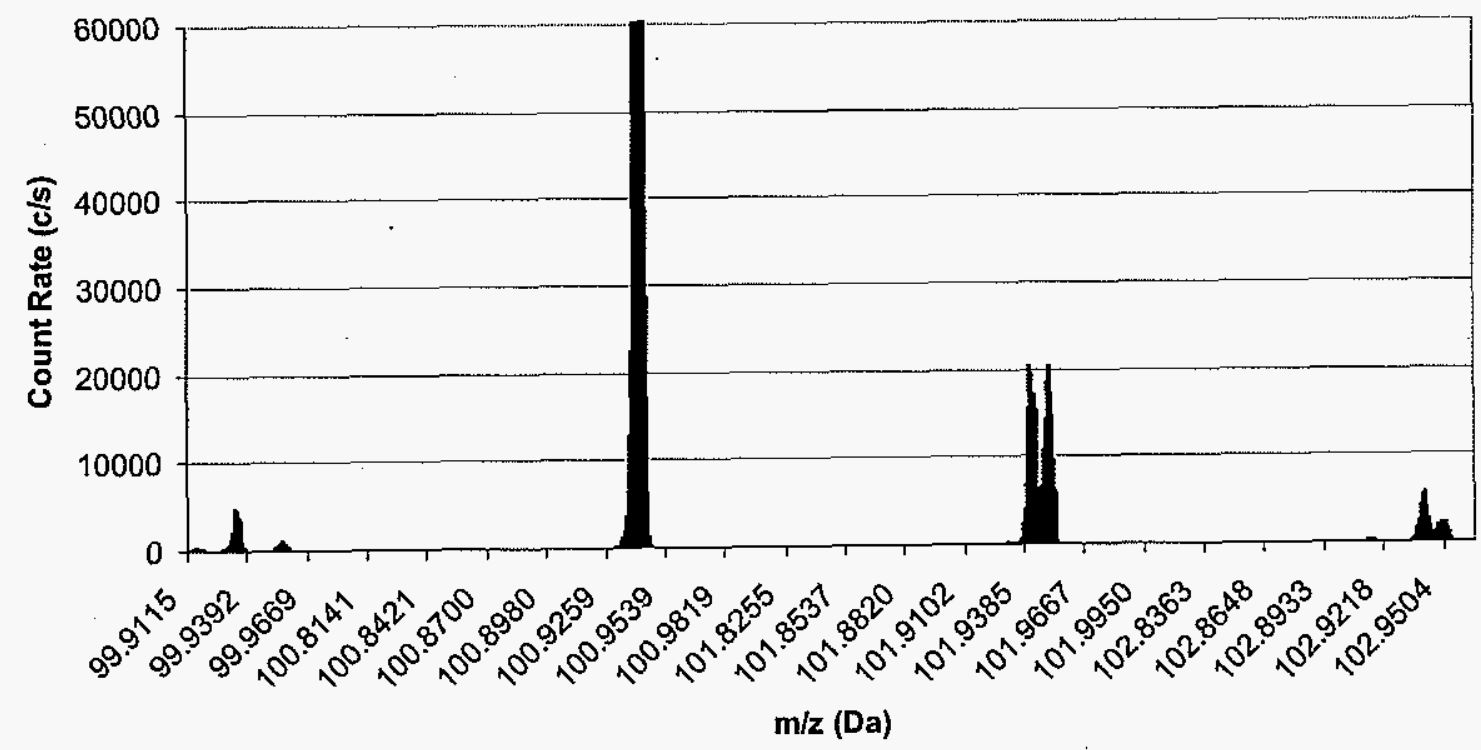


Figure 3: $\mathrm{CrO}_{\mathrm{x}} \mathrm{H}_{\mathrm{y}}^{+}$ion intensities. All ions shown are adjusted for mass bias and intensities have been normalized to $\mathrm{CrO}^{+}$.

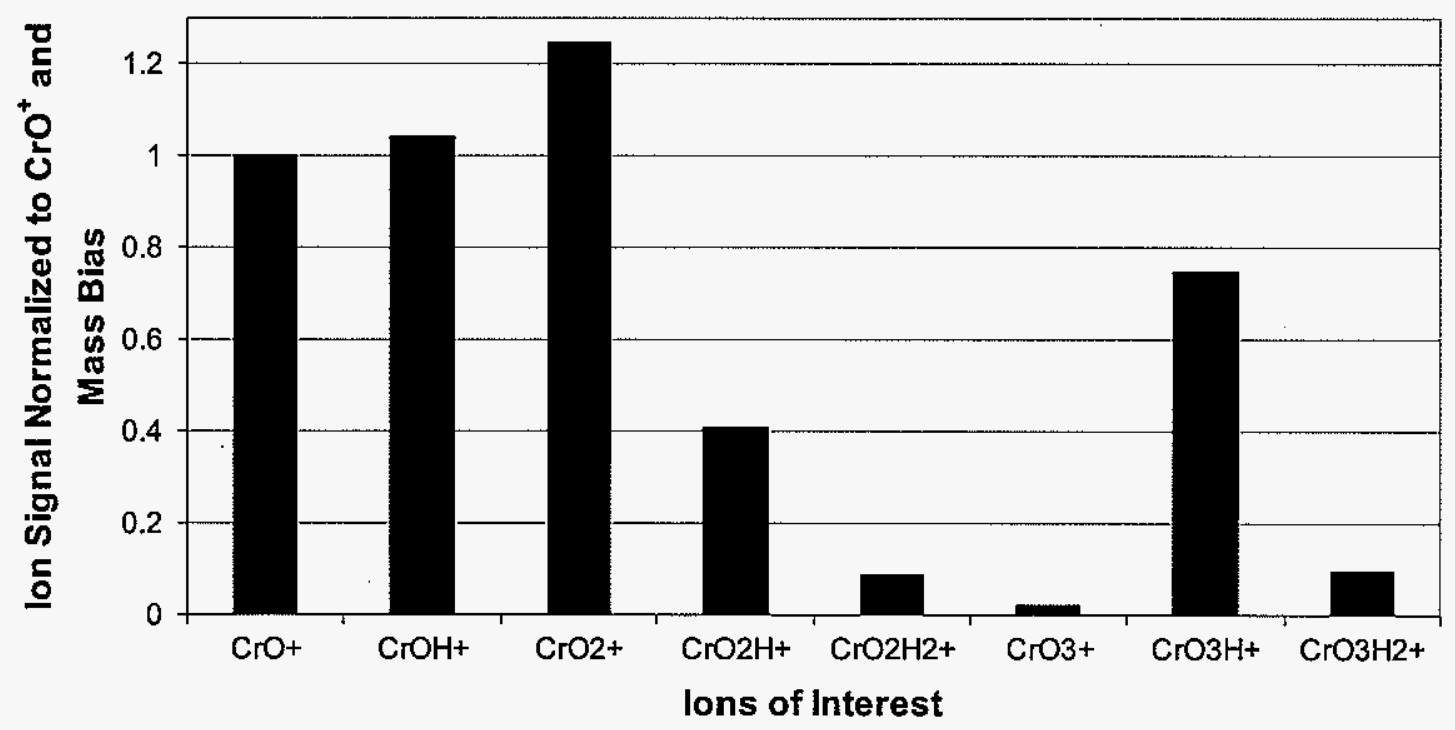

Figure 4: Comparison of ion abundances from different oxidation states of chromium. All ions have been adjusted for mass bias and concentration.

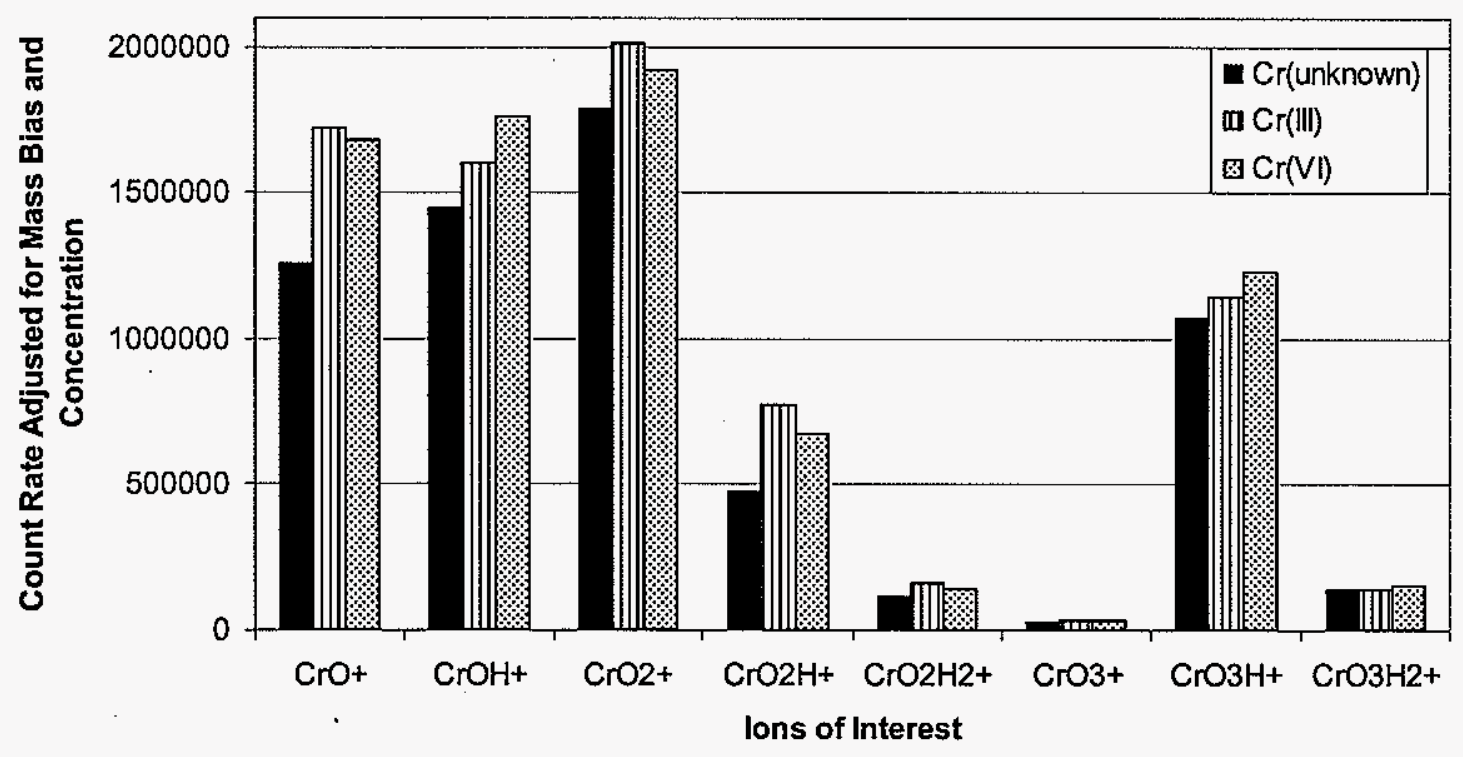


Figure 5: Comparison of different metals. Adjustments have been made for mass bias, concentration, and isotopic abundance. $\mathrm{Cr}$ has a value of 1.0 for each ion shown, and all other elements are normalized to $\mathrm{Cr}$.

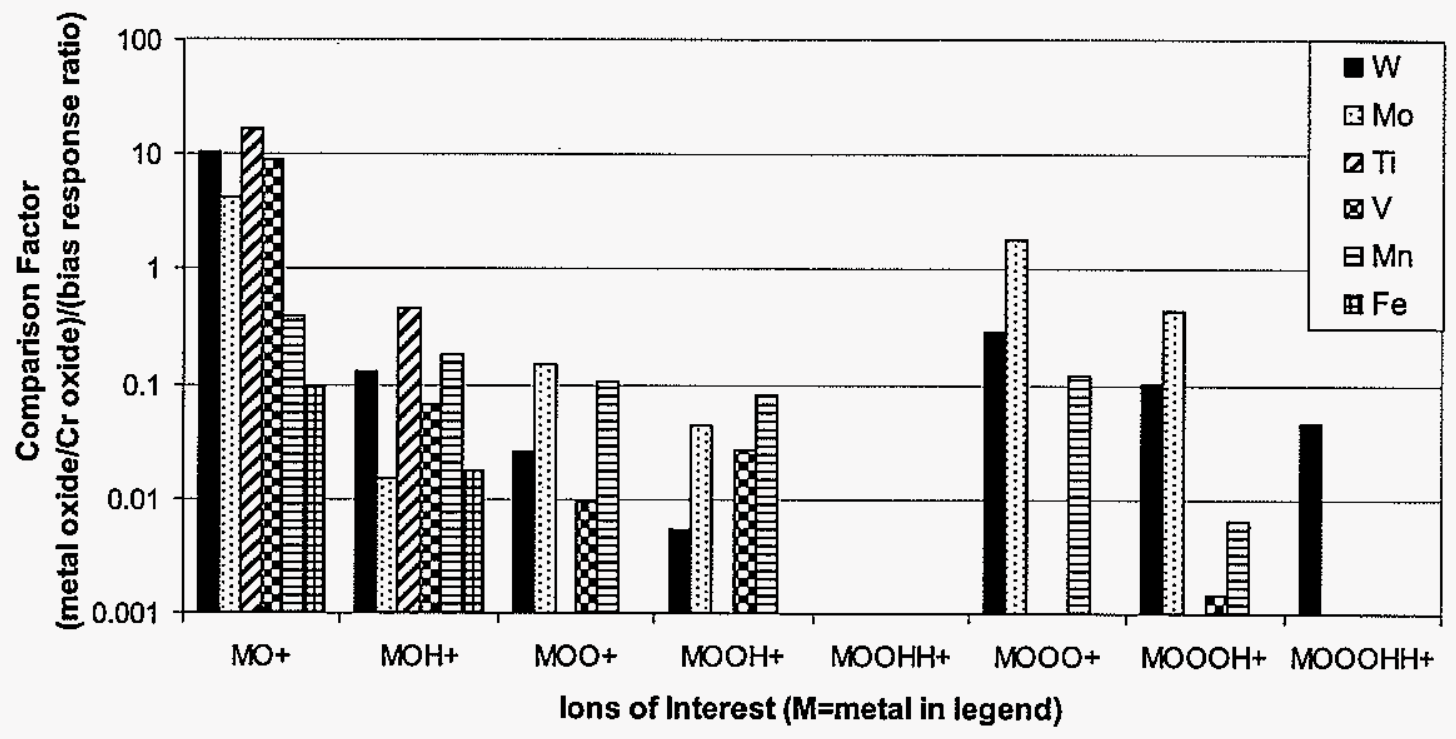




\section{CHAPTER 5. GENERAL CONCLUSIONS}

Polyatomic ions have been a known source of analyte interference in inductively coupled plasma - mass spectrometry since the early days of the technique. Explicit identification is the first aspect in studying any ion in ICP-MS, but one that is often glossed over, particularly in the discussion of polyatomic ions. In the work presented here, many polyatomic ions have been definitively identified. The use of high resolution, accurate $\mathrm{m} / \mathrm{z}$ measurements, measured mass defects at each magnet mass setting, isotope ratios, and the addition of specialized solvents allows for proposed ion identities to be confirmed.

Calculating the gas kinetic temperature to evaluate a dissociation constant for a proposed ion pair lends insight into the formation or removal process for the polyatomic ion. Common polyatomic ions such as $\mathrm{NO}^{+}$and $\mathrm{H}_{2} \mathrm{O}^{+}$have been investigated, as well as less studied ions such as $\mathrm{N}_{2} \mathrm{H}^{+}, \mathrm{COH}_{\mathrm{x}}^{+}$, and $\mathrm{CrO}_{\mathrm{x}} \mathrm{H}_{\mathrm{y}}^{+}$. Some of these ions have not been previously identified in the literature. Changes in cone material and extraction voltage have been studied to determine their impact on polyatomic ion formation. Additionally, different models of neutral gas density have been employed to represent different positions and conditions in the interface region.

In the future, an instrument interface region could be redesigned to reduce the formation of some of the polyatomic ions studied here. Cone angle, spacing, and material should be explored further, as these studies would only require minor adjustments to existing instruments. Polyatomic ions containing carbon, nitrogen, and hydrogen are prevalent in the mass spectrum, and further knowledge about these ions would improve the determination of aluminum, phosphorous, and sulfur, three elements for which ICP-MS faces some challenges. 
The research yet to be done on polyatomic ions in ICP-MS is boundless, as they exist in every region of the mass spectrum and seem to play a role in every analysis. My research has not only brought insight to the polyatomic ion issue, but has prepared me well for a wide variety of ICP-MS work that I hope to execute in the future. I look forward to the challenges this issue presents, and I feel confident that strides will continue to be made in the study of polyatomic ions by high resolution ICP-MS. 


\section{ACKNOWLEDGEMENTS}

This work was performed at Ames Laboratory under Contract No. W-7405-Eng-82 with the U.S. Department of Energy. The United States government has assigned the DOE Report number IS-T 2357 to this thesis. This work was funded by the National Science Foundation with program assistance from the Institute for Physical Research and Technology.

The work discussed in this text could not have been done without the guidance and support of Professor R. S. Houk. The camaraderie and assistance of past and present Houk group members has been much appreciated. I also thank Dr. Timothy Dudley for his work on calculating the energies of many of the ions discussed. I was honored to be awarded the Fassel fellowship for the 2005-2006 academic year, and for that I thank Mary K. Fassel.

Additionally, I wish to show appreciation to Andrew Wade Ferguson, for being my strongest advocate. 